\title{
BIOPROCESSING SEPARATIONS CONSORTIUM Three-Year Overview
}

Technical Advances, Process Economics Influence, and State of the Science 
Primary Authors

Bioprocessing Separations Consortium Analysis Team: Sue Jones (Pacific Northwest National Laboratory), Eric Tan (National Renewable Energy Laboratory), Jennifer B. Dunn and Lauren Valentino (Argonne National Laboratory)

Contributing Authors

Argonne National Laboratory: Edward Barry, Louis Edano, Patricia Ignacio-deLeon, Phil Laible, YuPo Lin

Los Alamos National Laboratory: Jim Coons, Taraka Dale, Cade Gasway, Benjamin Yap

Lawrence Berkeley National Laboratory: Ning Sun, Todd Pray, Eric Sundstrom, Jipeng Yan

National Renewable Energy Laboratory: Gregg Beckham, Mary Biddy, David Chiaramonte, Ryan Davis, Stefano Dell'Orco, Steve Deutch, Abhijit Dutta, Chai Engtrakul, Stefan Haugen, Eric Karp, Lorenz Manker, Kim Magrini, Bill Michener, Hanna Monroe, Brady Peterson, Patrick Saboe, Mike Sprague, Nolan Wilson

Oak Ridge National Laboratory: Michael Z. Hu, Brian L. Bischoff, Aimee Church, Jae-Soon Choi, Zhenglong Li, Ting Wu, Tim Theiss

Pacific Northwest National Laboratory: Charlie Freeman, Vanda Glezakou, Suh-Jane Lee, Jian Liu, Marie Swita, Michael Thorson, Huamin Wang,

Sandia National Laboratory: Ryan Davis

Acknowledgements

The Bioprocessing Separations Consortium would like to acknowledge support from Nichole Fitzgerald of the U.S. Department of Energy's Bioenergy Technologies Office (BETO) as well as Clayton Rohman of BETO. Each laboratory of the consortium acknowledges the following support.

Argonne is a U.S. Department of Energy laboratory managed by UChicago Argonne, LLC under contract DE-AC02-06CH11357.

Lawrence Berkeley National Laboratory is managed and operated by the University of California under contract number DE-AC02-05CH11231.

Los Alamos National Laboratory is operated by Triad National Security, LLC, for the National Nuclear Security Administration of U.S. Department of Energy (Contract No. 89233218CNA000001).

The work at the National Renewable Energy Laboratory was supported by the U.S. Department of Energy under Contract No. DE347-AC36-99G010337.

The work performed at Oak Ridge National Laboratory was conducted under the auspices of the U.S. Department of Energy under Contract DE-AC05-00OR22725 with UT-Battelle, LLC, which manages ORNL.

Pacific Northwest National Laboratory is operated by Battelle Memorial Institute for the U.S. Department of Energy under Contract No. DE-AC05-76RL01830.

Sandia National Laboratories is a multi-mission laboratory managed and operated by National Technology and Engineering Solutions of Sandia, LLC., a wholly owned subsidiary of Honeywell International, Inc., for the U.S. Department of Energy's National Nuclear Security Administration under contract DE-NA0003525. 


\section{Disclaimer}

This report was prepared as an account of work sponsored by an agency of the United States Government. Neither the United States Government nor any agency thereof, nor UChicago Argonne, LLC, nor any of their employees or officers, makes any warranty, express or implied, or assumes any legal liability or responsibility for the accuracy, completeness, or usefulness of any information, apparatus, product, or process disclosed, or represents that its use would not infringe privately owned rights. Reference herein to any specific commercial product, process, or service by trade name, trademark, manufacturer, or otherwise, does not necessarily constitute or imply its endorsement, recommendation, or favoring by the United States Government or any agency thereof. The views and opinions of document authors expressed herein do not necessarily state or reflect those of the United States Government or any agency thereof, Argonne National Laboratory, or UChicago Argonne, LLC. 


\section{Table of Contents}

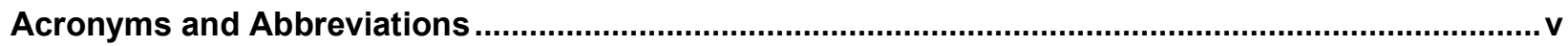

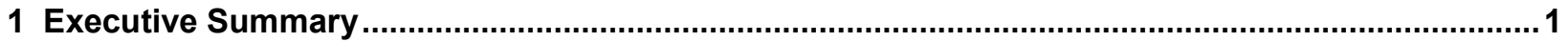

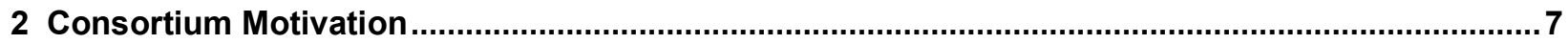

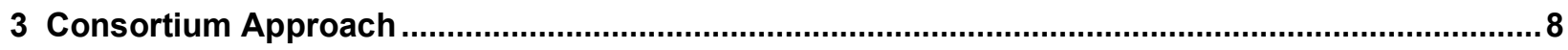

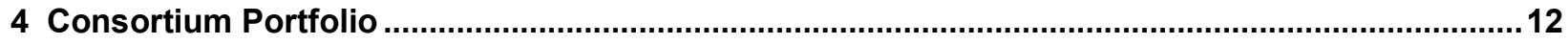

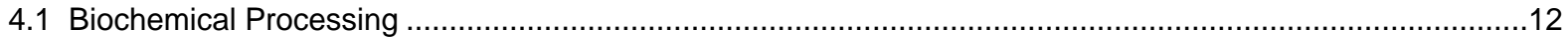

4.1.1 Polymeric and Ceramic Membrane Fractionation of Lignin....................................................13

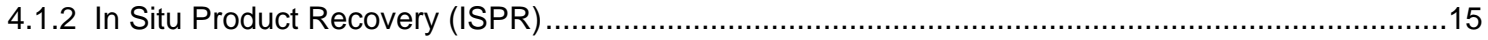

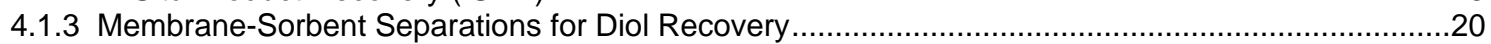

4.1.4 Ultrasonic Separation of Lignocellulosic Particles ..................................................................22

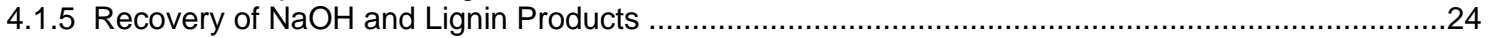

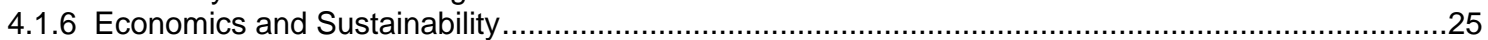

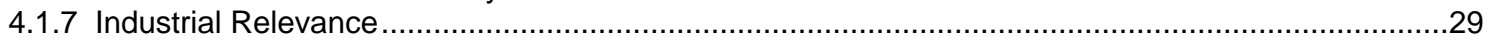

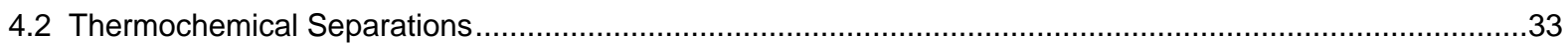

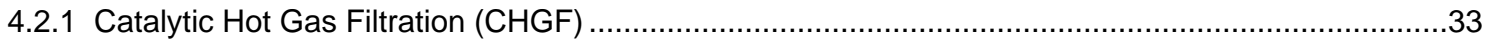

4.2.2 EDI-Based Recovery of Dilute Organic Carbon and Ammonia in the Aqueous Phase......................35

4.2.3 Removal of Ammonia from HTL Aqueous Streams as a Wastewater Treatment Option ...................37

4.2.4 Bio-oil and Biocrude Preprocessing with Adsorbents..................................................................

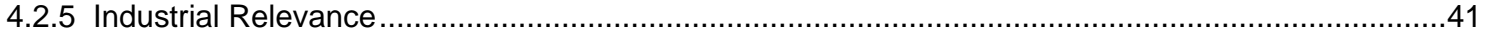

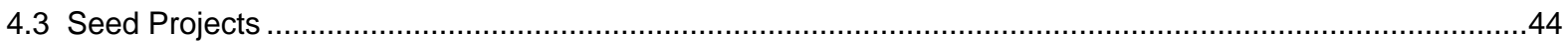

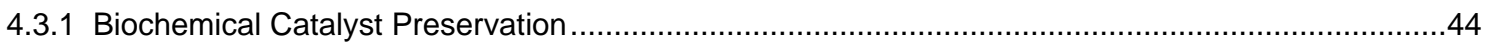

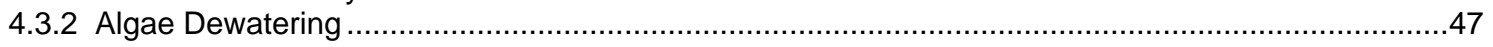

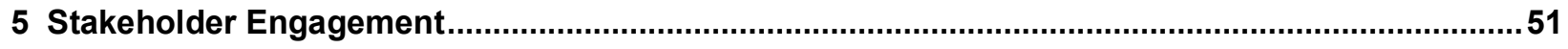

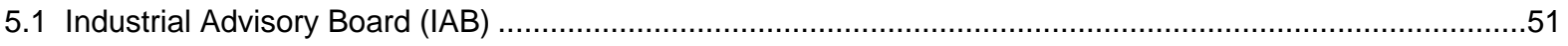

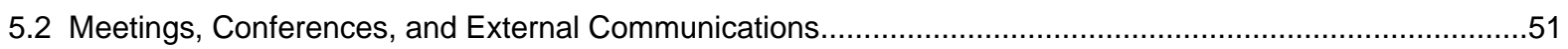

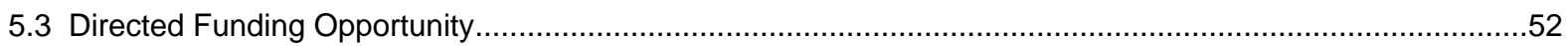

6 Summary

7 References 


\section{Figures}

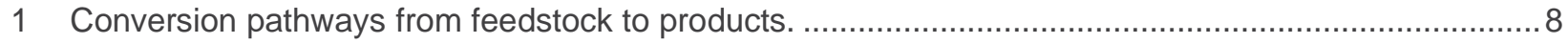

2 Approach to prioritizing research challenges to incorporate in the Consortium's portfolio....................9

3 Overarching challenges the Consortium addressed in its first 3 years............................................ 10

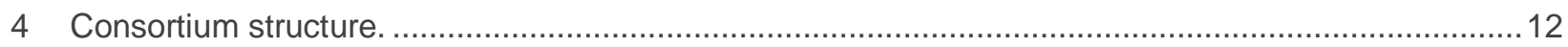

5 Experimental process for lignin separation via TFF membrane. …............................................... 13

6 Molecular weight response for lignin fractionation via polymeric membranes: $5 \mathrm{kDa}, 1 \mathrm{kDa}$, and nano represent the membrane pore sizes; the $y$-axis is based on ultraviolet absorbance of gel permeation chromatography; compounds over $1 \mathrm{kDa}$ that are present in the alkaline pretreatment liquor remain in the retentate..

7 Left: Visual product quality. Right: Molecular weight response for lignin fractionation via ceramic membranes.

8 Left: HED ISPR flow for carboxylic acid production and separation. Right: Conceptual separation effects.

9 Left: EDI ISPR acid recovery flow. Right: Conceptual separation effects.

10 HED-ISPR equilibrium concentration of butyric acid in the organic phase as a function of $\mathrm{pH}$ and the initial acid concentration in the aqueous phase

11 Bioreactor HED-ISPR for bio-ester production and separation.

12 Trioctylphosphine oxide (TOPO) results: (a) Process diagram of acetic acid separation from extractant. In the first distillation column, extractant is easily separated from water and acid with four stages. A second column is needed to separate water from acid. (b) Energy input of the process per kilogram of acetic acid product as a function of acid concentration in the bioreactor at $\mathrm{pH} 3$.

13 EC-ISPR acid recovery recovered $92 \%$ of butyric acid.

14 EDI membranes and performance for recovery of acetic acid from a dilute aqueous solution.

15 (a) Pervaporation membranes and sorbents evaluated for BDO separations; (b) Type-1 hydrophobic membrane performance at different vacuum pressures; (c) Type-2 superhydrophilic membrane performance at different temperatures.

16 Ultrasonic separation conceptual illustration.

17 Left: Ultrasonic experimental setup showing fines concentration in the standing wave.

Right: Experimental results of fines removal in continuous flow.

18 Vessel-limited energetics of cellulosic fines removal using ultrasonic filtration in baseline and LANL operating modes.

19 Left: EDI concept. Right: acid base separation results.

20 Box flow diagram for SMB, EDI, and pertractive separations.

21 Separation costs for SMB, EDI, and pertractive technologies 


\section{Figures (Cont.)}

22 Lifecycle GHG emissions for SMB, EDI, and pertractive technologies.

23 Life-cycle water consumption (L/MJ) in the production of renewable diesel through an acid intermediate.

24 Separation challenges for two types of thermochemical processes.

25 Hot gas filtration experimental setup.

26 Filtration and conversion results for various filter materials and catalysts.

27 Selective extraction of dilute organic acids from the thermochemical (TC) waste aqueous phase using the EDI platform system.

28 EDI results for acid and ammonia recovery from $\mathrm{HTL}$ aqueous phase.

29 Left: HiPAS membrane concept. Right: Acetic acid concentration over time in permeate stream as a result of pervaporation

30 Waste HTL flow diagram.

31 Potential cost reduction through use of EDI for acid and base recovery from HTL aqueous phase.

32 GHG reduction for EDI-based recovery of mixed acids and ammonia from HTL

aqueous phase.

33 Fossil energy consumption for EDI-based recovery of mixed acids and ammonia from HTL aqueous phase.

34 Water consumption for EDI-based recovery of mixed acids and bases from the HTL aqueous phase.

35 Effect of adsorbent type on carbonyl removal from bio-oil and nitrogen species removal from biocrude.

36 Economic impact of carbonyl removal from bio-oil.

37 Materials developed in the Consortium include nanoparticles, xerogels, and polymeric foams.

38 Adsorbent screening results for capturing three representative aldehydes: (a) formaldehyde, (b) acetaldehyde, and (c) benzaldehyde.

39 Experimental setups for separations via ultrasonics and membranes.

40 Characteristics of algae cultures used in the harvesting and dewatering study.....

41 Ultrasonic removal of algal species showing agreement between batch and (steady) flow tests, which indicates the insignificance of hydrodynamic effects over the range of conditions studied.

42 (a) Concentration factors obtained in flow tests increases according to the ratio of filtrate to concentrate flow rates shown in parenthesis. (b) Ultrasonic harvesting energy as a fraction of the energy in the microalgae removed using ultrasound. 


\section{Tables}

1 Summary of technologies developed in Bioprocessing Separations Consortium ..............................2

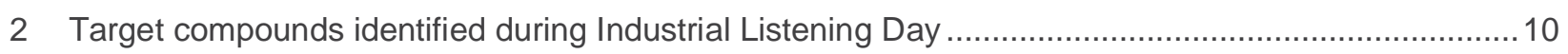

3 Industrial relevance of separation technologies applicable to biological conversion processes. ..........30

4 Industrial relevance for thermochemical separation applications. .................................................. 42

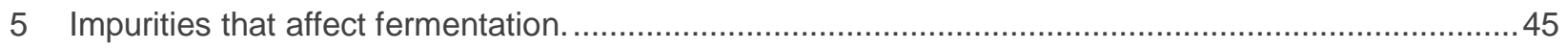

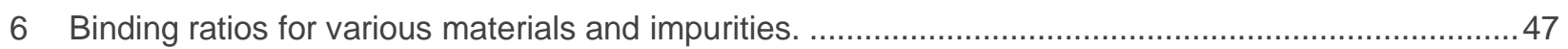

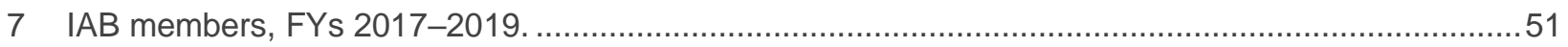

8 Direct Funding Opportunity projects between industry and Consortium members. ..........................52

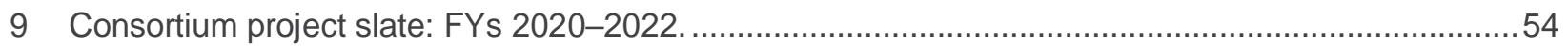




\section{Acronyms and Abbreviations}

APL

alkaline pretreatment liquor

Argonne

Argonne National Laboratory

BDO

BETO

butanediol

BNL

Bioenergy Technologies Office

Berkeley National Laboratory

EDI

electrodeionization

HED

HPA

hybrid extraction and distillation

HTL

heteropolyacid

hydrothermal liquefaction

GHG

greenhouse gas

ISPR

in situ product recovery

LANL

Los Alamos National Laboratory

LCA

lifecycle analysis

MFSP

minimum fuel selling price

NP

nanoparticle

NREL

National Renewable Energy Laboratory

ORNL

Oak Ridge National Laboratory

PNNL

Pacific Northwest National Laboratory

RW/PE

resin wafers with nonconductive polyethylene solid polymer binder

SMB

simulated moving bed

SNL

Sandia National Laboratory

state of technology

TEA

technoeconomic analysis

TFF

tangential flow filtration 
This page left intentionally blank. 


\section{Executive Summary}

The Bioprocessing Separations Consortium solves separations challenges that are unique to bioprocessing. To do this, the Consortium uses two methods: applying existing technologies to new challenges and developing new technologies that may address these unique challenges better than today's commercial technologies. In its research and development, the Consortium leverages its three core capabilities: materials development and evaluation, process development, and analysis and computation.

In its first three years, from 2016 to 2019, the Consortium addressed four critical challenges in biochemical and thermochemical processing. First, the Consortium targeted the fractionation of lignin to enable valorization of this portion of biomass that offers diverse, complex, and valuable building blocks and products. Second, Consortium researchers developed technologies to enable process intensification, which can reduce equipment needs, energy consumption, and waste generation, thereby cutting bioprocessing capital costs and rendering processes more efficient. Third, the Consortium sought to recover carbon from dilute aqueous streams that are common to bioprocessing; recovering dilute carbon can improve process efficiency and economics. Finally, Consortium researchers designed and developed new materials and catalysts to reduce targeted foulants and poisons in bioprocessing streams that can limit the lifetime of downstream catalysts or fermenting microorganisms. Table 1 lists the technologies that were examined and places them in the context of the Consortium's capabilities, types of bioprocesses, and critical challenges in bioprocessing separations. Overall, across these projects, we have developed separations technologies for 10 bioprocesses, addressed 9 target compounds in bioprocessing, developed 10 materials, and evaluated 4 processes for cost and sustainability. 
Table 1 Summary of technologies developed in Bioprocessing Separations Consortium.a

\begin{tabular}{|c|c|c|c|c|c|c|c|c|c|}
\hline \multirow[b]{3}{*}{ Technology } & \multirow{2}{*}{\multicolumn{2}{|c|}{$\begin{array}{c}\text { Conversion } \\
\text { Pathway }\end{array}$}} & \multicolumn{4}{|c|}{ Challenges Addressed } & \multicolumn{3}{|c|}{ Capabilities Applied } \\
\hline & & & & I & & & & & $\frac{100}{10}$ \\
\hline & BC & TC & Fractionation & Intensification & Recovery & Removal & Materials & Processes & Computation \\
\hline HED-ISPR & $\mathrm{X}$ & & & $x$ & & & & $\mathrm{X}$ & $x$ \\
\hline EDI-ISPR & $\mathrm{X}$ & & & $x$ & & & $x$ & $x$ & $x$ \\
\hline EDI & $\mathrm{X}$ & $x$ & & & $x$ & $x$ & $x$ & $x$ & $x$ \\
\hline Ultrasonic & $x$ & & $x$ & & & & & $X$ & $\mathrm{X}$ \\
\hline Pervaporation & $\mathrm{X}$ & & & $x$ & $x$ & & & $x$ & \\
\hline Distillation (membrane) & $\mathrm{X}$ & & & & $x$ & & & $x$ & \\
\hline Polymeric membranes & $\mathrm{X}$ & & $x$ & & $x$ & & & $x$ & \\
\hline Ceramic membranes & $\mathrm{X}$ & & $x$ & & & & & $x$ & \\
\hline Simulated moving bed & $\mathrm{X}$ & & & & $x$ & & & $x$ & \\
\hline Catalytic gas hot filtration & & $x$ & & $x$ & & $x$ & $x$ & $x$ & $x$ \\
\hline Adsorbents & $\mathrm{X}$ & $x$ & & & $x$ & $X$ & $X$ & $X$ & $X$ \\
\hline
\end{tabular}

a BC: Biochemical. TC: Thermochemical. ISPR: In situ product recovery. HED: Hybrid extraction and distillation. EDI: Electrodeionization. 
Particular Consortium research highlights include the following examples in Highlights 1-4.

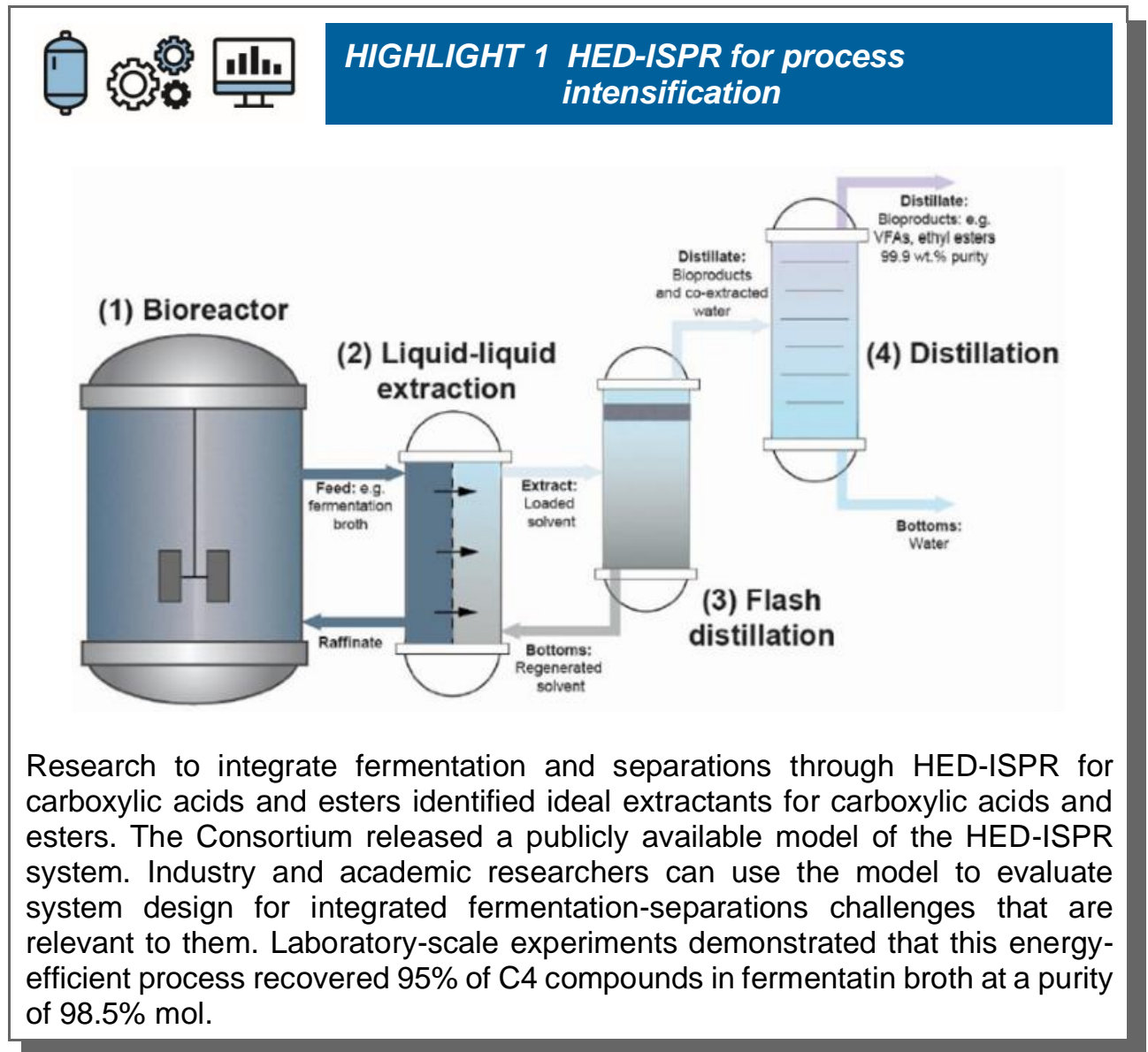




\section{[C 5 \\ 象田 \\ HIGHLIGHT 2 EDI for recovery of dilute \\ carbon in aqueous streams}

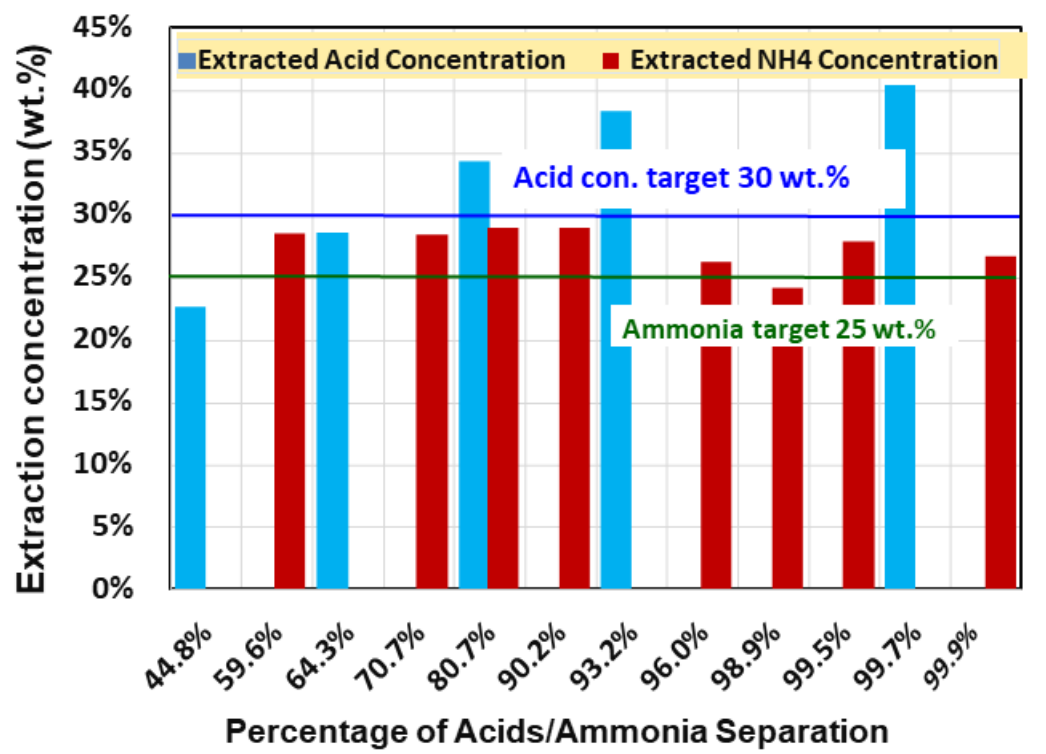

EDI-based separations maintained high concentrations of recovered acid and $\mathrm{NaOH}$ regardless of the percentage removal. Concentrations of each species exceeded the target level. 


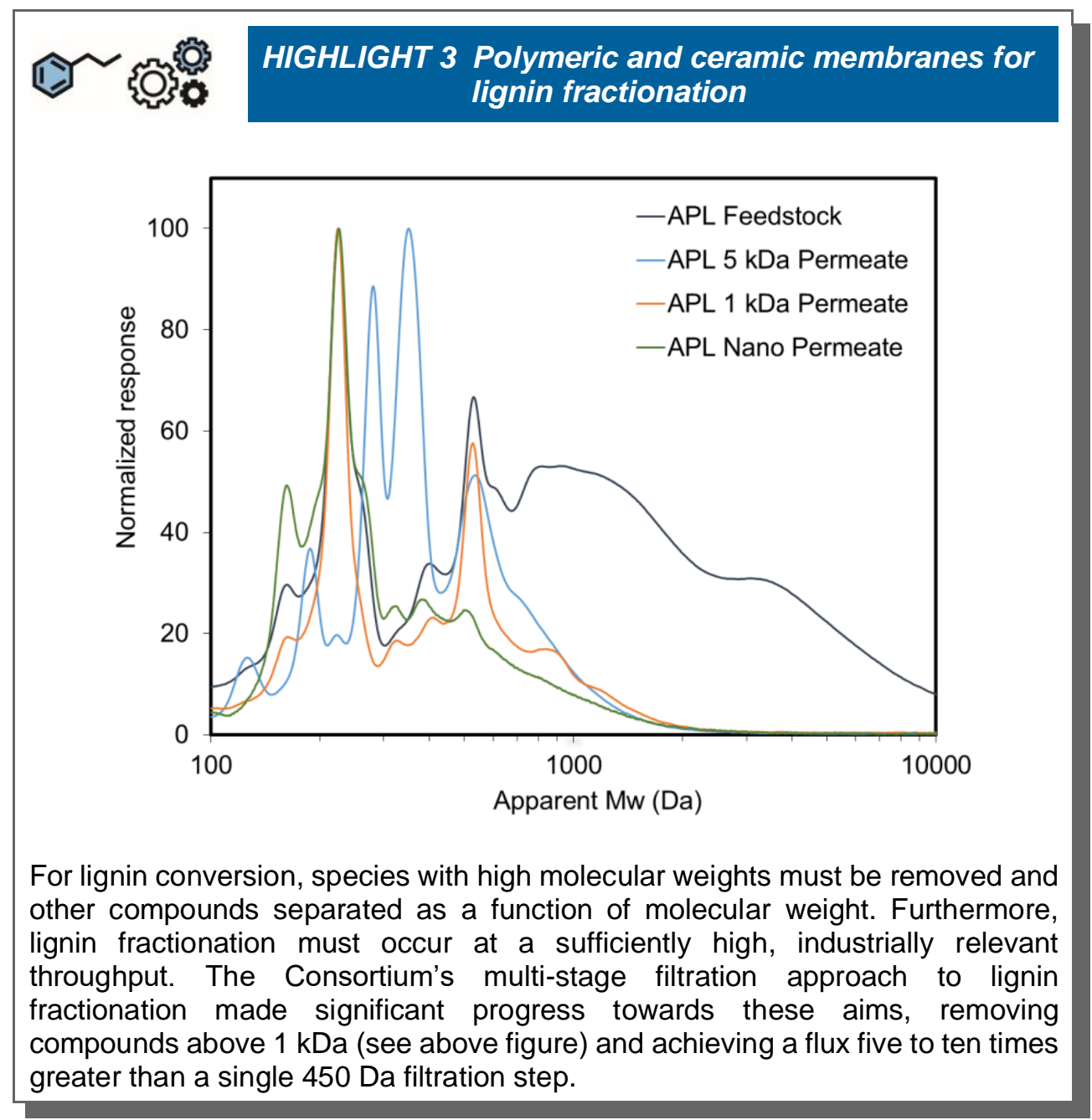




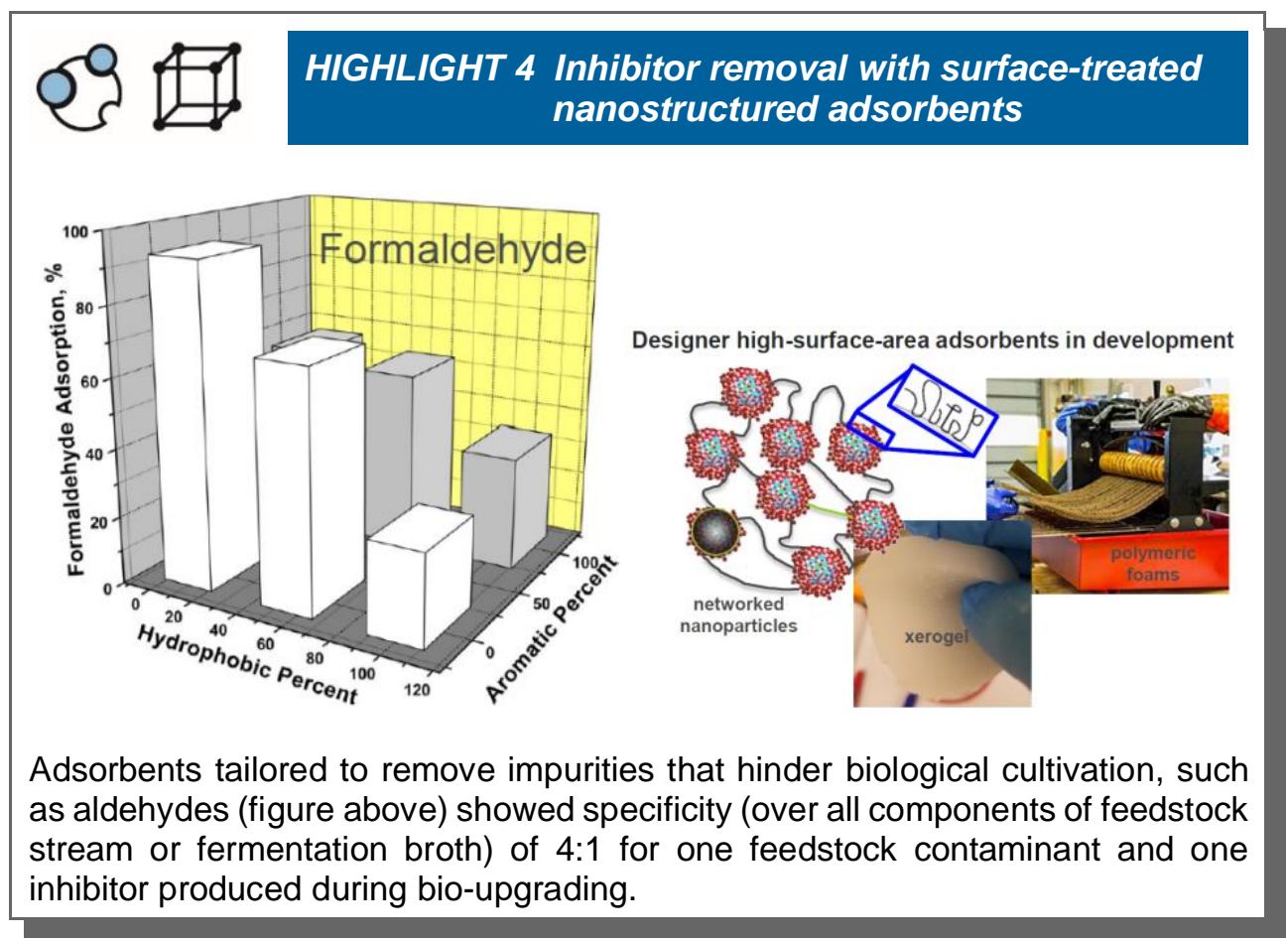

The Consortium is moving into its second three-year period and will continue to advance bioprocessing separations technologies, supporting research through analysis and interactions with the Consortium's Industrial Advisory Board (IAB). 


\section{Consortium Motivation}

Overall, industrial separations constitute up to $15 \%$ of total energy consumption in the United States (Scholl 2016). In the bio-based economy, bioprocessing separations are significantly less mature than industrial separations that are common in the established petrochemical industry. Bioprocess-relevant separations are universally costly and complex, regardless of the conversion pathway (biochemical, thermochemical, hybrid) used because products are dilute and often in aqueous environments, and the mixtures that result from biomass deconstruction are chemically complex. Accordingly, bioprocessing separations are often a key driver of process costs and suffer from a lack of selectivity. In many cases, separations approaches are inspired by unoptimized bench-scale procedures; therefore, a technology baseline, or definition of the state of technology (SOT), is often lacking.

BETO supported the Bioprocessing Separations Consortium's formation in Fiscal Year 2017 to address the technical challenges and opportunities bioprocessing separations pose and stakeholder feedback (EERE 2014, 2015) that separations challenges impede the costcompetitive production of biofuels and bioproducts. BETO's internal analysis supports this feedback, identifying separations challenges that, if resolved, could reduce minimum fuel selling price (MFSP) of biofuels by up to $50 \%$. The goal of the Bioprocessing Separations Consortium is to develop separations technologies that are cost-effective, high-performing, and scalable through coordinated research that targets industry-relevant bioprocessing separations challenges. As a result of the Consortium's efforts, biofuels and bioproducts industries will have new technologies available to them and they will be able to explore technology options through Consortium analysis.

Furthermore, the Consortium interfaces with several BETO consortia and projects including ChemCatBio (ChemCatBio 2020), Chemical Upgrading of Biological Intermediates (Elander et al. 2019), Lignin-First Biorefinery Development (Beckham 2019), the Agile BioFoundry (Agile BioFoundry 2020), Co-Optima (EERE 2020), Performance Advantaged Bioproducts (Fitzgerald and Bailey 2018), and the Consortium for Computational Physics and Chemistry (CCPC 2020). The Consortium has multiple roles and objectives in these interfaces, including producing difficult-to-obtain purified products from crude mixtures for further processing, as well as evaluating and identifying cost-effective separations routes to target products of interest.

Motivated by the need to reduce bioprocessing costs to make the production of biofuels and bioproducts more cost-effective, the Consortium sought to advance the science and technology of bioprocessing separations in its first three years. This report documents these advances and provides a brief overview of the Consortium's direction going forward. 


\section{Consortium Approach}

All biomass conversion pathways (Figure 1) require cost-effective, molecularly-efficient separations. The science and technology for the separations challenges encountered during biomass conversion remain at relatively early stages and at times must be developed on a case-by-case basis.

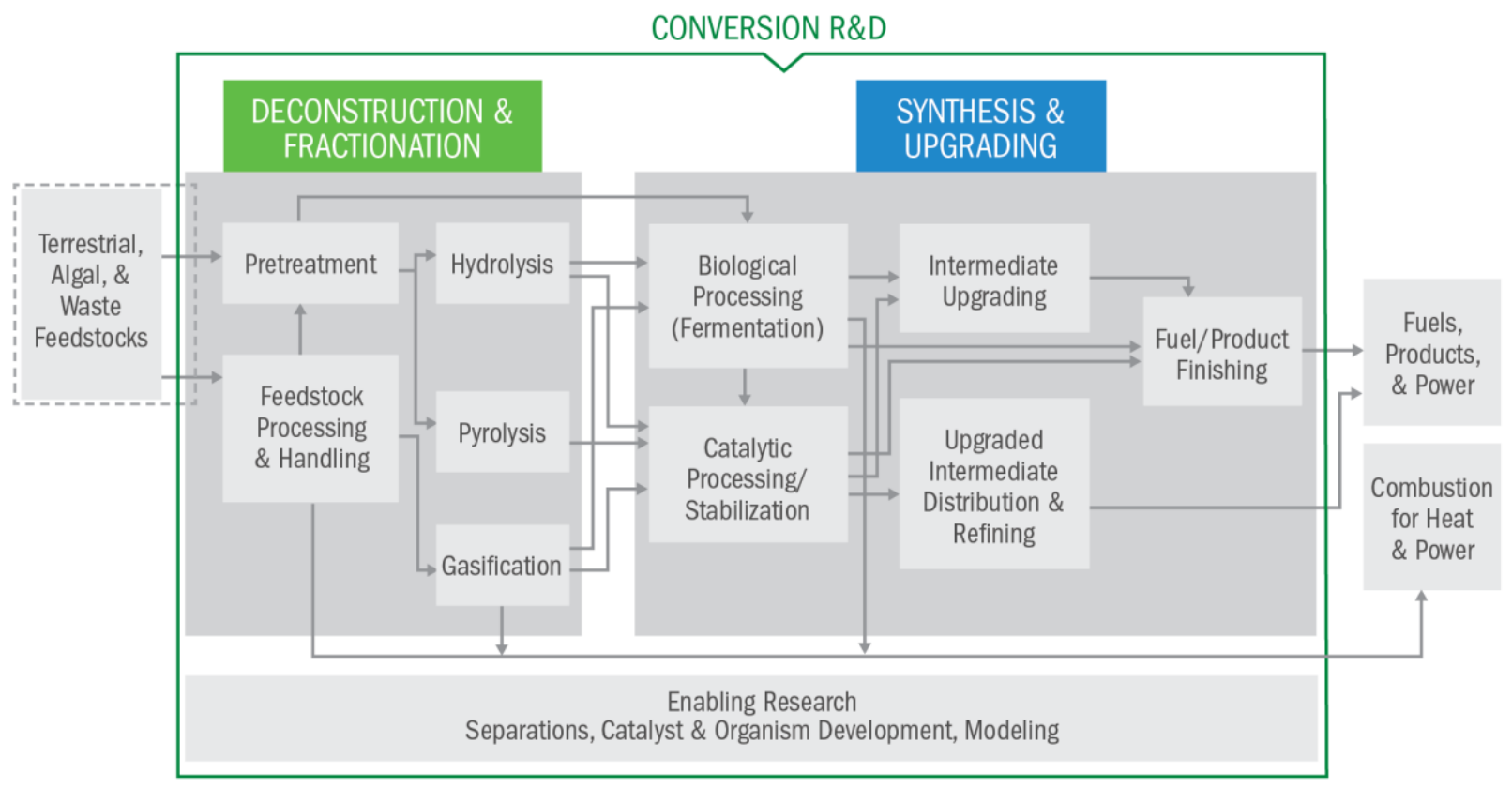

Figure 1 Conversion pathways from feedstock to products (Dunn et al. 2019).

Given the breadth of separations challenges, establishing research priorities for the Consortium requires a structured approach. Figure 2 outlines the approach the Consortium uses to select projects. To start, the Consortium gathers information regarding relevant separations challenges from a variety of external sources. For example, the Consortium confers with the advisory board (Section 5.1) at least twice a year during face-to-face meetings. It also seeks advice from the broader research and industrial community through activities such as the 2017 Listening Day (Bioprocessing Separations Consortium 2017). At this meeting, the Consortium gathered information about compounds of interest to the community (Table 2) and gaps in technologies available to recover them from bioprocesses. The Consortium also carried out a Directed Funding Opportunity (see Section 5.3) in which industry collaborates with national laboratories to solve separations challenges of direct interest to a partner company. Finally, we also solicit feedback from other research teams in the BETO research and development portfolio that face separations challenges. 

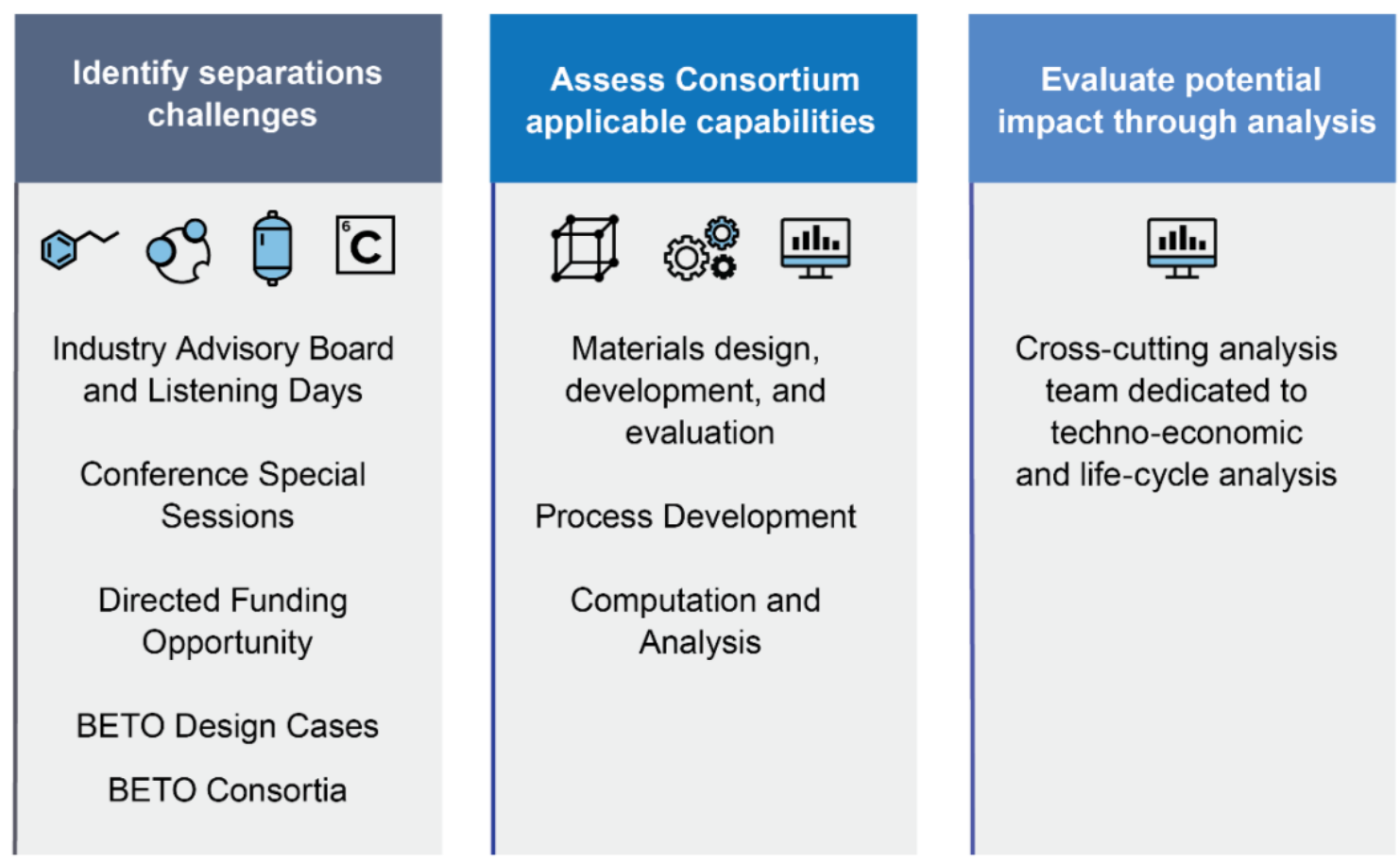

Figure 2 Approach to prioritizing research challenges to incorporate in the Consortium's portfolio.

The next step in identifying priority and viable projects is to assess whether Consortium capabilities are suitable to address the identified challenges. The Consortium's key capabilities center on materials design, development, and evaluation, process development, and computation and analysis. It is also important to assess whether the proposed technology can contribute to meeting cost targets for biofuels and bioproducts through overall improved bioprocessing. The Bioprocessing Separations Consortium analysis team addresses this issue and advises on this topic as the Consortium selects challenges for focus. With this process to guide project selection, the Consortium's research portfolio as described in this report has been designed to cover both biochemical and thermochemical process-related challenges and encompass a variety of technology solutions.

At its outset, the Consortium reviewed the existing design cases in the BETO portfolio and identified four overarching separations challenges that formed the basis of the Consortium's project portfolio for its first 3 years (Figure 3 ). 
Table 2 Target compounds identified during Industrial Listening Day.a

\begin{tabular}{|c|c|c|}
\hline Product Class & $\begin{array}{l}\text { Associated Barriers } \\
\text { Discussed }\end{array}$ & Possible Solutions Discussed \\
\hline Alcohols & $\begin{array}{l}\text { High energy requirements for } \\
\text { distillation and dewatering }\end{array}$ & $\begin{array}{l}\text { Membranes for dewatering, process configuration- } \\
\text { based approaches, and molecular interactions }\end{array}$ \\
\hline $\begin{array}{l}\text { Organic acids } \\
\text { (monomers of low } \\
\text { molecular weight acids, } \\
\text { short chain fatty acids) }\end{array}$ & $\begin{array}{l}\text { High purity necessary for } \\
\text { polymer applications }\end{array}$ & $\begin{array}{l}\text { Resin-based capture, moving bed-type } \\
\text { chromatography } \\
\text { Focus on removing the organic from the water } \\
\text { rather than dewatering } \\
\text { Improve predictions of acid-water interactions }\end{array}$ \\
\hline $\begin{array}{l}\text { Aldehydes and ketones } \\
\text { (furfural, butyraldehyde, } \\
\text { acetone) }\end{array}$ & Can inhibit fermentation & In-situ removal from fermentation broth \\
\hline $\begin{array}{l}\text { Oils and fatty acids } \\
\text { (oleic and linoleic acids), } \\
\text { hydrophobic biofuel } \\
\text { precursors }\end{array}$ & $\begin{array}{l}\text { Isolation of closely related } \\
\text { structures with different } \\
\text { properties }\end{array}$ & $\begin{array}{l}\text { Exploit charged character } \\
\text { Chromatography potentially with silver- } \\
\text { functionalized resin } \\
\text { In-situ removal } \\
\text { Intracellular product recovery through dewatering, } \\
\text { cell lysis, lipid secretion, and separating lipid } \\
\text { products from membrane lipids }\end{array}$ \\
\hline
\end{tabular}

a Source: Bioprocessing Separations Consortium (2017).

\section{Remove catalyst}

poisons from

feedstocks and

fermentation broth
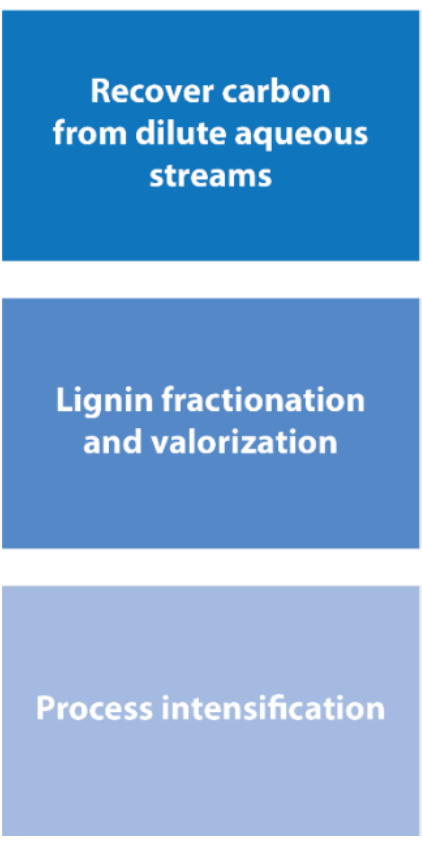

Poisons and foulants like carbonyls, furfural limit the lifetimes of upgrading catalysts and biocatalysts. Selective removal strategies to eliminate them will extend catalyst life and decrease processing costs.

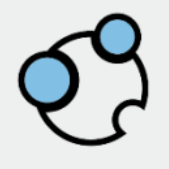

Increasing carbon efficiency of processes from recovery of valuable co-products can lead to improved process economics.

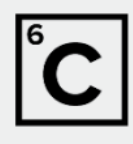

Lignin fractionation enables conversion to valuable co-products that can enhance process economics and sustainability.

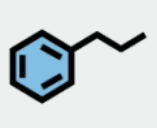

Reducing the number of processing steps associated with separations, including through reactive fermentation and in-situ product recovery, reduce process energy intensity and costs.

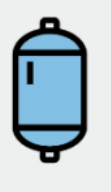

Figure 3 Overarching challenges the Consortium addressed in its first 3 years. 
First, the presence of low-molecular-weight foulants in bio-oil limits the performance and lifetime of catalysts used for upgrading thermochemical intermediates. This catalyst lifetime is a key driver of thermochemical processing costs, and the removal of catalyst poisons has the potential to enhance catalyst life downstream. Furthermore, reaction byproducts can poison microorganisms in biochemical processes; therefore, these microorganisms benefit from the removal of such inhibitory compounds to improve rate, titer, and yield of the desired product.

Second, improving the carbon efficiency of bioprocessing could improve processing costs through the recovery of additional carbon in the form of various coproducts. Dilute carbon products in both biochemical and thermochemical processes exist in aqueous streams, and their recovery could enhance carbon efficiency and process economics.

Third, the opportunity to convert lignin into value-added products could reduce the MFSP of biofuels. However, in order to do this the lignin must first be fractionated as a function of molecular weight.

Finally, process intensification is key to improving process economics by reducing capital and operating costs associated with processes. The projects described in the subsequent sections address these key themes, which were the focus of the Bioprocessing Separations Consortium from Fiscal Year (FY) 2017 through FY 2019. 


\section{Consortium Portfolio}

Figure 4 shows the Consortium structure for FYs 2017-2019. Experimental research was organized around separation issues related to biochemical processes (e.g., fermentation) and thermochemical processing (e.g., direct liquefaction). We also selected two seed projects that were performed in FY 2017.

\section{Bioenergy Technologies Office}

\section{Crosscutting Analysis}

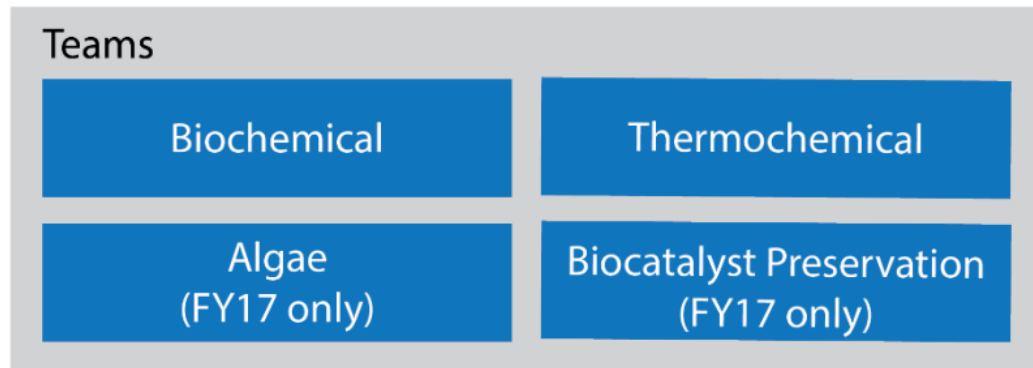

Figure 4 Consortium structure.

The Steering Committee is made up of Consortium lab members who work directly with BETO. They are charged with overseeing the research teams, providing guidance on technical direction, monitoring progress and impact, coordinating external communications, and managing Consortium business via reporting and monthly calls. Within the Consortium, the analysis team's purpose is to help direct research toward economic and sustainable outcomes, compare separation strategies, and consider risk in terms of applicability at a commercial biorefinery scale. The IAB provides real-world perspectives.

The following sections (4.1-4.2) describe the motivation, approach, outcomes, and gaps in the Biochemical and Thermochemical teams' work to date. We also report results for two consortium seed projects (4.3).

\subsection{Biochemical Processing}

Within biochemical processing, a key challenge is recovering products at necessary purity levels from fermentation broth, which is a complex and dilute mixture. Process integration could cut overall costs. Also, cost-effective routes to lignin utilization are essential for viable lignocellulosic biorefineries. 
Motivation. Lignin fractionation is key to its efficient and economically viable conversion to value added products (Humpert 2016). The Consortium continues to investigate multistage filtration to maximize lignin fractionation flux to reach industrially relevant throughput using three technologies, informed in part by interactions with the Lignin First Biorefinery Development and Lignin Utilization Projects, both also supported by BETO. The filtration stages are polymeric membranes in the range of $2-5 \mu \mathrm{m}$ followed by nanofiltration with ceramic membranes at approximately $450 \mathrm{Da}$.

Approach. The experimental setup consists of corn stover pretreatment with a base, then solid-liquid separation followed by membrane separation (Figure 5 ). Note that both polymeric and ceramic membranes are operated in tangential flow filtration (TFF) mode and both can foul (Arkel 2014). Ceramics have the

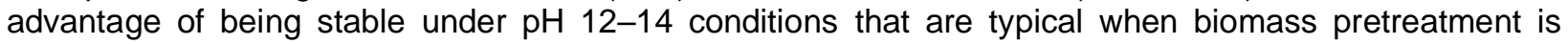
achieved with caustic-enabled mechanical deconstruction. Selected polymeric membranes can be operated within a $\mathrm{pH}$ range of $1.5-12$, and membrane regeneration has been demonstrated for this lignin fractionation application.

Although fouling was not a significant issue at the laboratory scale, it may become a challenge at larger scales. One option to reduce fouling on ceramic membranes is to use rotary disk filtration, a dynamic filtration technique that operates by rapidly moving the membrane surface to generate a high shear force at the filter surface. This high shear force constantly sloughs off material and reduces cake formation. This reduction in cake formation allows large reductions in volume while maintaining high permeance.

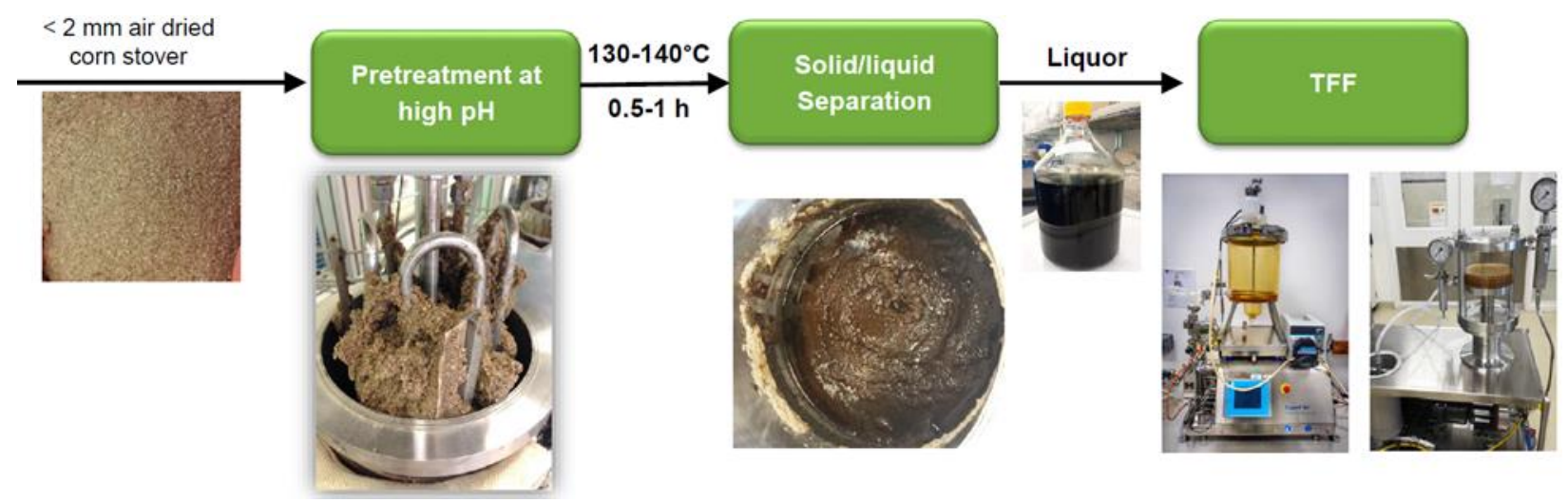

Figure 5 Experimental process for lignin separation via TFF membrane.

Results. Results for testing with different polymeric membrane materials are shown in Figure 6. The data demonstrate molecular weight fractionation using commercial TFF membrane separations.

The molecular weight response in Figure 6 indicates that large molecules $(>1 \mathrm{kDa}$ ) were separated by ultrafiltration ( $1 \mathrm{kDa}$ and $5 \mathrm{kDa}$ ) and nanofiltration. Compounds over $1 \mathrm{kDa}$ that initially are present in the alkaline pretreatment liquor (APL; black line) remain in the retentate. It is these large molecules that most impede lignin fractionation and subsequent processing. The ceramic membrane pore sizes of 5 and $1 \mathrm{kDa}$ were also effective at removing high-molecular-weight components and color (Figure 7).

The relative clarity of the $5-$ and $1-\mathrm{kDa}$ permeates compared to the lignin liquor feed indicates the absence of the high molecular weight compounds. Overall, this multistage approach to filtration improves flux The Consortium's multistage filtration approach to lignin fractionation achieved a flux 5-10 times greater than a single 450-Da filtration step. approximately 5 to 10 times compared a single-step 450$\mathrm{Da}$ filtration. Filters with this pore size are essential to remove high-molecular-weight components from 
lignin streams. Future work aims to increase permeance of these nanofiltration membranes to achieve industrially relevant processing throughput, which is at least $1 \mathrm{~L} / \mathrm{hr} / \mathrm{m}_{2} / \mathrm{bar}$.

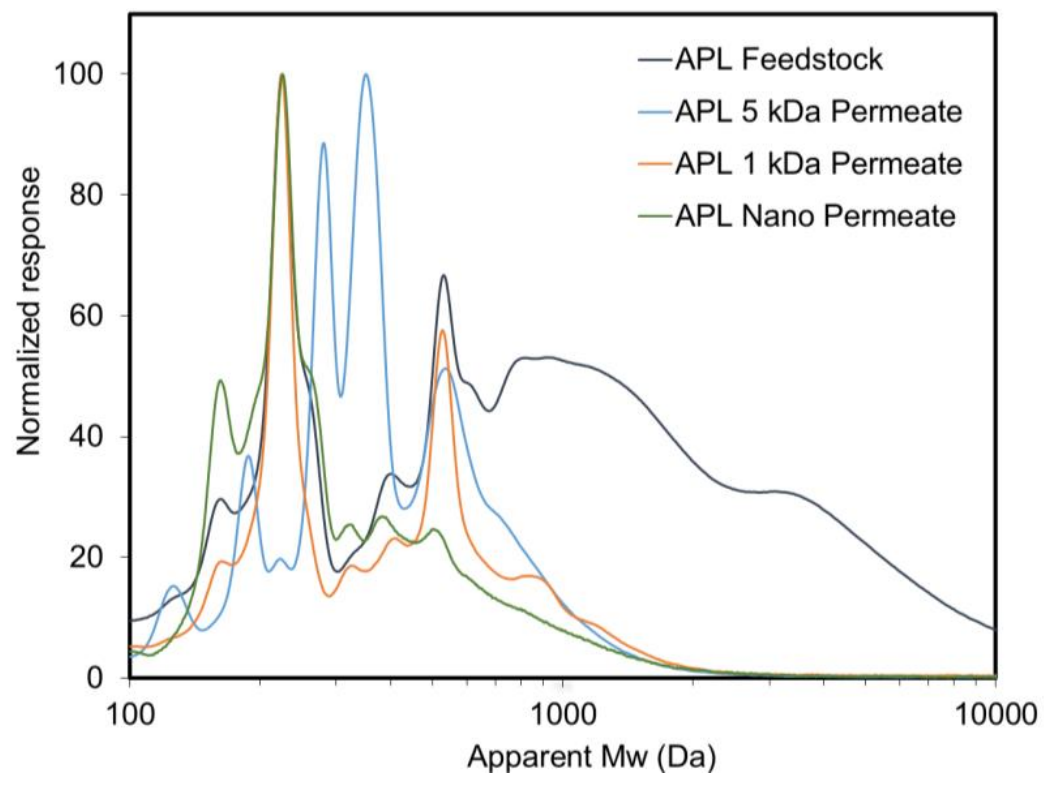

Figure 6 Molecular weight response for lignin fractionation via polymeric membranes: $5 \mathrm{kDa}, 1 \mathrm{kDa}$, and nano represent the membrane pore sizes; the $y$-axis is based on ultraviolet absorbance of gel permeation chromatography; compounds over $1 \mathrm{kDa}$ that are present in the alkaline pretreatment liquor (APL; black line) remain in the retentate.

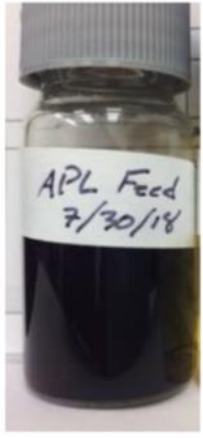

Lignin Liquor Feed
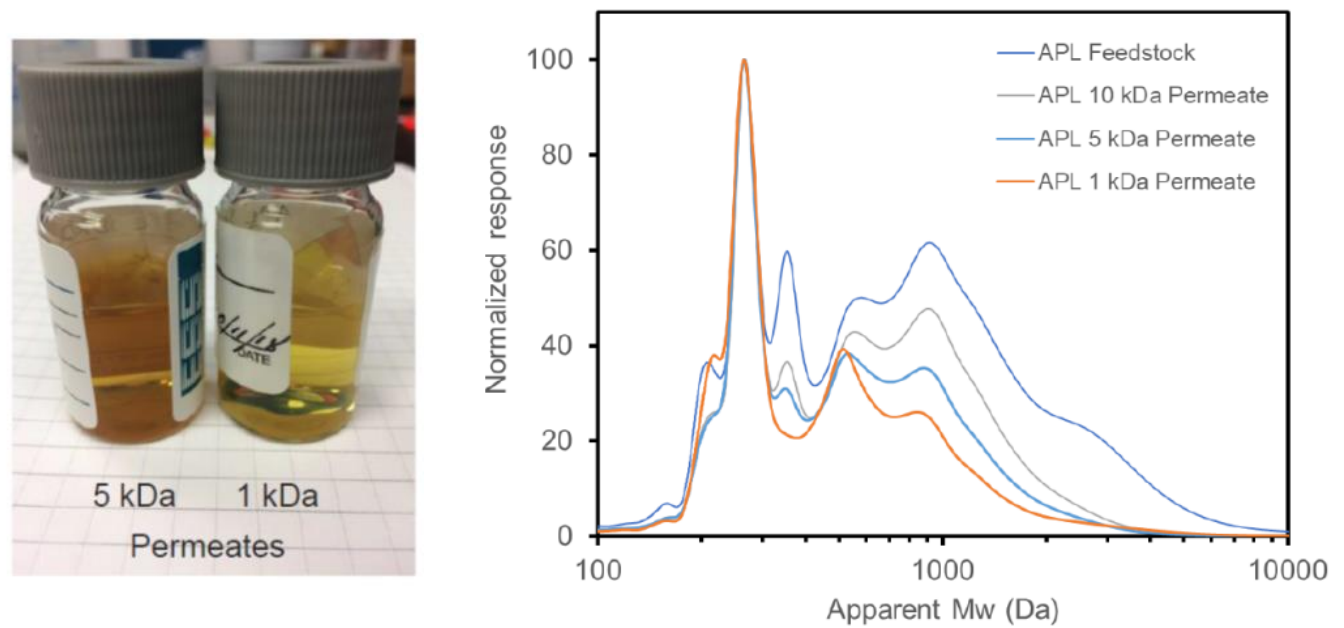

Figure 7 Left: Visual product quality. Right: Molecular weight response for lignin fractionation via ceramic membranes. Compounds over $1 \mathrm{kDa}$ that are present in the APL feedstock remain in the retentate. 


\subsubsection{In Situ Product Recovery (ISPR)}

Motivation. Often, distillation is the go-to separations strategy to recover products post-fermentation in a biorefinery. However, opportunities exist to leverage other separations techniques that could be less energy intensive and offer opportunities for process intensification.

The Biochemical Separations Team investigated ISPR to recover carboxylic acids from fermentation broth. Two technologies were used: hybrid extraction and distillation (HED) and electrodeionization (EDI).

In general, ISPR systems increase fermentation rate, titer, and yield by extracting a product from fermentation broth as it is produced. This ameliorates end-product inhibition, thereby allowing longer fermentation times with greater productivity.

Approach. The HED-ISPR apparatus developed in the Consortium (Figure 8) comprises a membrane contactor coupled with a distillation unit. In contrast, the EDI-ISPR separations (Figure 9) rely on ionexchange resins and electric fields to affect acid recovery.
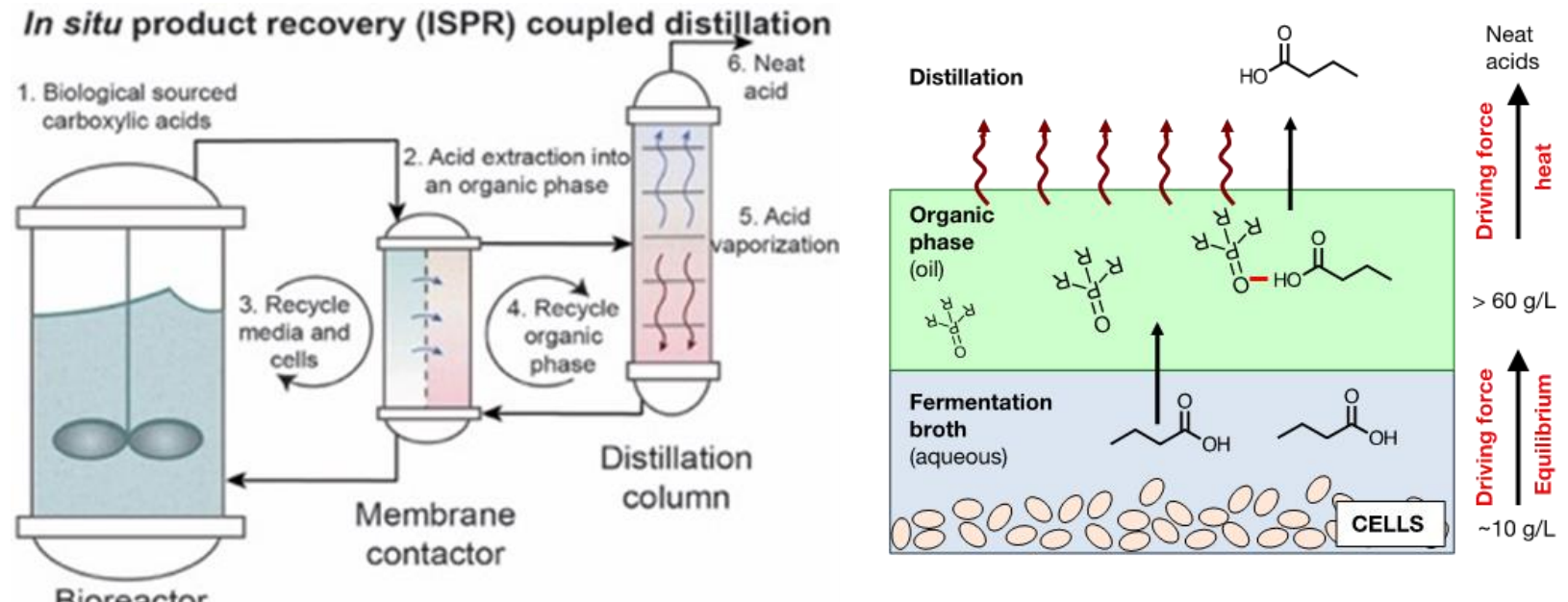

Figure 8 Left: HED-ISPR flow for carboxylic acid production and separation. Right: Conceptual separation effects (Saboe et al. 2018). 


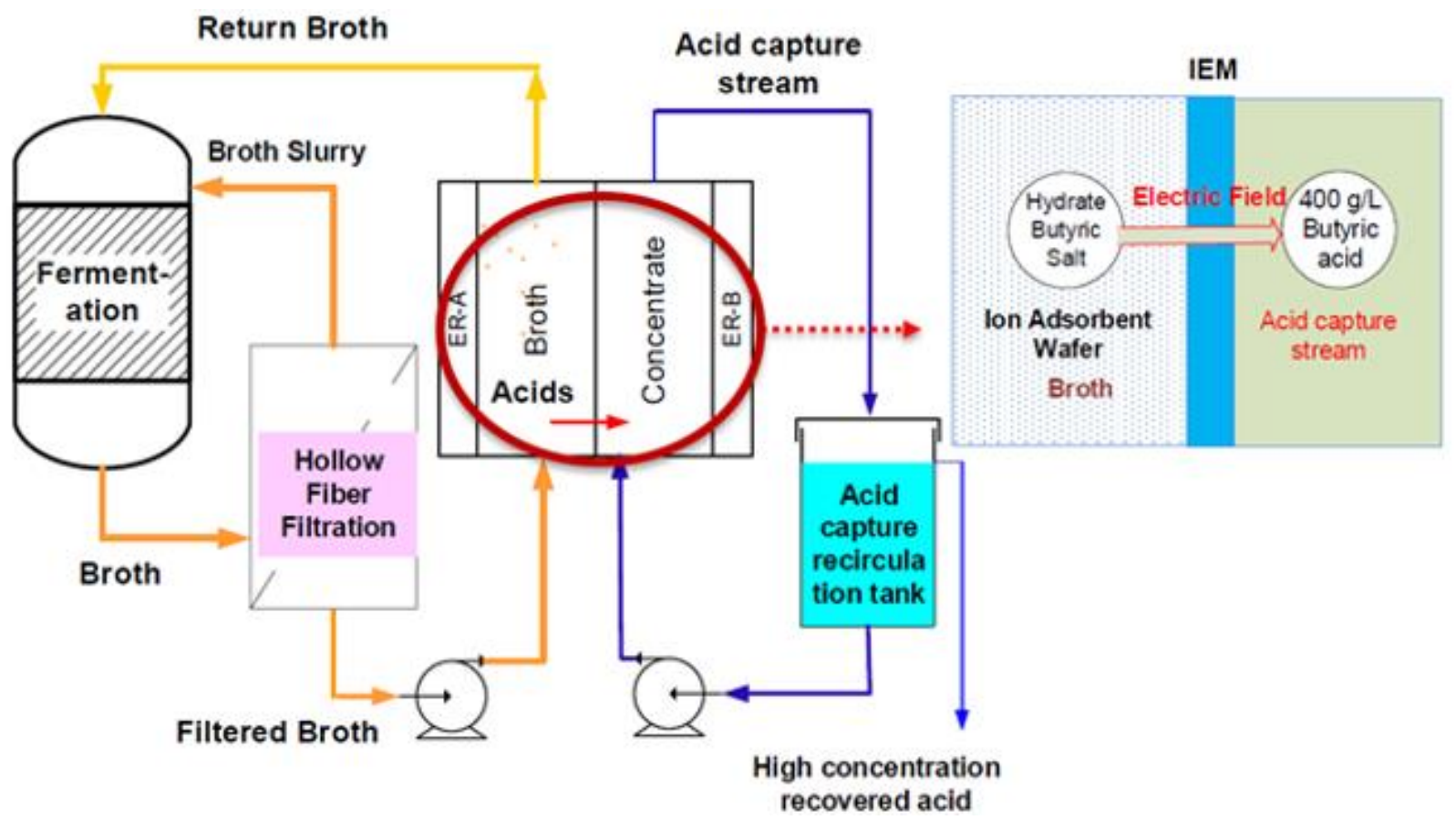

Figure 9 Left: EDI-ISPR acid recovery flow. Right: Conceptual separation effects.

Results: HED-ISPR. Research and development of HED-ISPR resulted in four key outcomes. First, a large number of extractants were evaluated for carboxylic acids and esters. Experimental screening of more than 20 extractants found the best extractant for carboxylic acid recovery is the commercial phosphine oxide extractant Cyanex 923 because of its ability to form strong acid base pairs with the acidic protons on carboxylic acids (Saboe et al. 2018). For esters, experimental screening found oleyl alcohol to be the most effective because its hydrostatic interaction with carbonyl functional groups in ester compounds is stronger (Saboe et al. 2019).

Second, important thermodynamic properties for carboxylic acids in fermentation systems were measured and reported for different solvents. These properties can be used in modeling and developing new processes to separate carboxylic acids.
HED-ISPR research led to identification of ideal extractants for carboxylic acids and esters. A publicly available model of the system is available to researchers exploring the technology. The energy-efficient process recovered $95 \%$ of $\mathrm{C} 4$ compounds in fermentation broth at a purity of $98.5 \% \mathrm{~mol}$. 
Third, a system model requiring only fermentation $\mathrm{pH}$ and maximum titer for microorganism productivity was developed (NREL 2019),1 made publicly available, and used to improve microbial performance. The model is an interactive $M A T L A B_{\circledast}$ application to easily predict organic phase acid loading for single and/or mixed acid systems (Figure 10). The model allows users to design a complete HED-ISPR system for a given carboxylic acid or ester bioproduct including the downstream distillation train needed for pure product recovery. Figure 11 illustrates an example of a system for bio-ester production and separation designed using this model.

Finally, the energy efficiency of the process was determined and compared to a benchmark to justify ongoing research and development. The HED-ISPR system has proven to be energy efficient; the energy footprint for the HED-ISPR does not exceed the combustion heat of the target product. For fuels, this means that the energy input into the system should not exceed approximately $20 \%$ of the HHV for that fuel to avoid gross energy inefficiencies. ASPEN modeling confirmed that the HED-ISPR system energy footprint was $<20 \%$ of the HHV of the separated acids at a target concentration of $>98 \%$ purity, meeting this target (Figure 12). Overall, the HED-ISPR system separated 98.5 mol\% pure $\mathrm{C}_{4}$ carboxylates from a live culture at a yield of approximately $95 \%$ of total butyric acid produced in the culture.

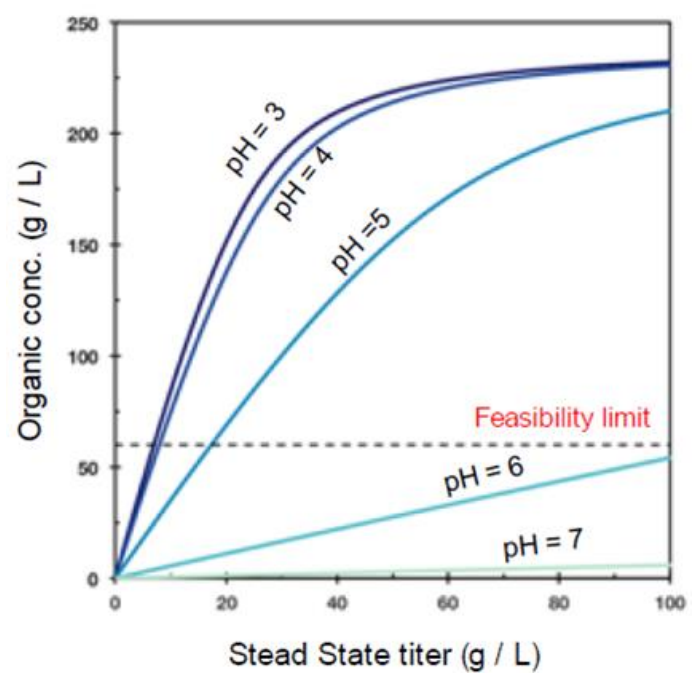

Figure 10 HED-ISPR equilibrium concentration of butyric acid in the organic phase as a function of $\mathrm{pH}$ and the initial acid concentration in the aqueous phase (i.e., steady state titer) (Saboe et al. 2018). The concentration in the organic phase must be $>60 \mathrm{~g} / \mathrm{L}$ to achieve a system energy footprint that is less than $20 \%$ of the carboxylic acid's higher heating value $(\mathrm{HHV})$.

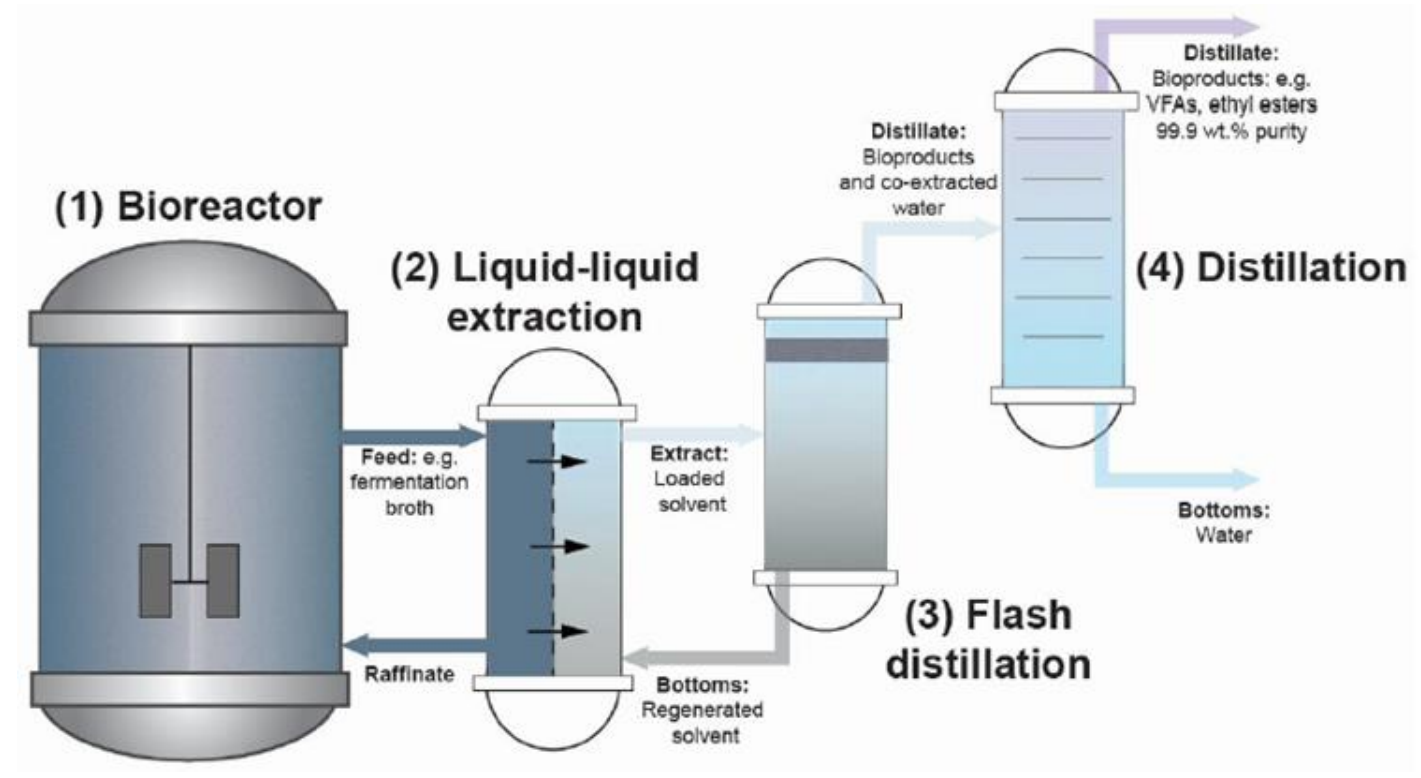

Figure 11 Bioreactor HED-ISPR for bio-ester production and separation (Saboe et al. 2019).

1 MATLAB code used to generate Fig. 7, S7 and S15† is available on GitHub.com (NREL-SEPCON/LLE Model_ISPR - https://github.com/NREL-SEPCON/LLE_Model_ISPR) 

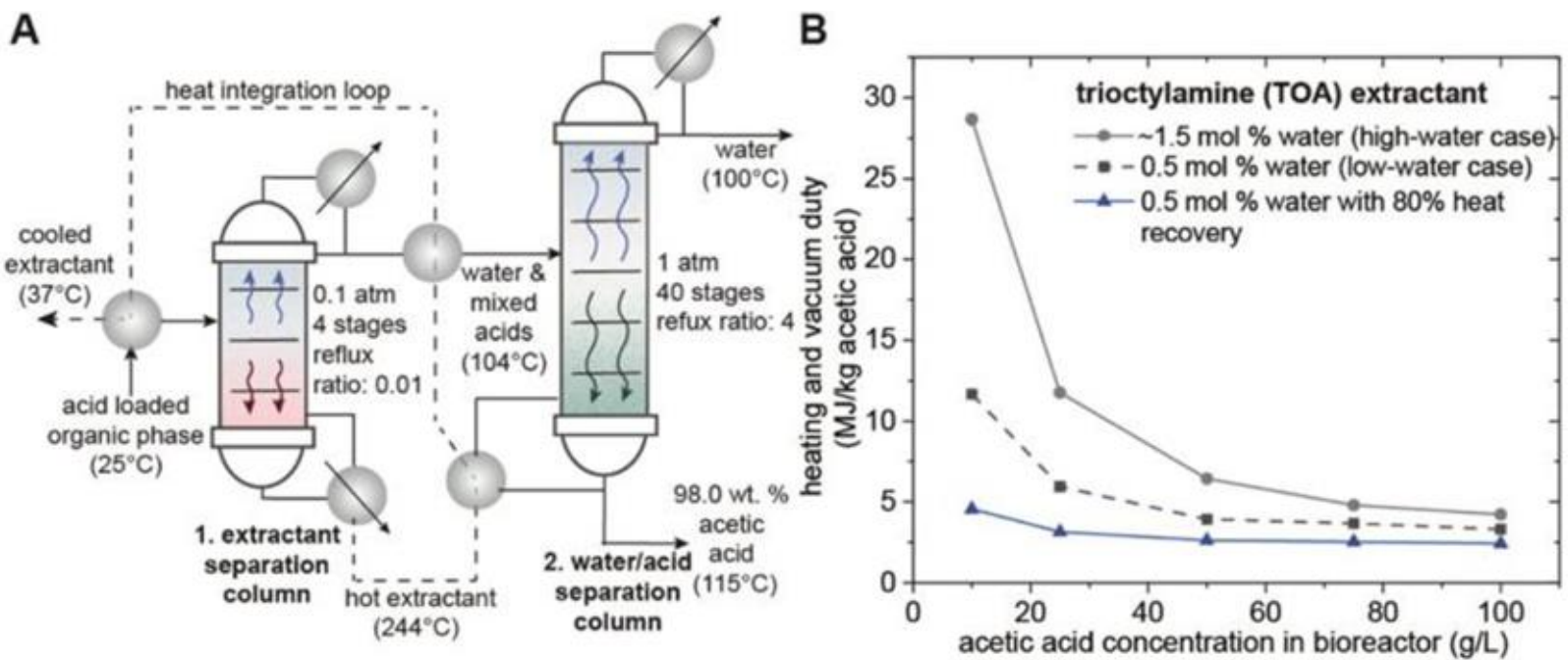

Figure 12 Trioctylphosphine oxide (TOPO) results: (A) Process diagram of acetic acid separation from extractant. In the first distillation column, extractant is easily separated from water and acid with four stages. A second column is needed to separate water from acid. (B) Energy input of the process per kilogram of acetic acid product as a function of acid concentration in the bioreactor at $\mathrm{pH} 3$. As acid titer in the bioreactor increases, the energy input decreases. Increasing water content in the organic phase increases the energy input (Saboe et al. 2018).

Results: EDI-ISPR. The second approach to ISPR incorporated resin-wafer EDI rather than HED. In EDI, the target organic acids are directly captured by ionadsorbent wafers. They are then extracted, converted, and concentrated without the use of solvent or acidification chemicals. Figure 13 illustrates EDl's ability to selectively capture the target carboxylic acid (butyric) at a constant concentration in the capture tank regardless of the remaining amount of acid in the fermentation broth.

Overall, the energy demand was $<1.0 \mathrm{kWh} / \mathrm{lb}$ acid, and more than $90 \%$ of the acid was recovered (Figure 13).
EDI-ISPR with modified resin wafers increased separation rates for acetic acid in a dilute aquesous solution 2.5 times above those achieved with conventional wafers. Energy consumption was simultaneosly cut by $60 \%$ Costs of carboxylic acid recovery were below the market price of these compounds. 


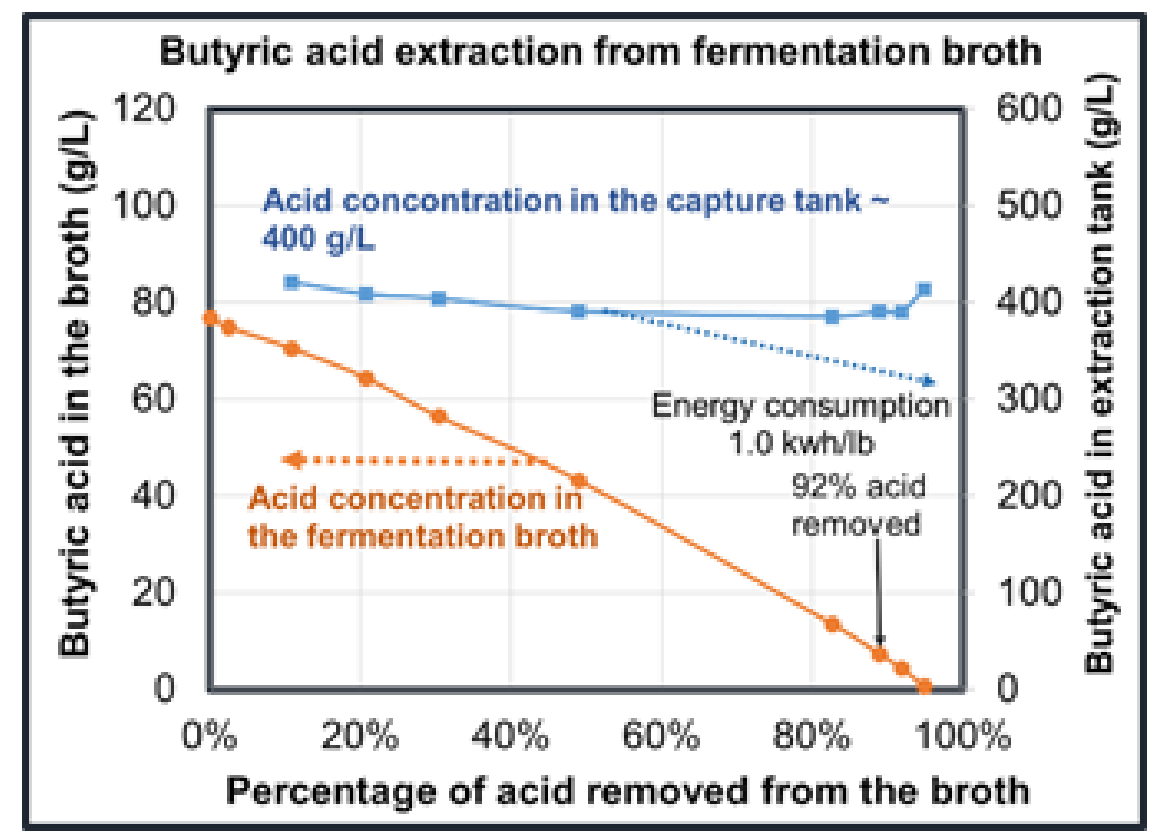

Figure 13 EC-ISPR acid recovery recovered $92 \%$ of butyric acid.

Further enhancing the separation efficiency requires improved resin wafer $(\mathrm{RW})$ material. A new conductive ionomer binder was developed in the laboratory to replace the nonconductive polyethylene binder in the conventional resin wafer (RW/PE). A 2.5-fold increase in separation rates was achieved with the novel ionomer bound RWs in comparison to RW/PE (Figure 14). The right panel of Figure 14 is a preliminary experimental result for the EDI-based recovery of acetic acid extraction from mock aqueous solution using the new wafer material. As an example of property characterization for the new wafer material, the middle panel displays its enhanced conductivity as compared to RW/PE.

Compared to experiments using RW/PE, experiments using the advanced wafer material exhibited over $60 \%$ less energy consumption and a nearly $2.5 \times$ higher capture rate. The acid extraction performance shows a potentially significant reduction of the processing cost of EDI operation stemming from lower energy consumption and greater capture rates.

Integrated experiments with EDI-ISPR achieved $>95 \%$ capture of the $65 \%$ yield $(\mathrm{g} / \mathrm{g})$ of $\mathrm{C}_{2} / \mathrm{C}_{4}$ carboxylic acids from the fermenter broth with a total energy consumption of approximately $<1.0 \mathrm{kWh} / \mathrm{lb}$. During the 70-hour integrated fermentation-separation operation, adding a neutralization chemical (i.e., $\mathrm{NaOH}$ ) was avoided due in-situ recycling of $\mathrm{NaOH}$ back to the fermenter. The captured carboxylic acid product titer was in the range of $180-250 \mathrm{~g} / \mathrm{L}$ in pure acid form. This separation performance will enable organic acid capture with an approximate cost in the range of $\$ 0.05-0.1 / \mathrm{lb}$ pure acid. Organic acids generally cost between $\$ 0.5-$ $2.0 / \mathrm{lb}$., so this result is a promising indication of economic viability.

Remaining research and development includes evaluation of the new resin wafer material's stability in an actual industrial processing stream over a long period of operation. Furthermore, the EDI-ISPR system needs a robust techno-economic analysis (TEA); this work is planned moving forward. Notably, EDI utilizing a three-compartment configuration can recover $\mathrm{NaOH}$ in addition to separating butyric acid. Further enhancements in process cost and sustainability may be possible if EDI-ISPR is used to capture $\mathrm{NaOH}$ for reuse in the fermenter where it is critical for $\mathrm{pH}$ adjustment. 


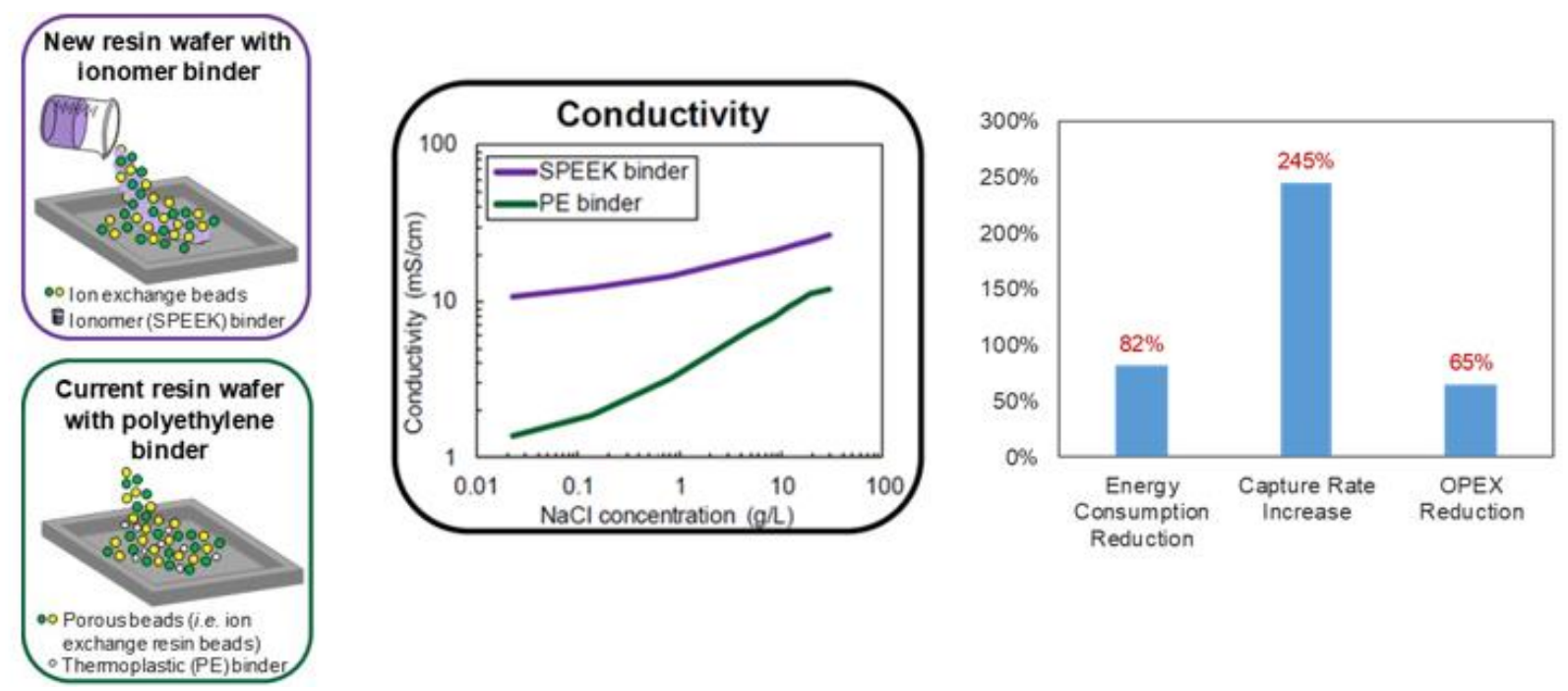

Figure 14 EDI membranes and performance for recovery of acetic acid from a dilute aqueous solution. Improvements in far-right figure are in comparison to RW/PE and demonstrate significant reduction in energy consumption with a 2.5 -fold increase in capture rate.

\section{${ }^{\circ} \mathrm{C}$

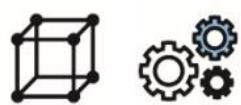 \\ 4.1.3 Membrane-Sorbent Separations for Diol Recovery}

Motivation. Organic acids are just one of the many products from fermentation; alcohol recovery is also important to industry and the BETO portfolio (Table 2). Distillation is often a standard separations approach for alcohols like ethanol. Heavier alcohols and diols, however, are not necessarily well-suited for distillation.

One diol of particular industrial interest is 2,3-butanediol (BDO). The Consortium has investigated new approaches to recover this diol from fermentation broth because current industrial methods for its recovery are energy-intensive, requiring multiple distillation stages at high temperatures. In addition, the process requires a hydrogenation reactor to decompose the oligomers produced at such high temperatures.

Approach. The new approach to BDO separations in the Consortium is to apply selective membranes that pull 2,3-BDO from the broth, which is a complex mixture of BDO, inorganic salts, proteins, and organic byproducts that is more than $90 \%$ water. Such a high water content required a membrane to be developed (Figure 15a) that allows for highly selective, high-throughput permeation of water and targeted removal of impurities at low temperatures (e.g., $60-80^{\circ} \mathrm{C}$ ).

Results. Membrane performance in separating BDO and water is shown in Figures 15b and 15c: The hydrophobic membrane achieved a separation factor (SF) of over 15 with a flux 0.4 liters per hour per square meter $\left(\mathrm{L} / \mathrm{hr} / \mathrm{m}_{2}\right.$ or

Newly developed superhydrophilic membranes exceed state-of-the art separation factor and flux by 7 times. $\mathrm{LMH})$ at a very mild vacuum pressure $(5 \mathrm{in} . \mathrm{Hg})$. In addition, newly synthesized superhydrophilic membranes achieved an even higher SF of approximately 160 , with a higher flux of $0.7 \mathrm{LMH}$. Both SF and flux of the superhydrophilic membranes are 7 times larger than literature state-of-the-art results (Xu et al. 2018; Shao et al. 2009). 
(a)

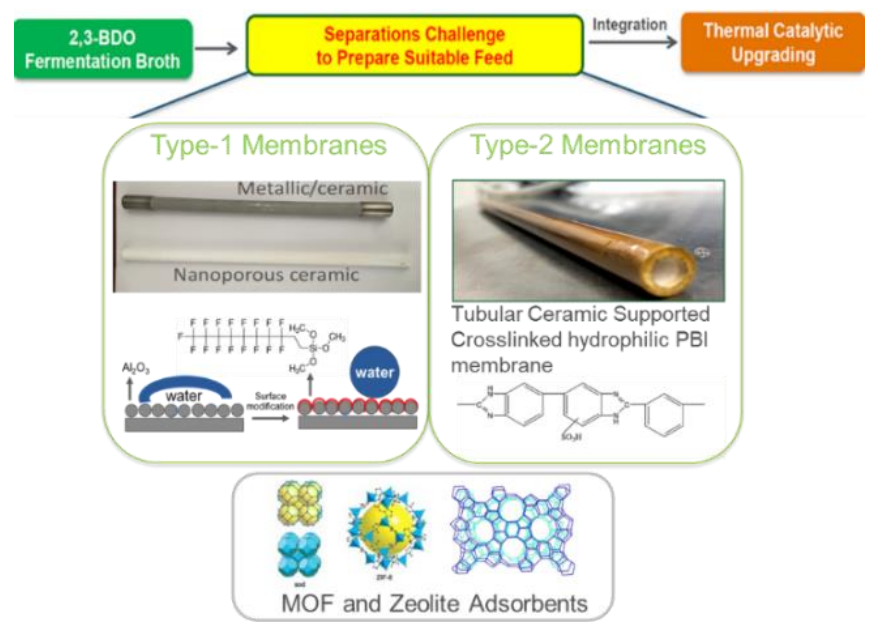

(b)

$10 \mathrm{wt} \%$ BDO Separation at different vacuum pressure at $80^{\circ} \mathrm{C}$

Separation factor $\cong$ Flux

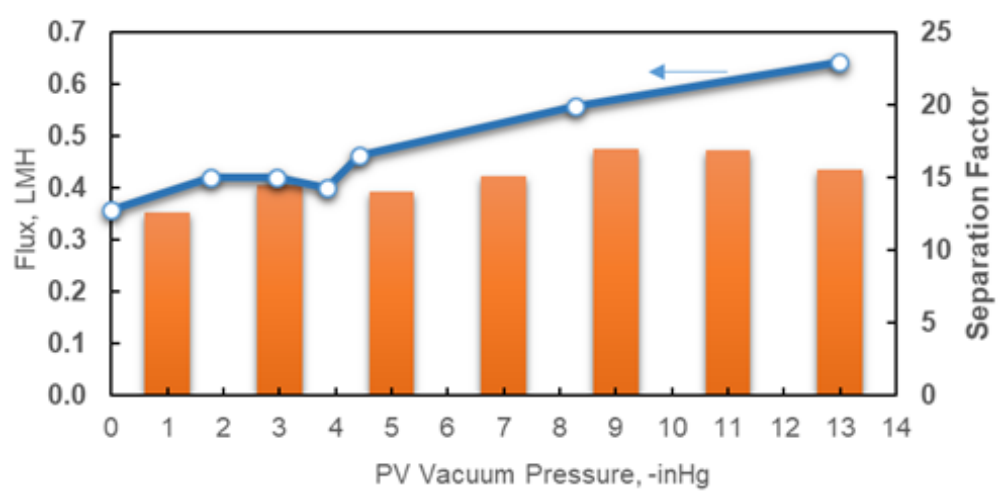

(c)

10 wt\% BDO Separation at Different Temperatures

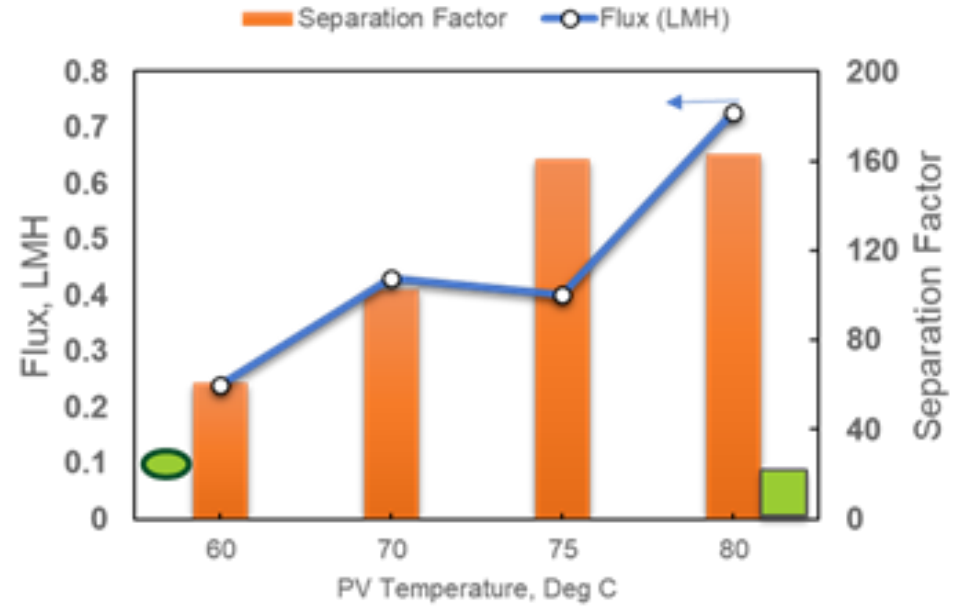

Figure 15 (a) Pervaporation membranes and sorbents evaluated for BDO separations; (b) Type-1 hydrophobic membrane performance at different vacuum pressures; (c) Type-2 superhydrophilic membrane performance at different temperatures. These results demonstrate that the separation factor and flux of the superhydrophilic membrane are seven times the state-of-the-art (green spots) based on literature data (Xu et al. 2018; Shao et al. 2009). 
In addition to enriching BDO, sorbent materials, including mordenite framework inverted-structured zeolites and zeolitic imidazolate frameworks tested in parallel with membrane pervaporation, have shown the potential to selectively separate BDO from catalyst coking molecules such as glycerol, acetoin, or sugars. The enriched, purified BDO stream serves as suitable feed to catalytic upgrading reactors to ultimately achieve better BDO conversion to fuels and chemicals at a lower cost. This will be quantified through analysis.

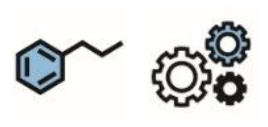

\subsubsection{Ultrasonic Separation of Lignocellulosic Particles}

Motivation. In biochemical processes that utilize lignin, fine particles foul equipment and impede lignin conversion. Ultrasound is one technology that could be used to remove lignocellulosic fines because standing acoustical waves concentrate particles at regularly spaced nodes (Figure 16). Particulates aggregate into larger entities and eventually precipitate out from solution.

Key research questions in the application of ultrasound to removal of lignocellulosic fines included whether particle size was in the range that works well for ultrasonic separations and how much energy is required to separate lignocellulosic fines using ultrasound.

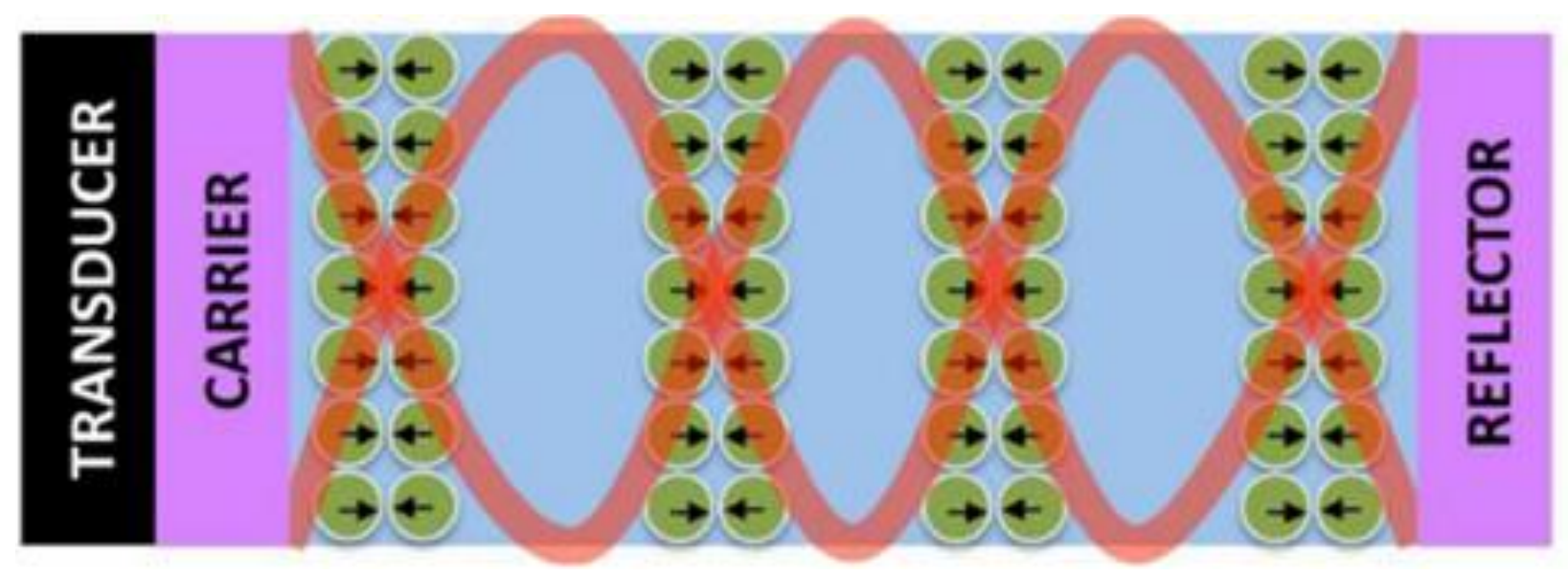

Figure 16 Ultrasonic separation conceptual illustration. Energy is applied to a system, generating a standing acoustic wave. Lignocellulosic fines concentrate at the nodes of waves and then precipitate.

Approach. Tests were carried out to establish energy requirements for a reference suspension of lignocellulosic particles using the experimental setup shown in Figure 17. To acquire sufficient volumes of suspended fines, washed alkali deacetylated corn stover was obtained from LBL, wet milled, and resuspended in water at a concentration of $0.56 \pm 0.03 \mathrm{~g} \mathrm{AFDW/L,} \mathrm{where} \mathrm{AFDW} \mathrm{is} \mathrm{ash} \mathrm{free} \mathrm{dry} \mathrm{weight.}$ Tests were carried out in two distinctly different operating modes: (1) a baseline mode representing current industry practice, and (2) a proprietary low-energy approach.

Results. Agreement was observed between quiescent batch and flow tests, which indicates that hydrodynamic drag forces did not impair performance under the conditions tested. Hydrodynamic effects, however, become apparent when the feed flow rate is too high and entrained solids are swept out of the vessel. Based on the fraction of fines removed in Figure $17(\sim 50 \%)$, it is likely that a significant portion of the milled fines in the reference suspension are too small for ultrasonic removal. 

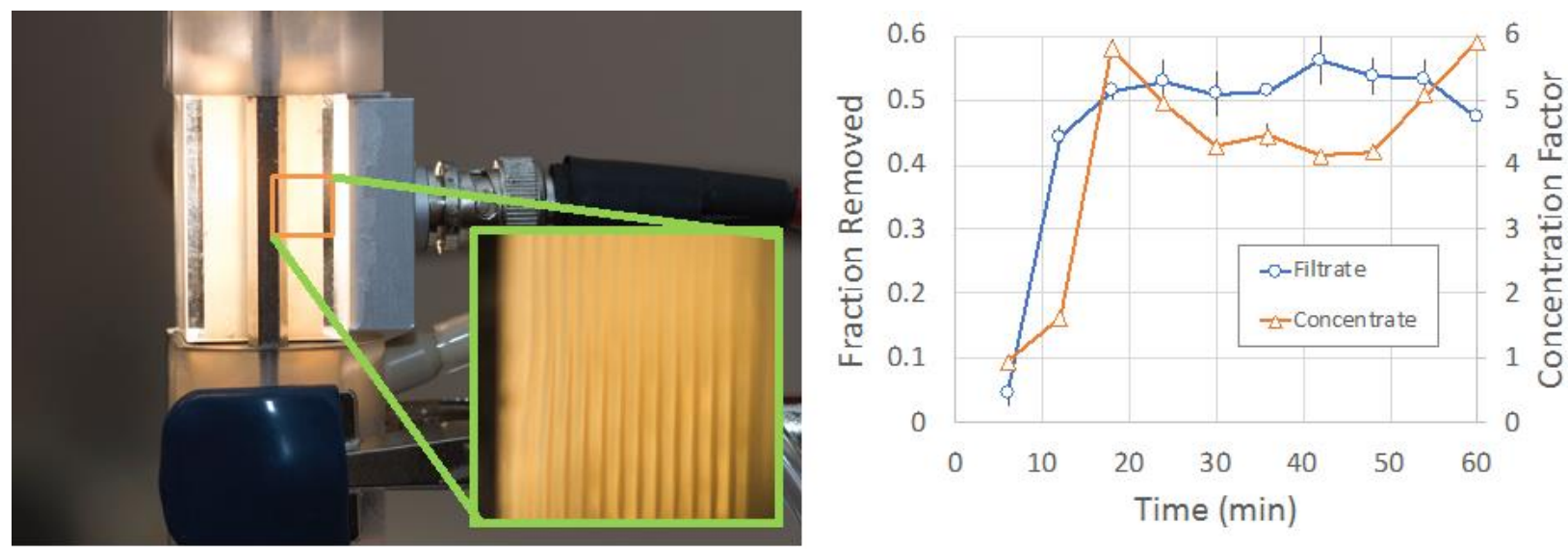

Figure 17 Left: Ultrasonic experimental setup showing fines concentration in the standing wave. Right: Experimental results of fines removal in continuous flow. Fines in both filtrate and concentrate streams reach near-steady-state concentrations after the first 20 minutes.

In order to assess the viability of ultrasonic technology for the separation for lignocellulosic particles, the energy required to remove lignocellulosic fines is compared to their energy content in Figure 18. The energy content serves as a general reference for fines suspensions and is calculated by assuming a HHV value of $17 \mathrm{MJ} / \mathrm{kg}$ AFDW. The relative energy costs, indicated by red and blue lines in Figure 18, display a minimum and illustrate that maximum fines removal comes at a higher fractional energy cost. The minimum can span a range of costs, but it generally corresponds to $40-60 \%$ of removable particles.

Although both operating modes are in the same energy band as centrifugation (i.e., $1-5 \mathrm{kWh} / \mathrm{m}_{3}$ ), the Consortium-developed mode removes more fines than conventional operation at a fixed energy input. The

Consortium-developed ultrasound technology can be more efficient at fines removal than conventional ultrasound technology. energetics shown in Figure 18 also serve as a master curve for lignocellulosic fines removal and can be diagonally shifted to obtain first-order performance estimates for suspensions with different concentrations of fines. For example, a suspension twice as concentrated as the reference suspension should yield twice the fines removal at the same energy input. By shifting the data at constant energy input until twice the removal is indicated, the performance curve at the more concentrated condition can be approximated.

However, the master curve paradigm does have limitations. First, at some point adding more particles to the feed suspension will start to degrade performance. Second, the paradigm fixes performance in the centrifugation energy band while lower energy bands are theoretically attainable. The energy band is determined by the test vessel used in this study and was optimized given the vessel constraints, but it is still relatively inefficient. Vessels capable of shifting the performance band to lower energies are on hand at LANL but require significantly more material for testing.

Although lower energies are theoretically attainable, they are likely within an order of magnitude of the results shown. This master curve approach provides insights useful for TEA in terms of estimating particle removal as a function of energy input under these two operating scenarios. However, it does not address the uncertainty originating from particle loading and energy band limitations. 


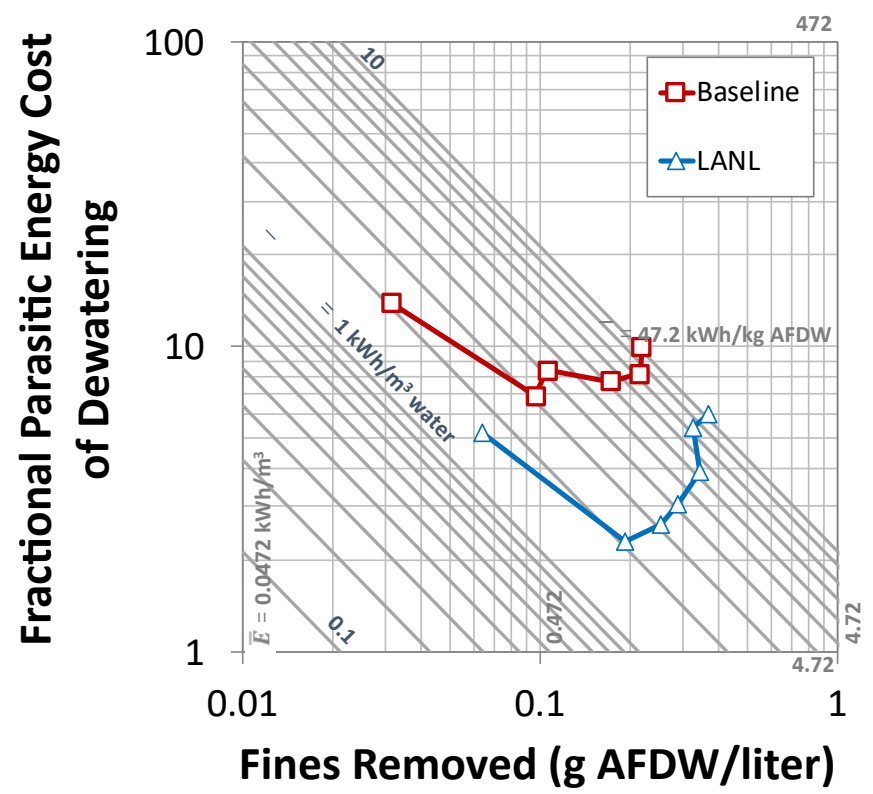

Figure 18 Vessel-limited energetics of cellulosic fines removal using ultrasonic filtration in baseline and LANL operating modes. The diagonal lines indicate the energy input per volume of suspension. Vertical and horizontal lines are referenced to the $\mathrm{HHV}$ of $17 \mathrm{MJ} / \mathrm{kg}$ to indicate the energy content of the removed fines and the energy input per unit mass of fines removed, respectively. The same feed suspension was used in both sets of tests shown. Additional fractional energy improvements require vessel optimization.

\subsubsection{Recovery of $\mathrm{NaOH}$ and Lignin Products}

Motivation. EDI is well-suited to recover charged species, including $\mathrm{NaOH}$ used in homogeneous lignin depolymerization. Recovery and reuse of $\mathrm{NaOH}$ avoids consumption of fresh $\mathrm{NaOH}$ in the process that incurs cost and environmental impacts.

Approach. EDI (Figure 19) was selected as the separations technology to recover $\mathrm{NaOH}$ because it has a unique capability to separate charged species from aqueous solutions. Please see Section 4.1.2 for more information about the EDI experimental apparatus.

Results. EDI recovered $99 \%$ of $\mathrm{NaOH}$ and $95 \%$ of carboxylic acids at a $35-40$ wt\% concentration (Figure 19). The cost of recovering $\mathrm{NaOH}$ is lower than

The cost of recovery of $\mathrm{NaOH}$ with this EDI approach is lower than the cost of $\mathrm{NaOH}$ used in TEA of bioprocessing $(\$ 0.52 / \mathrm{kg})$. the cost of $\mathrm{NaOH}$ used in TEA of bioprocessing $(\$ 0.52 / \mathrm{kg})$. This result is promising; however, the EDI process must be integrated into an overall process model to fully evaluate the benefits and drawbacks of its application. Accordingly, this approach was initially integrated in the preliminary TEA of biochemical conversion of hydrolysate sugars to hydrocarbon fuels via short-chain carboxylic acid intermediates. Data gaps that must be addressed to fully evaluate EDI in this application include the need for improved adsorption material to capture and extract acids from lignin and to purify the acids and bases after capture. 
Three-compartment Electrochemical

\section{Separation Device}

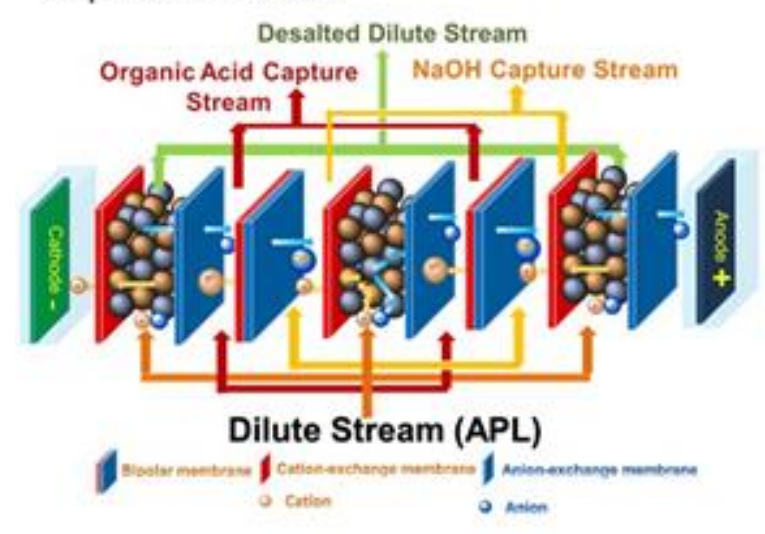

Simultaneous Capture of Carboxylic Acid and $\mathrm{NaOH}$ from $\mathrm{APL}$

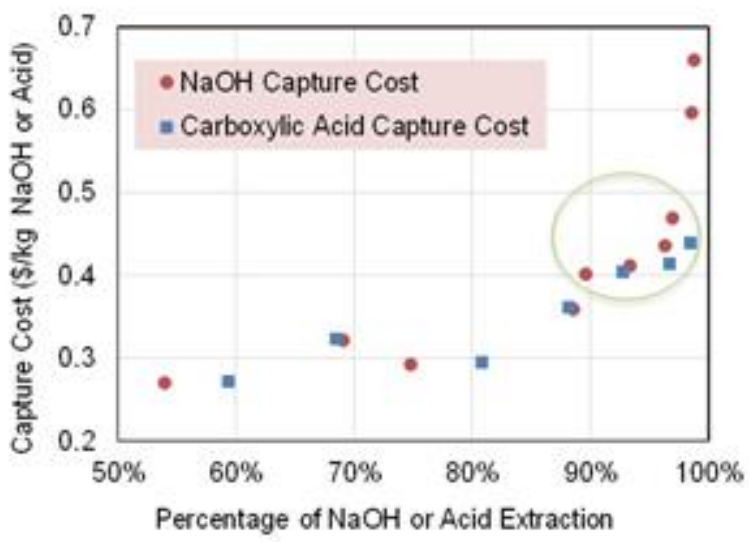

Figure 19 Left: EDI concept. Right: acid base separation results. EDI recovered $99 \%$ of $\mathrm{NaOH}$ and $95 \%$ of carboxylic acids at a 35-40 wt\% concentration. $\mathrm{NaOH}$ was captured at a cost below the market price used in techno-economic analysis $(\sim 0.52 / \mathrm{kg})$.

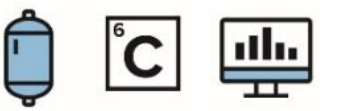

\subsubsection{Economics and Sustainability}

Within the Biochemical Separations Team, acid recovery is a common theme because acids are important as intermediates in the production of biofuels and as valuable products themselves. Analysis for biochemical separations therefore focused on acid recovery strategies, undertaking process modeling for three possible acid recovery techniques.

The baseline process was a simulated moving bed (SMB) system. Other strategies-EDI and pertractive separation-were compared to SMB. EDI was assessed within the context of a pH 7 fermentation, with the intent of later assessing lower $\mathrm{pH}$ cases. The third process was pertractive separation integrated with low$\mathrm{pH}$ fermentation. The processes, shown in Figure 20, were modeled within the context of a conceptual commercial-scale biorefinery using a biochemical design case as the framework (Davis et al. 2018).

The preliminary TEA results show the relative cost results compared to the baseline (Figure 21). Note that these costs assume that lignin is burned for power; lower fuel production costs can be achieved through the conversion of lignin to chemicals.

Pertractive technologies (HED-ISPR) showed the lowest overall MFSP. One driver of this result is higher targeted yields (at $100 \%$ ), and low raw material make up (i.e., salt wastes) because of the low-pH fermentation and limited electricity demand in this case.

In this separations approach, the liquid membrane results in less solvent loss. The EDI approach was more

Analysis results demonstrated that Consortiumdeveloped technologies of pertractive separations and EDI applied to acids separations in biochemical processes offered opportunities for reduced cost and enhanced sustainability as compared to off-the-shelf simulated moving bed technology. expensive than the pertractive approach, primarily because the yields of recovered acid were lower (at 95\%) and greater energy consumption. Because EDI does not require low-pH fermentation as modeled, EDI could potentially be a mitigation strategy that may perform better than HED-ISPR in the anaerobic acids pathway. HED-ISPR requires a fermentation step that operates best at lower $\mathrm{pH}$. Some organisms, however, cannot tolerate $\mathrm{pH} \leq 5$. In those cases, EDIISPR is a better technology solution. 
The cost results were reviewed by the IAB and were included HED-ISPR was adopted for the acid pathway in the FY 2018 Biochemical Design Report (Davis et al. 2018).

Using the material and energy flows from the process modeling that informed the TEA, lifecycle analysis (LCA) was carried out using corn stover as a feedstock to estimate lifecycle greenhouse gas (GHG) emissions and water consumption. Compared to the SMB technology, EDI and pertractive separations exhibit lower life-cycle GHG emissions of the renewable diesel product produced by the biorefinery (Figure 22). Lower yields in the SMB case is one underlying factor of these results. Another key driver of GHG emissions in conversion (represented in the fuel portion of the biofuel lifecycle) is $\mathrm{NaOH}$ consumption used during biomass deconstruction. 


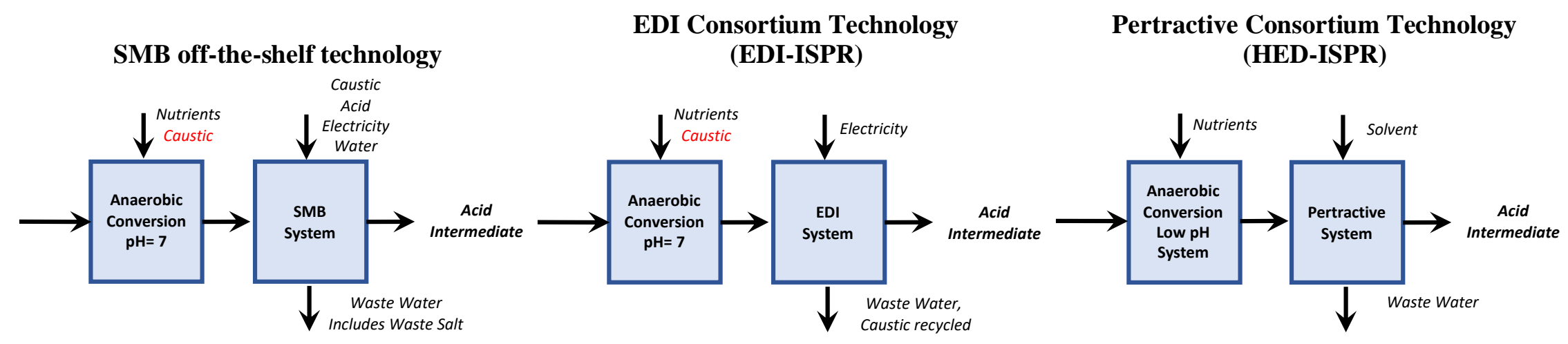

Figure 20 Box flow diagram for SMB, EDI-ISPR, and pertractive (HED-ISPR) separations. 


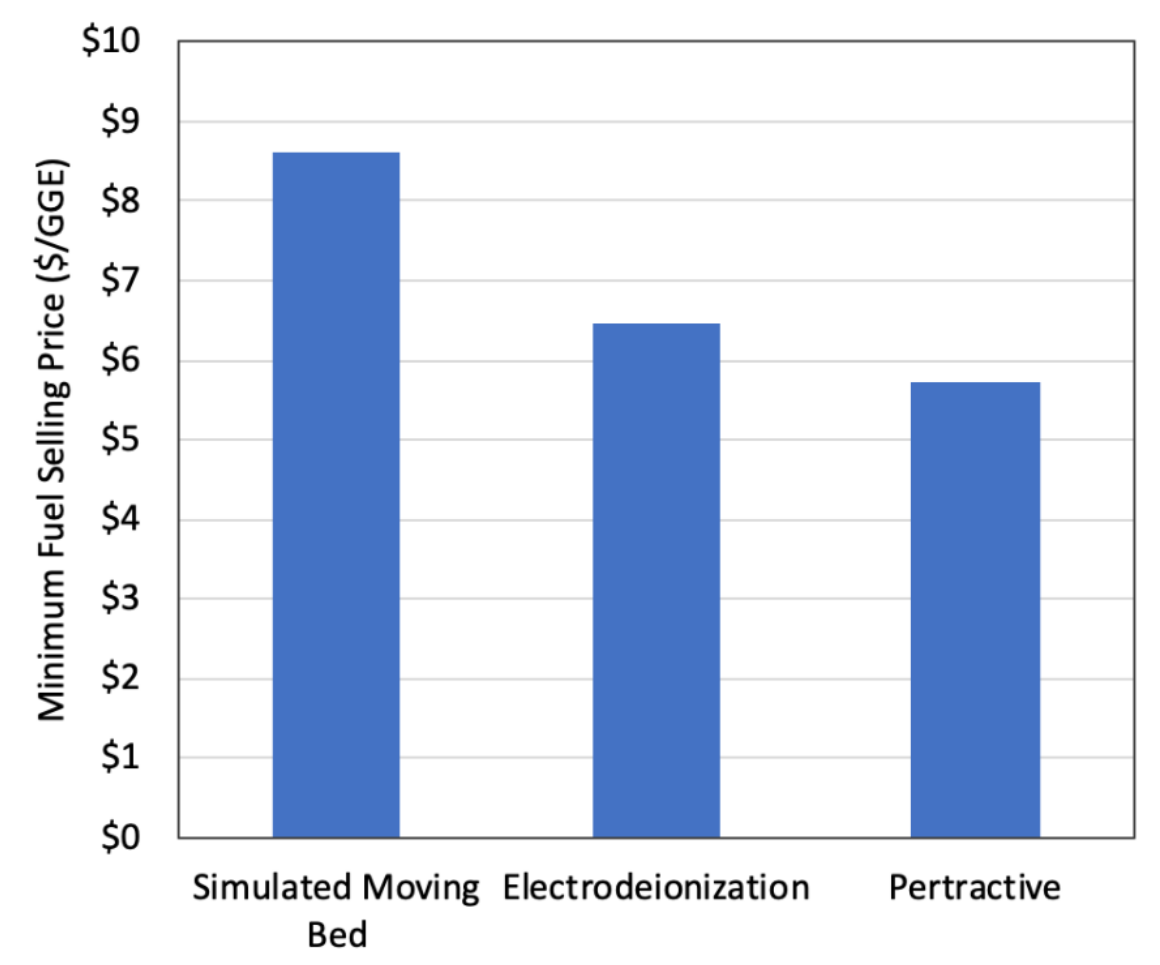

Figure 21 Separation costs for SMB, EDI, and pertractive technologies for an example biorefinery configuration (Davis et al. 2018). In this configuration, lignin is burned in a boiler; lower MFSP results are possible by alternative routes upgrading lignin to value-added coproducts.

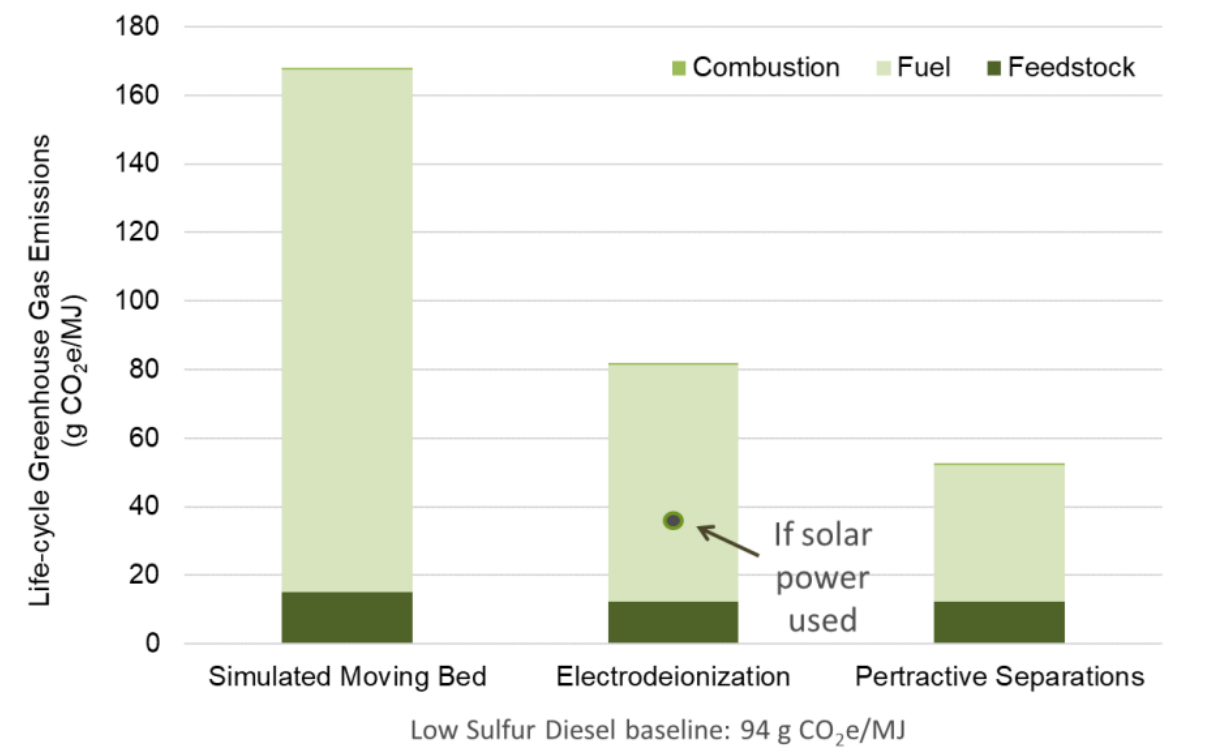

Low sulfur diesel baseline: $94 \mathrm{~g} \mathrm{CO}_{2} \mathrm{e} / \mathrm{MJ}$

Figure 22 Lifecycle GHG emissions for SMB, EDI, and pertractive technologies. Emissions for EDI are lower than that of both alternatives if solar power is used. 
Life-cycle water consumption was also estimated for the three separations approaches (SMB, EDI, and pertractive separations) that could be used in the production of the acid intermediate (Figure 23).

As for GHG emissions, the low yield in the SMB case resulted in more water consumed per MJ fuel than in the other cases. The SMB case also consumes more chemicals, such as $\mathrm{H}_{2} \mathrm{SO}_{4}$, to regenerate the resin in the moving beds.

Overall, the pertractive approach to separating the acid intermediate is most promising from a cost and sustainability perspective if a low-pH fermentation can be achieved. If this is not feasible, the EDI approach outperforms the SMB approach.

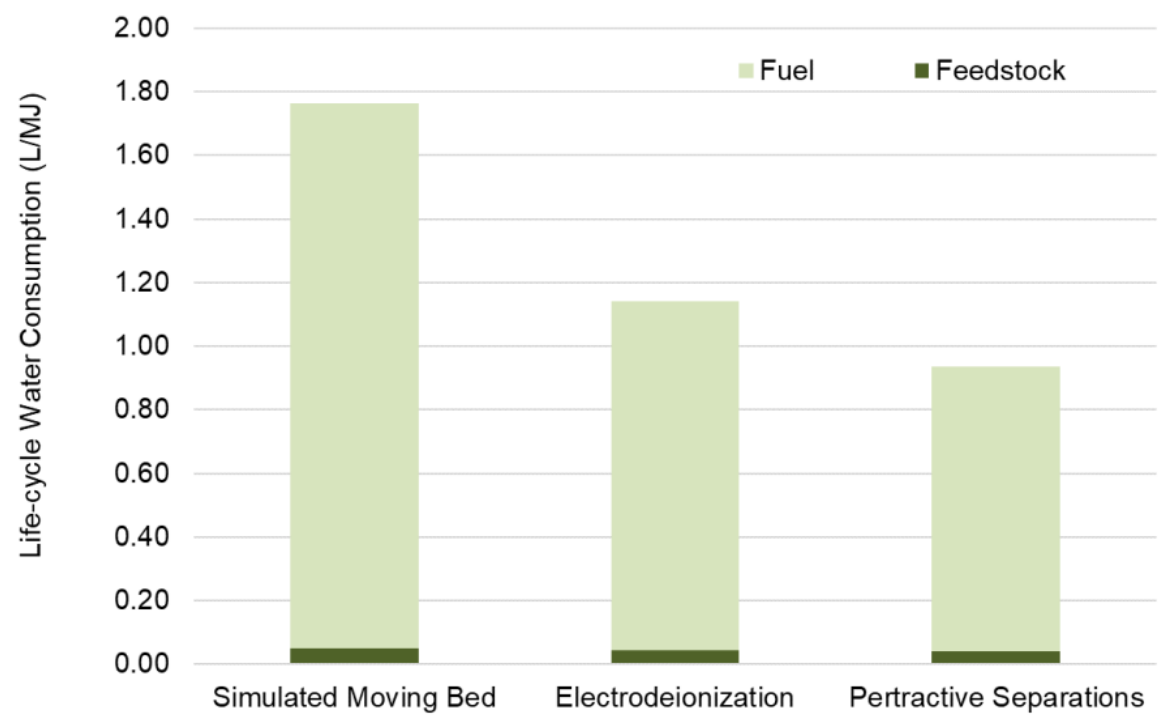

Figure 23 Life-cycle water consumption (L/MJ) in the production of renewable diesel through an acid intermediate.

\subsubsection{Industrial Relevance}

The Consortium seeks to advance the understanding and performance of existing and new separations technologies towards solving industrially relevant separation problems. Table 3 summarizes the Consortium technologies with respect to organic acid and alcohol recovery from biological reactor system broths, and lignin fractionation and recovery. 
Table 3 Industrial relevance of separation technologies applicable to biological conversion processes.

\begin{tabular}{|c|c|c|c|c|c|c|c|}
\hline $\begin{array}{l}\text { Separation } \\
\text { technology }\end{array}$ & $\begin{array}{c}\text { Current } \\
\text { applications }\end{array}$ & $\begin{array}{c}\text { Potential } \\
\text { applications }\end{array}$ & Current Scale & $\begin{array}{l}\text { Projected } \\
\text { future scale }\end{array}$ & $\begin{array}{l}\text { Types of } \\
\text { compounds }\end{array}$ & $\begin{array}{l}\text { Advantage } \\
\text { over other } \\
\text { technologies }\end{array}$ & $\begin{array}{l}\text { Remaining } \\
\text { gaps }\end{array}$ \\
\hline HED-ISPR & $\begin{array}{l}\text { Organic acid } \\
\text { recovery from } \\
\text { fermenter broth }\end{array}$ & $\begin{array}{l}\text { Organic acid } \\
\text { separation from } \\
\text { aqueous streams. } \\
\text { Carboxylic acid } \\
\text { recovery from } \\
\text { aqueous HTL. } \\
\text { Carboxylic acid } \\
\text { recovery from } \\
\text { aqueous catalytic } \\
\text { fast pyrolysis } \\
\text { stream. }\end{array}$ & $\sim 100-400 \mathrm{~g}$ & $4-10 \mathrm{~kg}$ & $\begin{array}{l}\text { Organic acids/ } \\
\text { carboxylic acids }\end{array}$ & $\begin{array}{l}\text { ISPR allows } \\
\text { amelioration of } \\
\text { end-product } \\
\text { inhibition increasing } \\
\text { bioprocess titers } \\
\text { rates and yields. } \\
\text { Lowers water } \\
\text { footprint of system } \\
\sim 10 \text {-fold. }\end{array}$ & $\begin{array}{l}\text { Integrate distillation } \\
\text { system directly to } \\
\text { extraction loop for } \\
\text { full proof of } \\
\text { concept. }\end{array}$ \\
\hline EDI & $\begin{array}{l}\text { ISPR organic acid } \\
\text { recovery from } \\
\text { fermenter broth; } \\
\text { lignin, and } \mathrm{NaOH} \\
\text { recovery from } \\
\text { aqueous streams. }\end{array}$ & $\begin{array}{l}\text { Acid and base } \\
\text { recovery from } \\
\text { aqueous streams. } \\
\text { Organic acid } \\
\text { separation from } \\
\text { aqueous streams. } \\
\text { Carboxylic acid } \\
\text { recovery from } \\
\text { aqueous HTL. } \\
\text { Phenolic acid } \\
\text { capture from APL. } \\
\text { Biogas upgrading. }\end{array}$ & $\begin{array}{l}5-20 \mathrm{~g} / \mathrm{hour}(250 \\
\text { gallons/day) at } \\
\text { the bench scale }\end{array}$ & $\begin{array}{l}1-10 \mathrm{~kg} / \mathrm{hour} \\
(>5,000 \\
\text { gallons/day) } \\
\text { at the field- } \\
\text { pilot scale }\end{array}$ & $\begin{array}{l}\text { Organic acids/ } \\
\text { inorganic acid \& } \\
\text { base/ ammonia }\end{array}$ & $\begin{array}{l}\text { Enable continuous } \\
\text { fermentation } \\
\text { without } \\
\text { neutralization. } \\
\text { Produce }>30 \text { wt.\% } \\
\text { pure organic acid } \\
\text { capture without the } \\
\text { use of solvent or } \\
\text { acidification } \\
\text { chemicals. }\end{array}$ & $\begin{array}{l}\text { Full assessment of } \\
\text { EDI technologies' } \\
\text { costs and potential } \\
\text { to reduce overall } \\
\text { processing costs. }\end{array}$ \\
\hline Ultrasonic & $\begin{array}{l}\text { Lignocellulosic } \\
\text { fines; microalgae } \\
\text { and bacteria } \\
\text { culture harvesting; } \\
\text { protein } \\
\text { suspension } \\
\text { dewatering. }\end{array}$ & $\begin{array}{l}\text { Organic/inorganic } \\
\text { particle } \\
\text { suspensions; liquid } \\
\text { emulsions; } \\
\text { molecular separation } \\
\text { via adsorption. }\end{array}$ & $\begin{array}{l}\text { A range of scales } \\
\text { available. } \\
\text { Suspension or } \\
\text { emulsion flow } \\
\text { rates vary from } \\
\text { around } \\
100-500 \mathrm{~mL} / \mathrm{hr} \\
\text { for the smallest } \\
\text { vessel, up to } \\
18 \mathrm{~L} / \mathrm{hr} \text { for the } \\
\text { largest. }\end{array}$ & $\begin{array}{l}\text { Larger scales } \\
\text { accessible via } \\
\text { multiple } \\
\text { modular } \\
\text { designs. }\end{array}$ & $\begin{array}{l}\text { Phase- } \\
\text { separated } \\
\text { particles or } \\
\text { aggregates from } \\
\sim 1-100 \mu \mathrm{m} . \\
\text { Particle density } \\
\text { must deviate } \\
\text { from the media } \\
\text { density. }\end{array}$ & $\begin{array}{l}\text { Acts as a } \\
\text { membrane-less } \\
\text { filter, avoiding } \\
\text { chemical cleaning } \\
\text { and backflush } \\
\text { operations. No } \\
\text { chemical additives. } \\
\text { No moving parts. }\end{array}$ & $\begin{array}{l}\text { TEA of an } \\
\text { integrated } \\
\text { ultrasonic } \\
\text { separator. }\end{array}$ \\
\hline
\end{tabular}


Table 3 (Cont.)

\begin{tabular}{|c|c|c|c|c|c|c|c|}
\hline $\begin{array}{l}\text { Separation } \\
\text { technology }\end{array}$ & $\begin{array}{c}\text { Current } \\
\text { applications }\end{array}$ & $\begin{array}{c}\text { Potential } \\
\text { applications }\end{array}$ & Current Scale & $\begin{array}{l}\text { Projected } \\
\text { future scale }\end{array}$ & $\begin{array}{l}\text { Types of } \\
\text { compounds }\end{array}$ & $\begin{array}{l}\text { Advantage } \\
\text { over other } \\
\text { technologies }\end{array}$ & $\begin{array}{l}\text { Remaining } \\
\text { gaps }\end{array}$ \\
\hline $\begin{array}{l}\text { Pervaporative } \\
\text { Membrane } \\
\text { and } \\
\text { Distillation }\end{array}$ & $\begin{array}{l}\text { Higher alcohol } \\
\text { recovery from } \\
\text { fermentation broth }\end{array}$ & $\begin{array}{l}\text { Molecular } \\
\text { enrichment of } \\
\text { various aqueous } \\
\text { solutions, including } \\
\text { organic acids, } \\
\text { alcohols, diols, and } \\
\text { other oxygenates. }\end{array}$ & $0.1-1 \mathrm{~L}$ & $1-10 \mathrm{~L}$ & $\begin{array}{l}\text { Organic acids/ } \\
\text { carboxylic } \\
\text { acids. }\end{array}$ & $\begin{array}{l}\text { Less energy } \\
\text { intensive, lower } \\
\text { cost. }\end{array}$ & $\begin{array}{l}\text { Advancement of } \\
\text { selectivity, } \\
\text { flux/capacity, and } \\
\text { stability of } \\
\text { separation materials } \\
\text { (membranes and } \\
\text { sorbents) }\end{array}$ \\
\hline $\begin{array}{l}\text { Polymeric } \\
\text { Membrane }\end{array}$ & $\begin{array}{l}\text { Lignin molecular } \\
\text { weight } \\
\text { fractionation, cell } \\
\text { and debris } \\
\text { removal from } \\
\text { fermentation } \\
\text { broth, protein or } \\
\text { biopolymer } \\
\text { purification and } \\
\text { recovery }\end{array}$ & $\begin{array}{l}\text { Biopharmaceutical } \\
\text { manufacturing, } \\
\text { enzyme production, } \\
\text { bacteria removal, } \\
\text { gas separation, and } \\
\text { wastewater } \\
\text { treatment }\end{array}$ & $100 \mathrm{~mL}$ to $600 \mathrm{~L}$ & $>1,000 \mathrm{~L}$ & $\begin{array}{l}\text { Biofuels and } \\
\text { bioproducts } \\
\text { such as protein, } \\
\text { enzymes, } \\
\text { bipolymer or } \\
\text { fuel molecules } \\
\text { ranging from } \\
150 \mathrm{Da} \text { to } \\
700 \mathrm{KDa}\end{array}$ & $\begin{array}{l}\text { High selectivity, } \\
\text { reusability }\end{array}$ & $\begin{array}{l}\text { Membrane fouling, } \\
\text { surface area and } \\
\text { pump capacity need } \\
\text { to be increased }\end{array}$ \\
\hline $\begin{array}{l}\text { Ceramic } \\
\text { Membrane }\end{array}$ & $\begin{array}{l}\text { Lignin molecular } \\
\text { weight } \\
\text { fractionation; cell } \\
\text { and debris } \\
\text { removal from } \\
\text { fermentation broth }\end{array}$ & $\begin{array}{l}\text { Filtration of crude } \\
\text { extracts and } \\
\text { biomass } \\
\text { pretreatment } \\
\text { streams; color } \\
\text { removal } \\
\text { depolymerized } \\
\text { stream filtration; } \\
\text { filter sterilization; } \\
\text { pretreatment for } \\
\text { SMB process; } \\
\text { solvent recovery }\end{array}$ & $1-10 \mathrm{~kg}$ & $\begin{array}{l}\text { Current pilot } \\
\text { plant units } \\
\text { are } \sim 1,000- \\
10,000 \mathrm{~kg} \text { of } \\
\text { solution } \\
\text { filtration } \\
\text { throughput) }\end{array}$ & $\begin{array}{l}\text { Aqueous } \\
\text { streams and oil- } \\
\text { based streams. } \\
\text { Depolymerized } \\
\text { materials. } \\
\text { Solvent } \\
\text { purification. }\end{array}$ & $\begin{array}{l}\text { Low energy, } \\
\text { durable with high } \\
\text { up time, can be } \\
\text { implemented in } \\
\text { rotating units for } \\
\text { high uptimes. }\end{array}$ & $\begin{array}{l}\text { Cleaning cycles } \\
\text { need to be defined, } \\
\text { energy analysis has } \\
\text { never been } \\
\text { performed, color } \\
\text { removal pore sizes } \\
\text { need to be defined. }\end{array}$ \\
\hline
\end{tabular}


Table 3 (Cont.)

\begin{tabular}{|c|c|c|c|c|c|c|c|}
\hline $\begin{array}{l}\text { Separation } \\
\text { technology }\end{array}$ & $\begin{array}{c}\text { Current } \\
\text { applications }\end{array}$ & $\begin{array}{c}\text { Potential } \\
\text { applications }\end{array}$ & Current Scale & $\begin{array}{l}\text { Projected } \\
\text { future scale }\end{array}$ & $\begin{array}{c}\text { Types of } \\
\text { compounds }\end{array}$ & $\begin{array}{l}\text { Advantage } \\
\text { over other } \\
\text { technologies }\end{array}$ & $\begin{array}{l}\text { Remaining } \\
\text { gaps }\end{array}$ \\
\hline SMB & $\begin{array}{l}\text { Lactic acid } \\
\text { purification } \\
\text { (Cargill); } \\
\text { commodity } \\
\text { chemical } \\
\text { purification; } \\
\text { natural product } \\
\text { purification }\end{array}$ & $\begin{array}{l}\text { SOT for } \\
\text { purification of } \\
\text { molecules from } \\
\text { complex mixtures }\end{array}$ & $\begin{array}{l}\text { NREL } 1-10 \mathrm{~kg} \text { of } \\
\text { purified product. } \\
\text { Industrially millions } \\
\text { of kilograms/day } \\
\text { scale (e.g., paraffin } \\
\text { separation from } \\
\text { gasoline) }\end{array}$ & $\begin{array}{l}\text { Operates today } \\
\text { at } 21,000 \mathrm{t} / \mathrm{yr} \text { to } \\
1,6000,000 \mathrm{t} / \mathrm{yr} \\
\text { and possibly } \\
\text { larger scale }\end{array}$ & $\begin{array}{l}\text { Low-molecular- } \\
\text { weight organic } \\
\text { compounds }\end{array}$ & $\begin{array}{l}\text { Continuous, lower } \\
\text { solvent load than } \\
\text { column } \\
\text { chromatography, } \\
\text { energy efficient, } \\
\text { can apply to almost } \\
\text { any separation, } \\
\text { allows separation } \\
\text { of many molecules } \\
\text { that cannot be } \\
\text { separated by } \\
\text { distillation. }\end{array}$ & $\begin{array}{l}\text { High cost of } \\
\text { stationary phase, } \\
\text { solvent recovery } \\
\text { operation rarely } \\
\text { factored into } \\
\text { analysis of } \\
\text { technology, middle } \\
\text { cuts can be } \\
\text { challenging, } \\
\text { generally limited to } \\
\text { A/B separations, } \\
\text { resin fouling can } \\
\text { require extensive } \\
\text { upfront filtration. }\end{array}$ \\
\hline
\end{tabular}




\subsection{Thermochemical Separations}

Thermochemical processes cover a wide range of methods and applications. However, a common problem is catalyst fouling and premature deactivation. Another challenge shared with biological conversion processes is product recovery from dilute aqueous streams. The thermochemical separations challenge areas of Consortium research are illustrated in Figure 24.

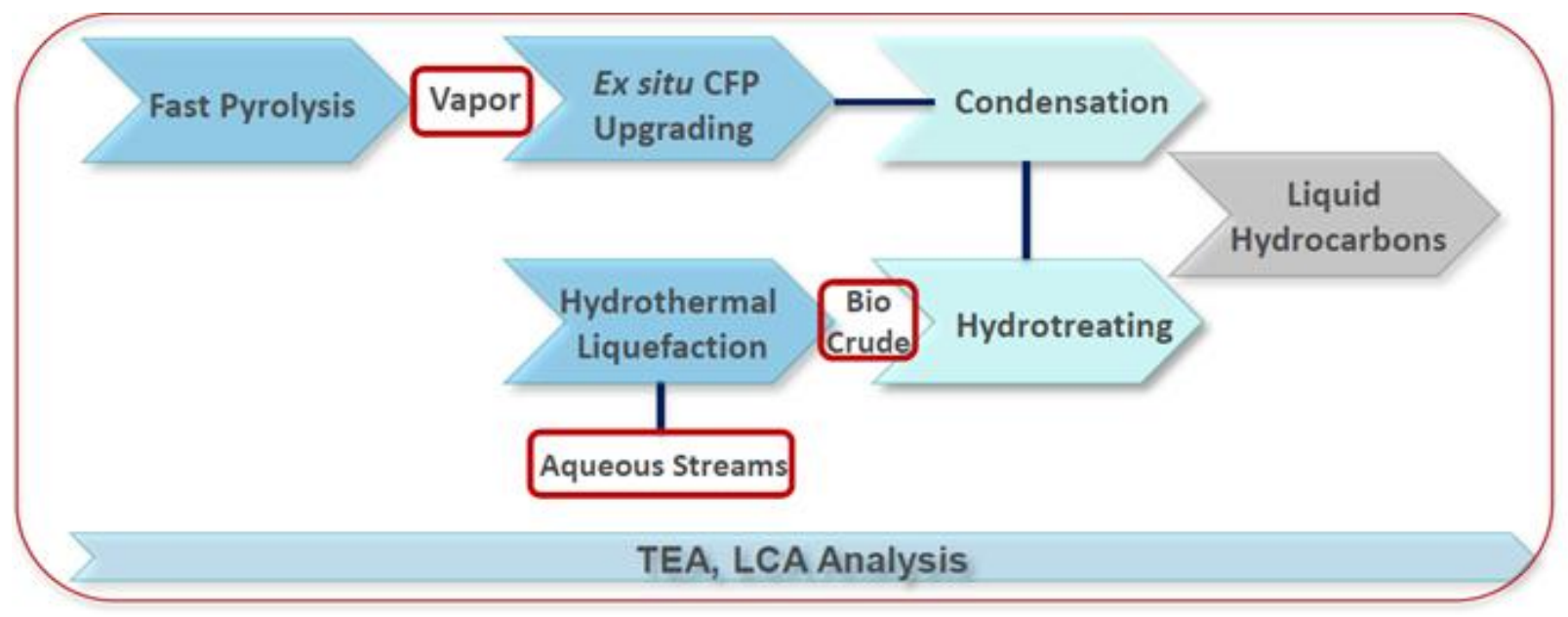

Figure 24 Separation challenges for two types of thermochemical processes.

Catalyst longevity is a key driver of TEA results for thermochemical processes. A key barrier to increased catalyst longevity is the presence of toxins in processing streams that deactivate the catalyst. Furthermore, aqueous streams formed in thermochemical processing can contain potentially valuable carbon species that could be recovered to improve process economics. Finally, the benefits of process intensification in thermochemical processes have been subject to exploration within this area of the Consortium.
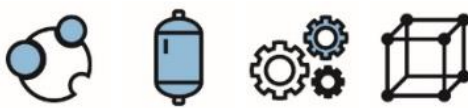

\subsubsection{Catalytic Hot Gas Filtration (CHGF)}

Motivation. Biomass fast pyrolysis vapors contain char, alkali aerosols, and carbonyls. These impurities destabilize the bio-oil vapors fed to upgrading catalysts. They also destabilize the condensed vapors that are further upgraded over fixed bed catalytic reactors. These compounds also poison catalysts.

A Consortium project investigated CHGF both to trap inorganic material and to convert small organics into material that is easier to upgrade. The use of a CHGF downstream of a fast pyrolysis reactor is based on the premise that hosting catalysts within an HGF system can reduce capital costs by eliminating one or more reactor systems that would otherwise host the catalyst. The greatest benefits of CHGF can come from increased organic liquid-range yields and improved carbon efficiency via coupling chemistry to prevent carbon losses to the gas phase. Downstream catalytic reactors can benefit from the ease of catalyst maintenance and can be further tailored towards selectivity improvements for better quality fuels and valuable coproducts.

Previous sensitivity studies have quantified the impacts of these changes (Dutta et al. 2018) including on capital costs, carbon efficiency, catalyst maintainability, and cost savings from reduced oxygen content in the pyrolysis oil.

Approach. Figure 25 illustrates the CHGF research apparatus setup in which the industrially available Pall ceramic filter is (a) housed in a metal holder; the filter can be (b) coated with catalyst or (c) packed with 
particulate catalyst in its interior. The right panel in Figure 25 shows the placement of the CHGF unit between the biomass pyrolyzer and the liquid product condensation train. Alternatively, clean vapors can be supplied to the DCR upgrading unit for catalytic conversion to fuels and chemicals.
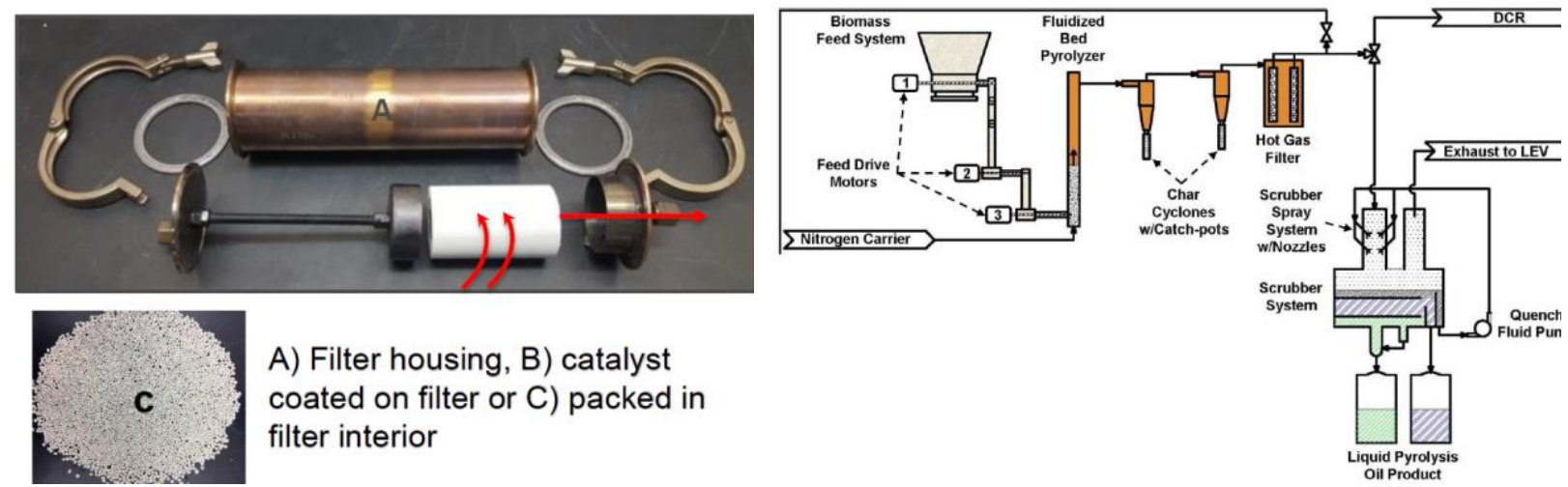

A) Filter housing, B) catalyst coated on filter or C) packed in filter interior

Figure 25 Hot gas filtration experimental setup (Peterson et al. 2019).

Results. The biomass type and catalyst type both affect the catalytic pyrolysis vapor composition. This composition in turn affects downstream catalyst lifetime and oil stability. Research into biomass composition effects on pyrolysis vapor composition determined that vapor from pyrolysis of pine and pine residues exhibited similar responses to reaction over zeolites. Acetic acid in these vapors was converted to acetone, which is easier to upgrade, when doped carbides ( $\mathrm{Lu}$ et al. 2018) and $\mathrm{CeO}_{2}$ were used as catalysts. Furthermore, the ceramic hot gas filter removed $>99 \%$ char and alkali from the pyrolysis vapor (Figure 26), particulates that if left in the vapor enhance coking and organic cracking. In addition, the removal of heavy vapor components, such as benzene, toluene, xylene (BTX), anthracenes, and naphthalenes, reduces the carbon losses to upgrading catalyst coking.

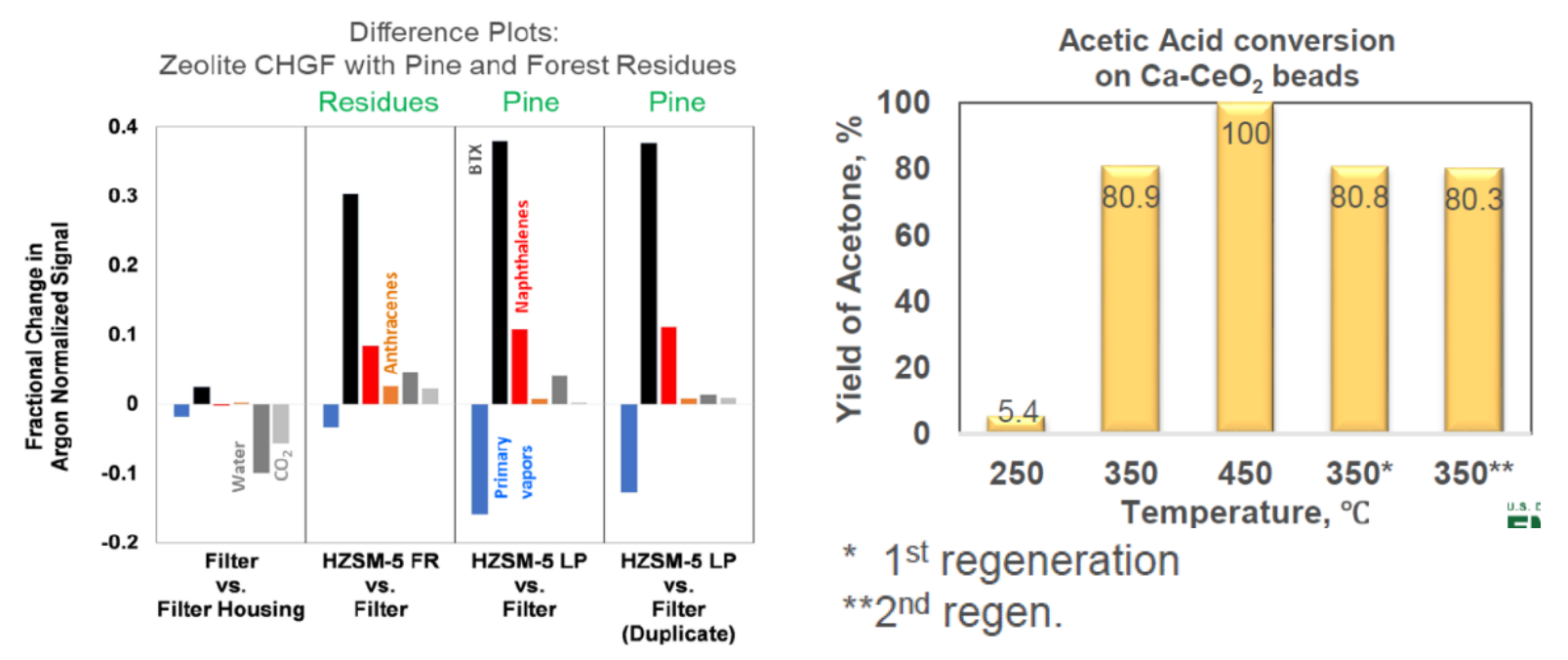

Figure 26 Filtration and conversion results for various filter materials and catalysts (Peterson et al. 2019).

The process was intensified by adding $\mathrm{CeO}_{2}$ and zeolite catalysts to the interior of the filter to convert unreactive oxygenates to upgradable components, thereby increasing carbon conversion to products. Overall, tuneability of the vapor chemistry was demonstrated using an industry-accepted filter along with catalyst sorbent performance, lifetime, and regenerability. 
Another alternative, a titania-supported molybdenum heteropolyacid (Mo-HPA/TiO 2 ) catalyst, was developed in FY 2019 to target further improvements in fast pyrolysis vapor quality. The HPA catalyst demonstrated vapor hydrodeoxygenation by reducing the concentration of

Catalysts tested for CHGF exhibited promising performance in removing or converting catalyst foulants. To realize these benefits, it is essential to develop an HPA catalyst regeneration method. reactive species such as sugars and acids, alkylation activity allowing the conversion of lighter molecules to liquid range products, and reduced carbon losses to the aqueous phase (Peterson et al. 2019). In summary, the catalyst's performance was promising. However, the greatest challenge of this approach lies in the development of an efficient HPA catalyst regeneration method within the environment and operating protocols of the HGF system.

Typically, continuous operation of HGF systems involves regular blowback to remove particulates. Blowbacks are short gas flow pulses in the reverse direction of process flow. They help dislodge solid material the filter candle traps. Short pulses will allow efficient regeneration only if the catalyst on-stream time is at least an order of magnitude or longer than the regeneration time. Longer regeneration times, as exhibited in the current state of technology, will require significant spare capacity in the filtration system.

The requirement for this spare capacity defeats the premise that a CHGF reduces capital costs. Thus, future research should focus on quicker catalyst regeneration and longer catalyst on-stream times to help reduce the requirement of spare CHGF capacity during continuous operation.
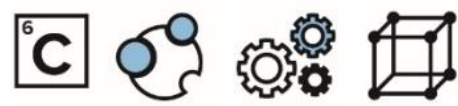

4.2.2 EDI-Based Recovery of Dilute Organic Carbon and Ammonia in the Aqueous Phase

Motivation. The hydrothermal liquefaction (HTL) aqueous phase, and to a much lesser extent, the catalytic pyrolysis aqueous phase, contains a significant amount of organic carbon, much of which is in the form of organic acids. If the organic acids in the aqueous stream are recovered, their sale can offset some of the cost to produce biocrude.

Approach. EDI (Figure 27) was applied to the HTL aqueous stream to evaluate its potential for acid recovery and, as described later, ammonia recovery. By applying EDI, organic acids were recovered as a single product stream. At high concentrations of recovery, the costs to recover acids and ammonia using EDI alone becomes prohibitive. To achieve greater acid concentration, membrane-based techniques were explored following EDI.

Results. EDI was implemented in a three-compartment configuration to recover ammonia in a separate mixed alkaline stream (Figure 28). As shown, organic acids and ammonia were continuously removed from the fermentation broth and transferred into separate acid and

EDI-based separations maintained high concentrations of acid and $\mathrm{NH}_{3}$ regardless of the percentage removal. Concentrations of each species exceeded the target levels. base product streams. Regardless of the percentage removal (x-axis), high concentrations of acid and base were continuously extracted into the product streams (y-axis). For comparison, the target levels of acid and ammonia concentration in the acid and base streams are indicated by the horizontal blue and green lines, respectively.

The results from testing with acid surrogates (Figure 29) indicate $>50 w t \%$ acetic acid concentration is possible when a HiPAS membrane (Lu et al. 2019) is applied following EDI. HiPAS membranes are made of modified polymer coated ceramic tubular supports. They can be operated continuously at high temperatures, and they both are acid-resistant and scalable. 


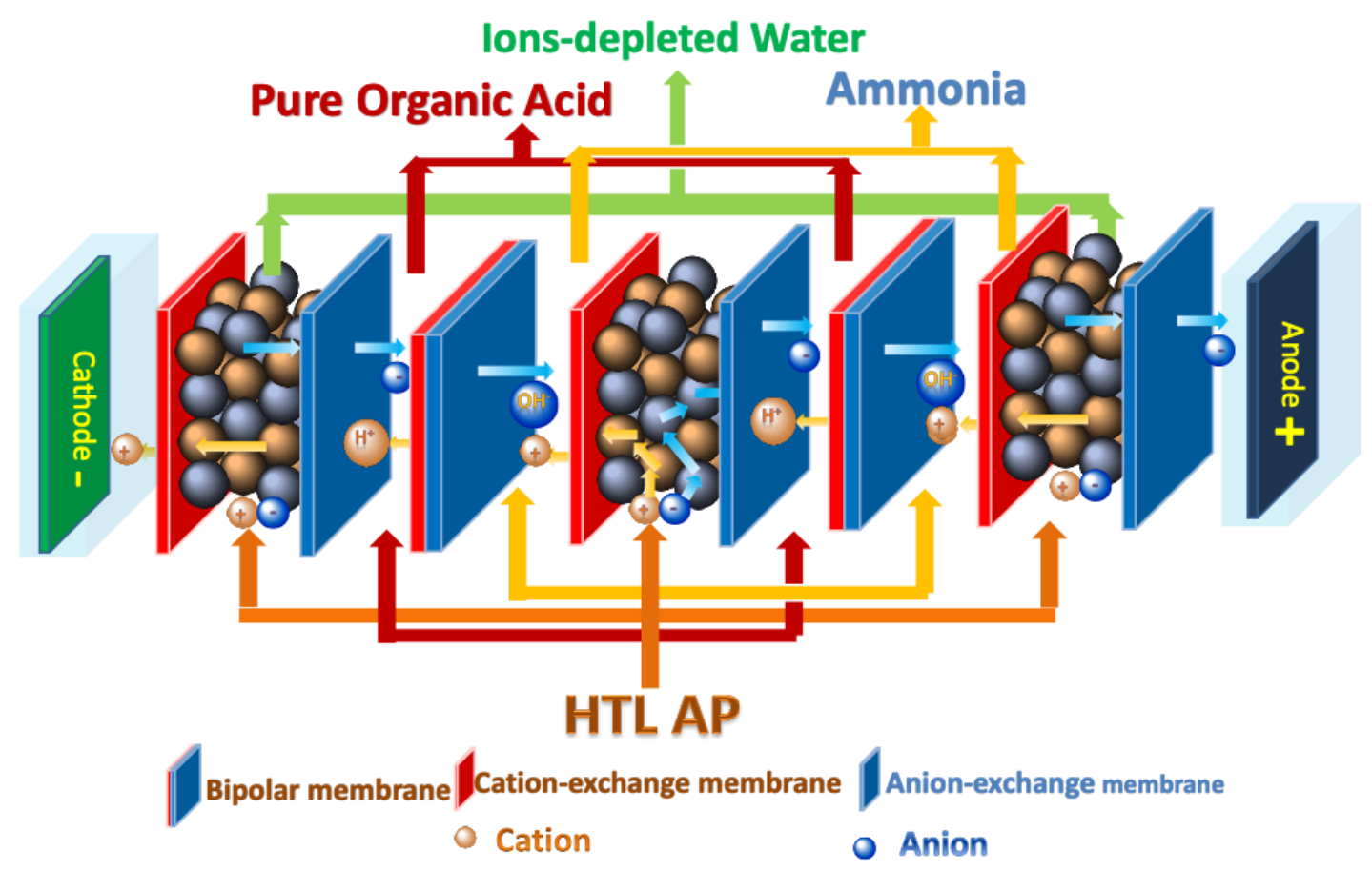

Figure 27 Selective extraction of dilute organic acids from the thermochemical (TC) waste aqueous phase using the EDI platform system.

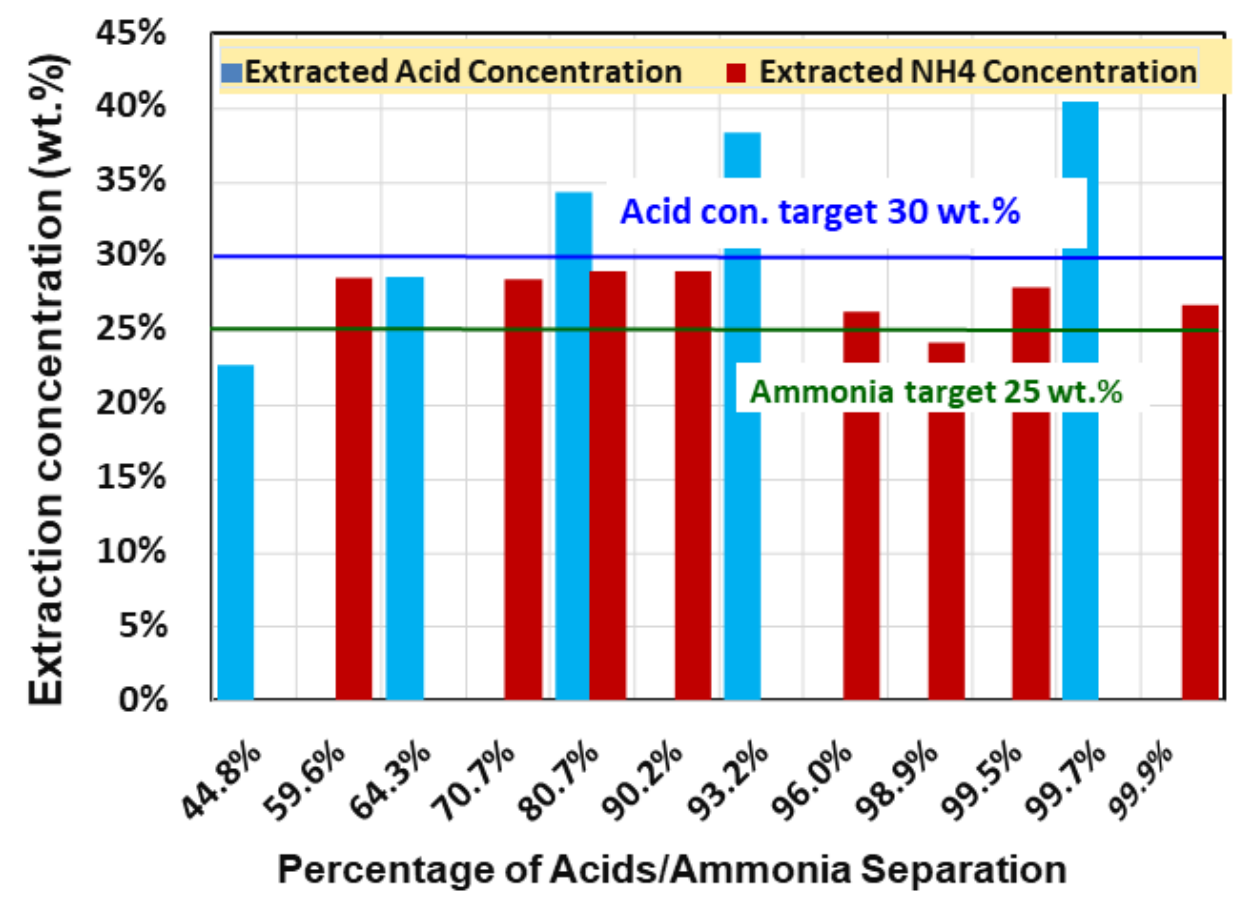

Figure 28 EDI results for acid and ammonia recovery from HTL aqueous phase.

The concentration of acid and ammonia each exceeded the target concentrations. 

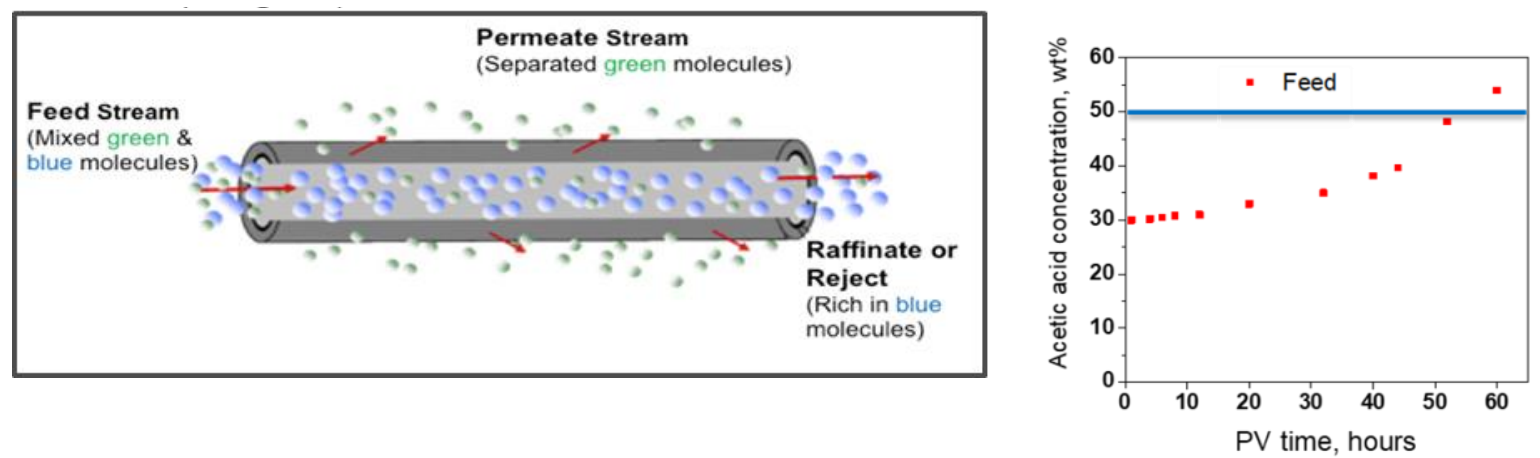

Figure 29 Left: HiPAS membrane concept. Right: Acetic acid concentration over time in permeate stream as a result of pervaporation (PV). The target concentration was exceeded after 50 hours.

Development gaps include the need to separate the mixed acid stream into individual components, which would add cost, and to purify the ammonia stream by removing sodium and other contaminants. In addition, the recovery of non-ionic species, such as alcohols in the aqueous stream, could potentially add value (Hu et al. 2018).
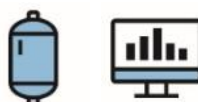

\subsubsection{Removal of Ammonia from HTL Aqueous Streams as a Wastewater Treatment Option}

Motivation. In addition to acids, HTL aqueous streams also contain dissolved ammonia. This presents a costly problem if the ammonia has to be removed prior to downstream use or before the aqueous stream can be recycled (Figure 30). Recovering ammonia can eliminate the cost to treat the aqueous stream prior to recycling when the wastewater treatment plant (WWTP) has nitrogen restrictions. In addition, ammonia could provide another revenue source for the biocrude plant. Figure 30 illustrates the flow sheet, showing EDI as part of the biocrude production pathway.

Approach. Experimental results from Section 4.2.2 were applied in TEA and LCA to evaluate the benefits of ammonia removal with EDI for reducing ammonia concentrations to levels allowed at wastewater treatment plants. These levels vary by location; in some cases, there is no restriction on ammonia levels and removal is unnecessary.

Results. Preliminary TEA results that evaluate EDI's viability to remove ammonia cost effectively are shown in Figure 31. When the EDI process is used-at $90 \%$ ammonia recovery, $30 \%$ ammonia concentration, and no impurities - the selling price for the finished (hydrotreated) fuel is below the design target. Similarly, assuming a discounted value for mixed acids (as opposed to separated and purified acids), it is possible to reach the cost target (Figure 31). 


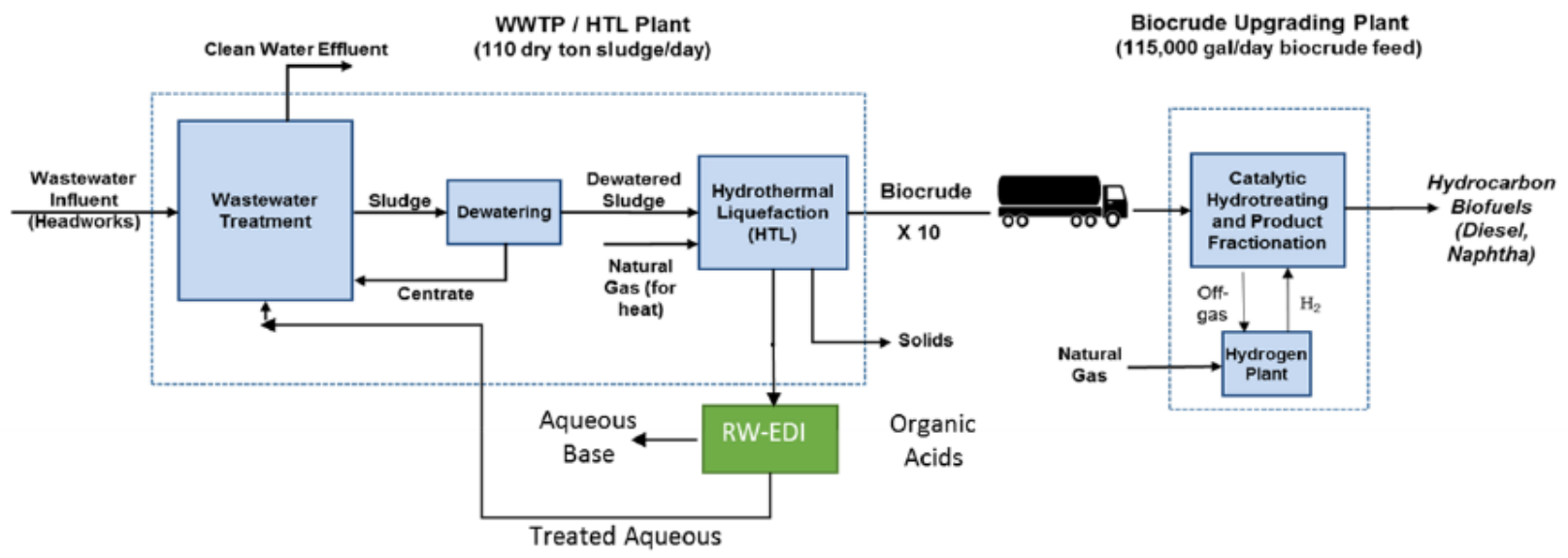

Figure 30 Waste HTL flow diagram.

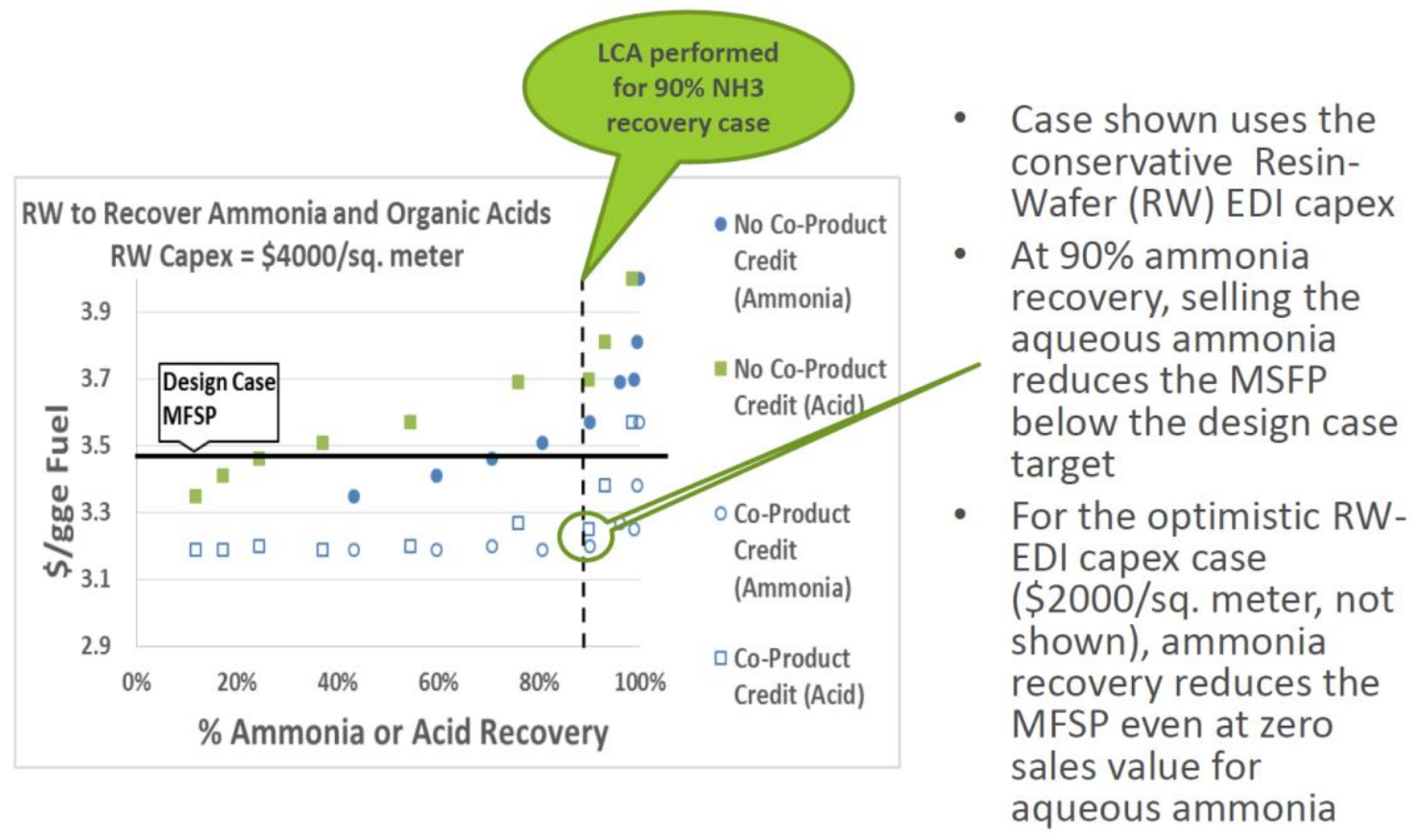

Figure 31 Potential cost reduction through use of EDI for acid and base recovery from HTL aqueous phase.

The preliminary LCA (Figure 32) was completed assuming ammonia and acid coproducts are recovered. In the case of acids, acetic acid was adopted as the type of acid that would be sold as a coproduct. It was assumed that no energy or materials were consumed to separate and purify the acetic acid. The EDI case in Figure 32 is then a best-case result. If, however, there were no displacement credit for acetic acid, the EDI case would still outperform conventional $\mathrm{NH}_{3}$ removal.

Fossil fuel consumption shown in Figure 33 is lower for the EDI case than for the conventional ammonia removal case. Again, these are preliminary best-case scenarios because energy, emissions, and water associated with separating acid coproducts are not yet included. 


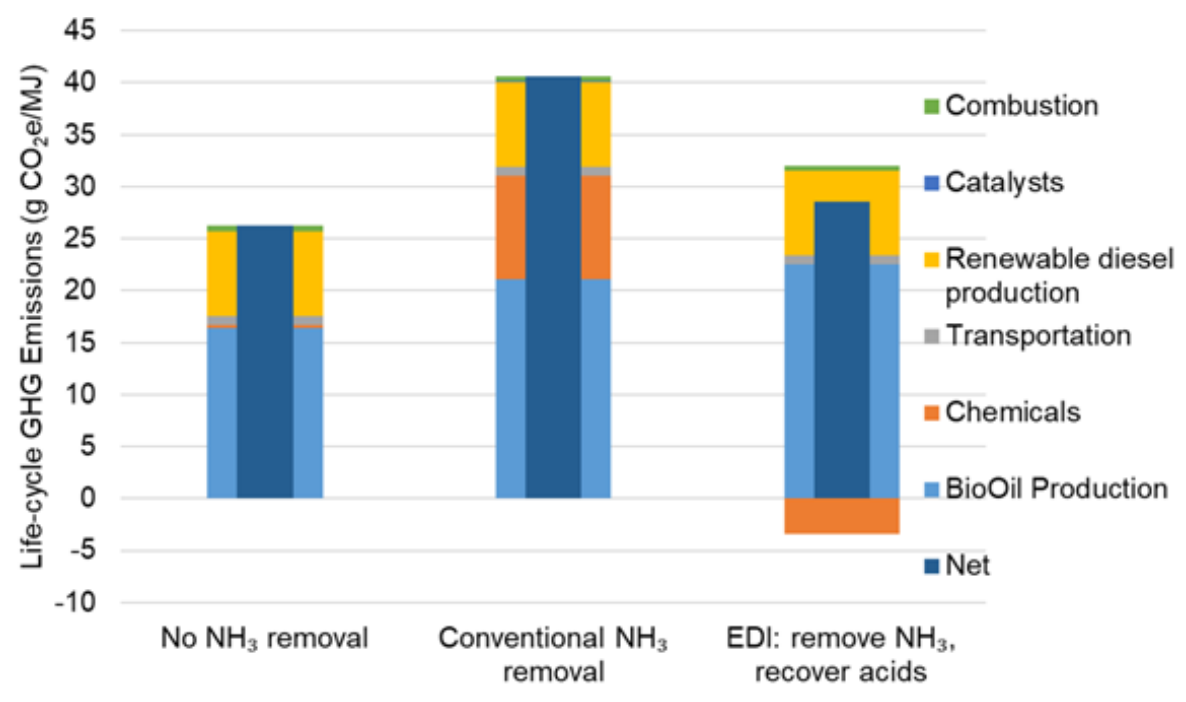

Figure 32 GHG reduction for EDI-based recovery of mixed acids and ammonia from HTL aqueous phase.

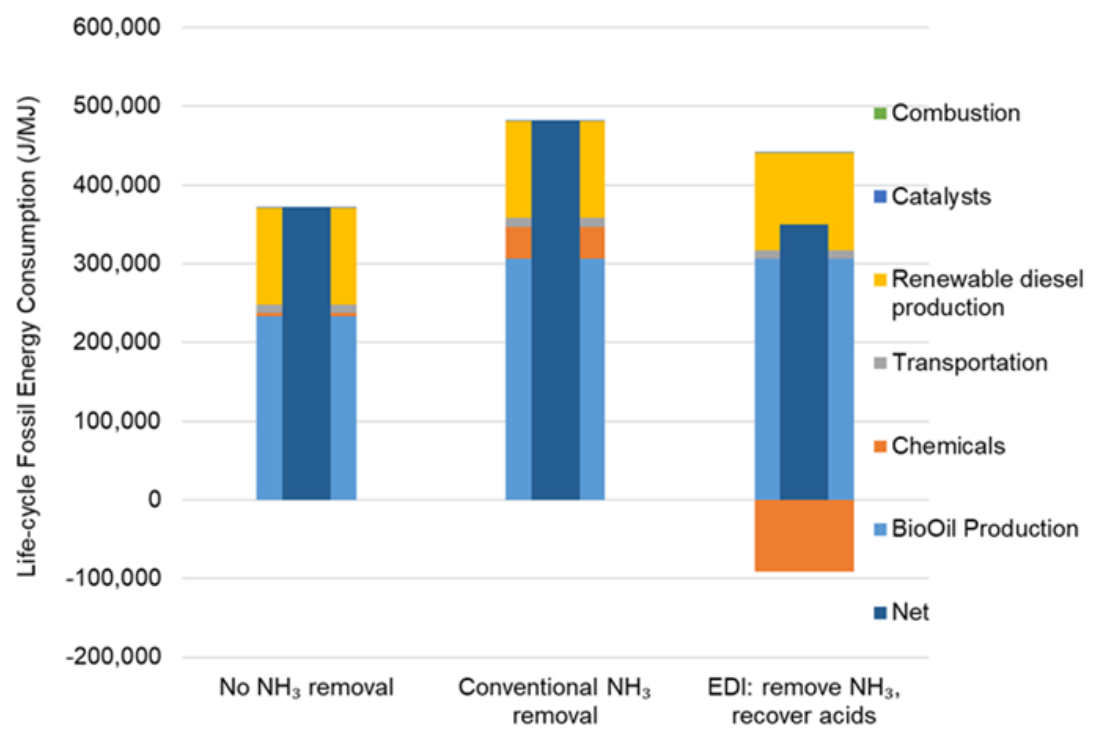

Figure 33 Fossil energy consumption for EDI-based recovery of mixed acids and ammonia from HTL aqueous phase.

Water consumption was also less compared with the conventional ammonia removal case (Figure 34). In the conventional case, quick lime $(\mathrm{CaO})$ consumption mainly drives water consumption. 


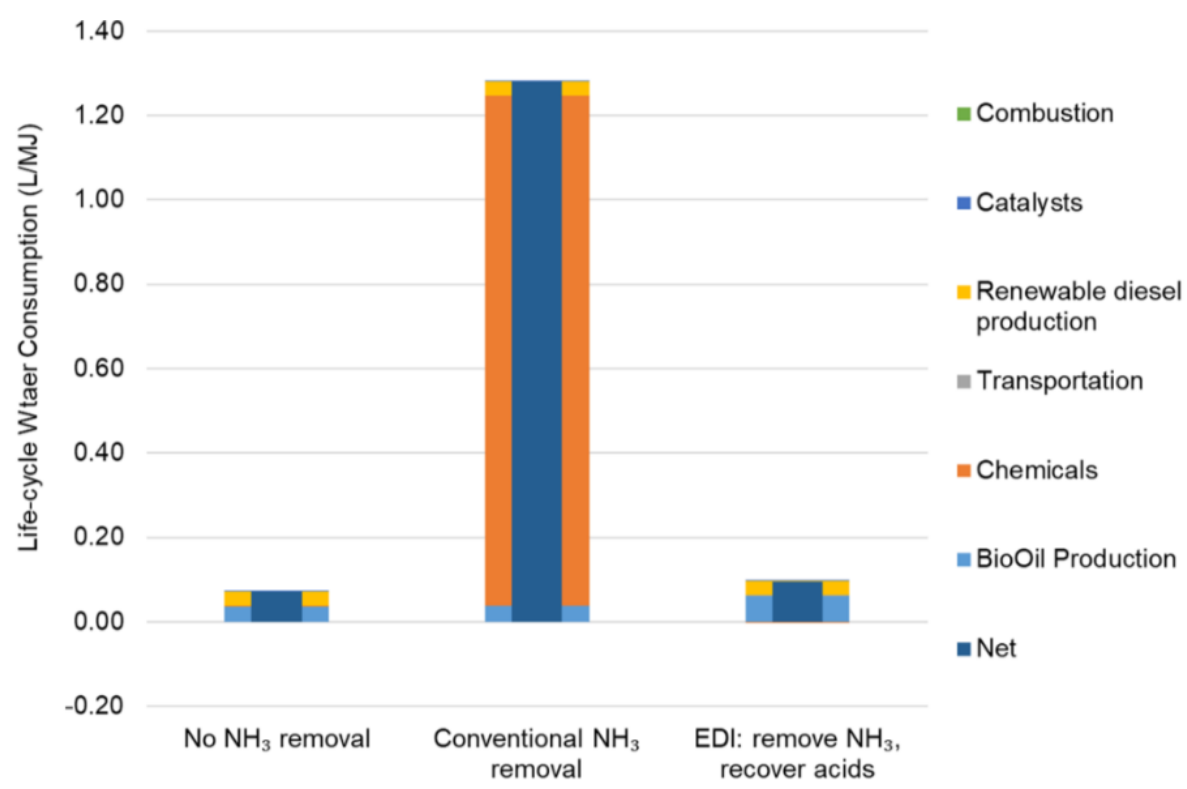

Figure 34 Water consumption for EDI-based recovery of mixed acids and bases from the HTL aqueous phase.

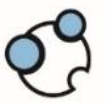

\subsubsection{Bio-oil and Biocrude Preprocessing with Adsorbents}

Motivation. Early work has also focused on developing polymer and inorganic adsorbents to remove nitrogen species from HTL biocrude and carbonyl species from woody bio-oil. The species removal prior to hydrotreating was intended to reduce hydrogen consumption, reduce hydrotreating catalyst costs, and recover high-value nitrogen-containing species.

Approach. Molecular sieves and several different types of resins were evaluated as adsorbents for removal of the targeted species.

Results. Carbonyl removal from fast pyrolysis bio-oil was 34\%, exceeding the $25 \%$ target (Figure 35 , left; Lu et al. 2019). For nitrogen species removal from HTL biocrude with pyridine as a nitrogen surrogate, $52 \%$ pyridine removal was achieved (Figure 35, right).
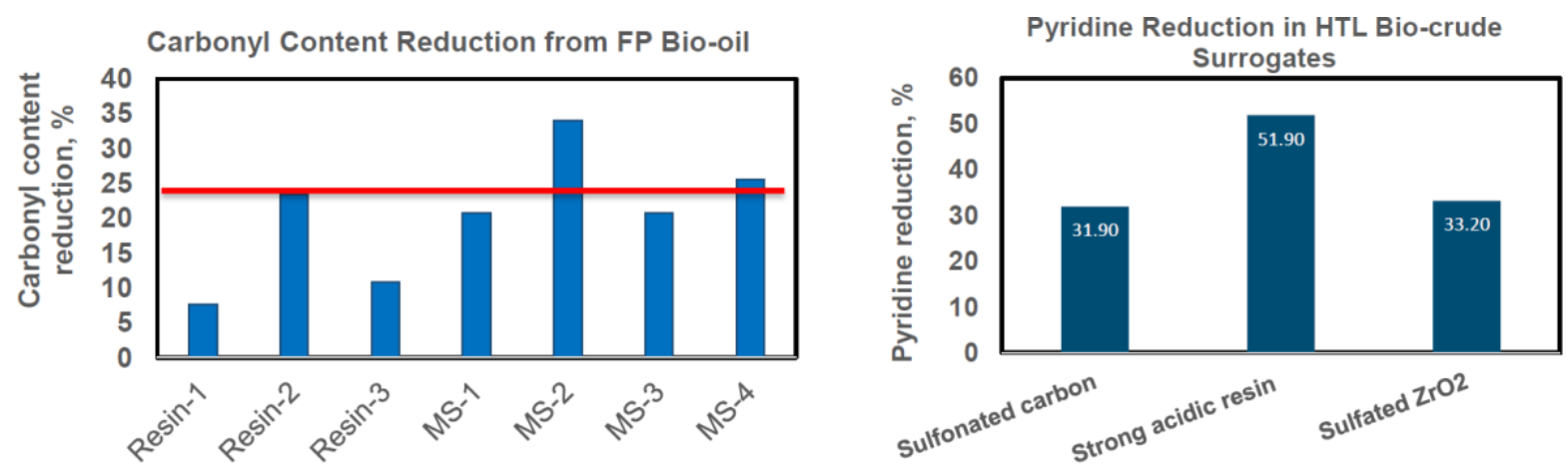

Figure 35 Effect of adsorbent type on carbonyl removal from bio-oil and nitrogen species removal from biocrude. Carbonyl adsorption surpassed the target for two molecular sieves and pyridine removal reached $52 \%$. 
For carbonyl reduction in pyrolysis oil, preliminary TEA (Figure 36) suggests that carbonyl reduction could significantly reduce the cost to produce hydrocarbon fuel from fast pyrolysis oil. The largest impact would come from eliminating the stabilizer cost (a pretreatment reactor ahead of the hydrotreater that uses very expensive catalyst) and using the removed carbonyls as heating oil rather than further processing them to produce additional fuel.

Data gaps for carbonyl removal include downstream hydrotreating testing to correlate carbonyl removal with downstream hydrotreating catalyst maintenance. Data gaps for nitrogen removal from HTL biocrude include testing with real biocrude, developing sorbents with strong acidity and high site density for biocrude cleaning, understanding membrane maintenance, and downstream hydrotreating testing. Results from experimental work with carbonyl removal were published in 2019 (Lu et al. 2019).

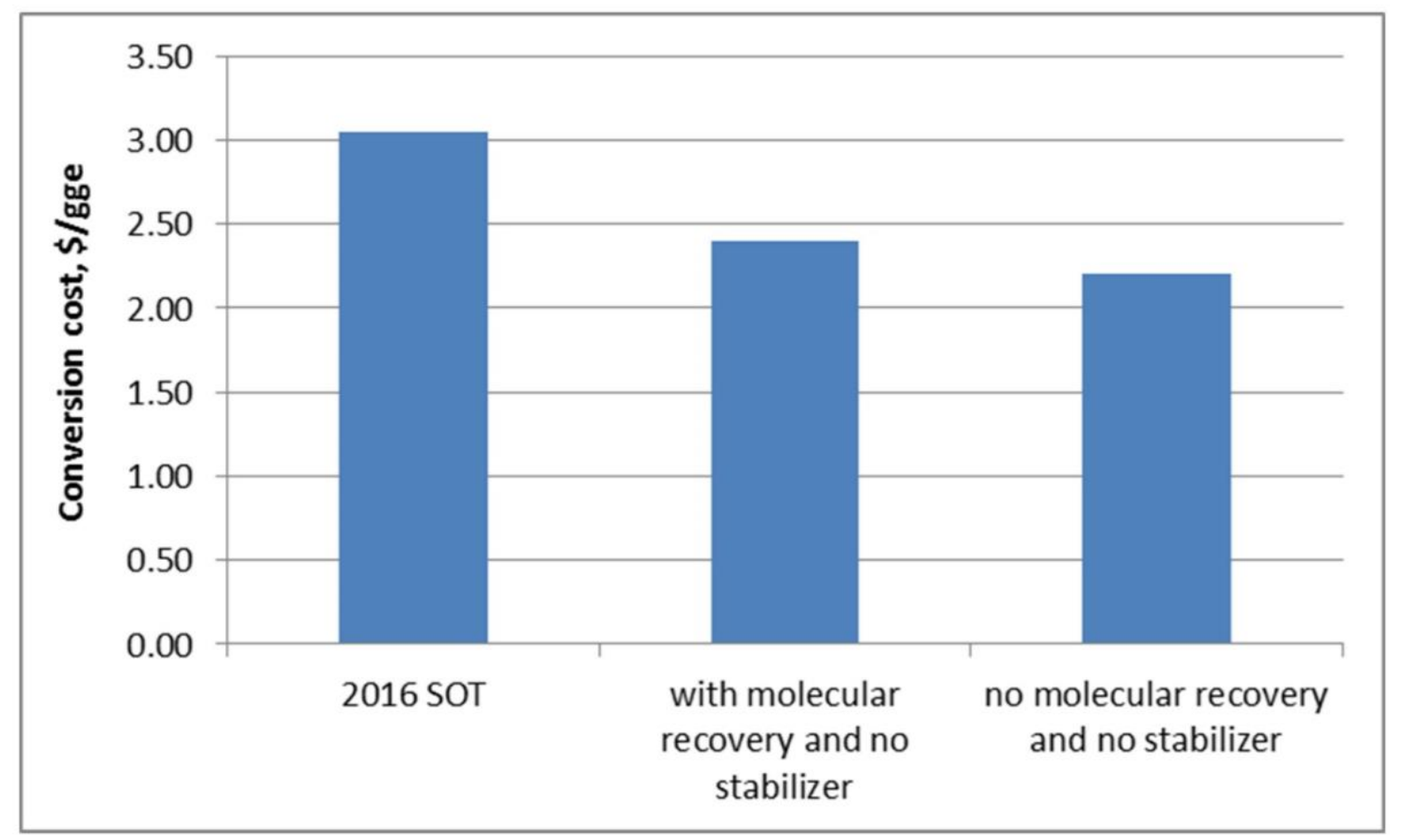

Figure 36 Economic impact of carbonyl removal from bio-oil.

\subsubsection{Industrial Relevance}

As described in Section 4.1.6, the Consortium seeks to advance the understanding and performance of existing and new separations technologies toward solving industrially relevant separation problems. Table 4 summarizes the Consortium technologies with respect to thermochemical processes. 
Table 4 Industrial relevance for thermochemical separation applications.

\begin{tabular}{|c|c|c|c|c|c|c|c|}
\hline $\begin{array}{l}\text { Separation } \\
\text { technology }\end{array}$ & $\begin{array}{c}\text { Current } \\
\text { applications }\end{array}$ & $\begin{array}{c}\text { Potential } \\
\text { applications }\end{array}$ & $\begin{array}{l}\text { Current } \\
\text { Scale }\end{array}$ & $\begin{array}{l}\text { Projected } \\
\text { future scale }\end{array}$ & $\begin{array}{c}\text { Types of } \\
\text { compounds }\end{array}$ & $\begin{array}{c}\text { Advantage over } \\
\text { other } \\
\text { technologies }\end{array}$ & Remaining gaps \\
\hline CHGF & $\begin{array}{l}\text { Removal of } \\
\text { particulates from } \\
\text { the vapor phase. } \\
\text { Current } \\
\text { applications do } \\
\text { not involve } \\
\text { inclusion of a } \\
\text { catalyst. }\end{array}$ & $\begin{array}{l}\text { Current } \\
\text { applications during } \\
\text { biomass } \\
\text { conversion can be } \\
\text { in biomass } \\
\text { pyrolysis and } \\
\text { gasification } \\
\text { processes; } \\
\text { particulate } \\
\text { carryover can be } \\
\text { problematic } \\
\text { downstream. } \\
\text { Inclusion of a } \\
\text { catalyst can add } \\
\text { catalytic upgrading } \\
\text { of the chemical } \\
\text { species in the } \\
\text { vapor, in addition to } \\
\text { particulate removal. }\end{array}$ & $\begin{array}{l}\text { Catalytic hot gas } \\
\text { filtration is } \\
\text { currently in the } \\
\text { research stage, } \\
\text { typically in bench- } \\
\text { scale test } \\
\text { systems. }\end{array}$ & $\begin{array}{l}\text { Vapor upgrading } \\
\text { of biomass fast } \\
\text { pyrolysis vapors } \\
\text { at a commercial } \\
\text { scale. However, } \\
\text { technology } \\
\text { development is } \\
\text { at an early stage } \\
\text { for such } \\
\text { applications, as } \\
\text { described in } \\
\text { "remaining } \\
\text { gaps." }\end{array}$ & $\begin{array}{l}\text { Reactive } \\
\text { oxygenated } \\
\text { vapor species } \\
\text { from fast } \\
\text { pyrolysis are } \\
\text { candidates for } \\
\text { conversion in } \\
\text { this step. This } \\
\text { conversion can } \\
\text { help stabilize } \\
\text { fast pyrolysis } \\
\text { vapors for } \\
\text { further } \\
\text { downstream } \\
\text { upgrading. }\end{array}$ & $\begin{array}{l}\text { If successful, the } \\
\text { greatest benefit will } \\
\text { be savings on } \\
\text { reactor system } \\
\text { capital costs, with } \\
\text { the potential } \\
\text { elimination of a } \\
\text { dedicated reactor } \\
\text { system, because } \\
\text { the catalyst and } \\
\text { associated } \\
\text { reactions can occur } \\
\text { in CHGF. }\end{array}$ & $\begin{array}{l}\text { Development of } \\
\text { catalysts with } \\
\text { regeneration } \\
\text { protocols (and } \\
\text { associated on } \\
\text { stream times) that } \\
\text { allow regeneration } \\
\text { within the hot gas } \\
\text { filter (where the } \\
\text { catalyst is } \\
\text { housed), without } \\
\text { significant } \\
\text { redundant } \\
\text { equipment. In this } \\
\text { context, it may be } \\
\text { necessary to } \\
\text { regenerate the } \\
\text { catalyst using the } \\
\text { blowback cycle of } \\
\text { the hot gas filter. }\end{array}$ \\
\hline EDI & $\begin{array}{l}\text { Removal/ } \\
\text { capture/ } \\
\text { concentration of } \\
\text { organic acids } \\
\text { from dilute } \\
\text { carbon aqueous } \\
\text { phase; } \\
\text { simultaneous } \\
\text { removal/ capture/ } \\
\text { concentration of } \\
\text { ammonia and } \\
\text { organic acid }\end{array}$ & $\begin{array}{l}\text { Recycle, purify, and } \\
\text { concentrate N } \\
\text { molecules in waste } \\
\text { stream of HTL. The } \\
\text { resin wafer can } \\
\text { also incorporate } \\
\text { catalyst material for } \\
\text { in-situ esterification } \\
\text { of organic acid into } \\
\text { esters. }\end{array}$ & $\begin{array}{l}\text { Currently, we } \\
\text { operate at } 5 \mathrm{~g} / \mathrm{h} \\
\text { organic acid } \\
\text { capture with } \\
>30 \text { wt.\% titer in } \\
\text { the capture } \\
\text { stream; }>99.5 \% \\
\text { ammonia removal } \\
\text { from the HTL } \\
\text { waste stream }\end{array}$ & $\begin{array}{l}\text { EDI is ready for } \\
>10 \mathrm{~kg} / \mathrm{h} \text { acid } \\
\text { capture }(>5,000 \\
\text { gallons/day) } \\
\text { operations }\end{array}$ & & $\begin{array}{l}\text { High productivity } \\
\text { (throughput) of } \\
\text { capture organic } \\
\text { acids or other } \\
\text { charges species in } \\
\text { single stage and } \\
\text { without chemical } \\
\text { additives. }\end{array}$ & $\begin{array}{l}\text { Improve capture } \\
\text { productivity to } \\
\text { achieve a }>3 \text {-fold } \\
\text { increase and } \\
\text { halve energy } \\
\text { consumption. }\end{array}$ \\
\hline Membrane & $\begin{array}{l}\text { Acid-resistance } \\
\text { separations to } \\
\text { enrich carboxylic } \\
\text { acid in the HTL } \\
\text { aqueous phase }\end{array}$ & $\begin{array}{l}\text { Applicable to } \\
\text { concentrations } \\
\text { (dewatering) of } \\
\text { other oxygenates } \\
\text { such as organic } \\
\text { acids, alcohols, } \\
\text { diols, etc. }\end{array}$ & $0.1-1.0 \mathrm{~L}$ & $\sim 10 \mathrm{~L}$ & $\begin{array}{l}\text { Organic } \\
\text { (carboxylic) } \\
\text { acids, alcohols, } \\
\text { diols, other } \\
\text { water-soluble } \\
\text { oxygenates, } \\
\text { etc. }\end{array}$ & $\begin{array}{l}\text { Less energy } \\
\text { intensive, high- } \\
\text { selectivity } \\
\text { separations, low } \\
\text { cost }\end{array}$ & $\begin{array}{l}\text { Need to further } \\
\text { enhance the } \\
\text { membrane flux to } \\
\text { reduce the } \\
\text { processing time. }\end{array}$ \\
\hline
\end{tabular}


Table 4 (Cont.)

\begin{tabular}{|c|c|c|c|c|c|c|c|}
\hline $\begin{array}{l}\text { Separation } \\
\text { technology }\end{array}$ & $\begin{array}{c}\text { Current } \\
\text { applications }\end{array}$ & $\begin{array}{c}\text { Potential } \\
\text { applications }\end{array}$ & $\begin{array}{l}\text { Current } \\
\text { Scale }\end{array}$ & $\begin{array}{l}\text { Projected } \\
\text { future scale }\end{array}$ & $\begin{array}{l}\text { Types of } \\
\text { compounds }\end{array}$ & $\begin{array}{c}\text { Advantage over } \\
\text { other } \\
\text { technologies }\end{array}$ & Remaining gaps \\
\hline Adsorbents & $\begin{array}{l}\text { Carbonyl/ } \\
\text { carboxylic acid } \\
\text { reduction from } \\
\text { woody pyrolysis } \\
\text { bio-oils; removal } \\
\text { of cyclic N } \\
\text { compounds from } \\
\text { HTL biocrudes }\end{array}$ & $\begin{array}{l}\text { Clean up TC } \\
\text { streams for catalyst } \\
\text { preservation and } \\
\text { product purification }\end{array}$ & $0.1-0.5 \mathrm{~L}$ & $1-100 \mathrm{~L}$ & $\begin{array}{l}\text { Carbonyls, } \\
\text { carboxylic } \\
\text { acids; cyclic N- } \\
\text { compounds }\end{array}$ & $\begin{array}{l}\text { Less } \mathrm{H}_{2} \\
\text { consumption, less } \\
\text { catalyst } \\
\text { deactivation, less } \\
\text { ammonia gas } \\
\text { emission, better } \\
\text { energy efficiency } \\
\text { and process } \\
\text { economics }\end{array}$ & $\begin{array}{l}\text { Need to improve } \\
\text { adsorption } \\
\text { selectivity, } \\
\text { capacity, and } \\
\text { regeneration of } \\
\text { sorbent materials }\end{array}$ \\
\hline
\end{tabular}




\subsection{Seed Projects}

In FY 2017, exploratory research was conducted within two small tasks: biochemical catalyst preservation and algae processing.

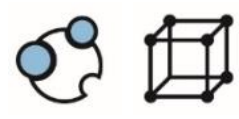

\subsubsection{Biochemical Catalyst Preservation}

Motivation. Organisms used in biochemical conversion can be severely affected by contaminants in the bioreactor feed. These impurities arise from feedstocks, contamination during processing, and inhibitors produced during fermentation. This challenge prompted research into advanced materials (Figure 37) for low-cost, selective separations and initially targeted common interfering chemical classes such as aldehydes and carboxylic acids. The intended impact is to drive down bioconversion costs through increased titers, rates, and yield along with decreased lag phases of culture and to potentially reinvigorate consolidated bioprocessing.

Contaminant concentrations can be addressed through the use of adsorbents such as:

- Solid, high-surface area adsorbents candidates, including:

- Surface-treated nanostructured adsorbents with high binding and recovery that can be magnetically manipulated (cycling has been demonstrated), and

- Reusable, environmentally benign adsorbent foams.

- Flexible aerogels with highly microporous silica network with high capacities (e.g., adsorbing eight times their weight of product for some hydrophobic targets), good specificity and reusable.

Approach. Experimental work focused initially on nanoparticle (NP) networks because they are uniform and adaptable to small-scale synthesis. In contrast, polyurethane foams at small scales have heterogeneity issues, and aerogels were considered too new and unpredictable. 


\section{Designer high-surface-area adsorbents in development}

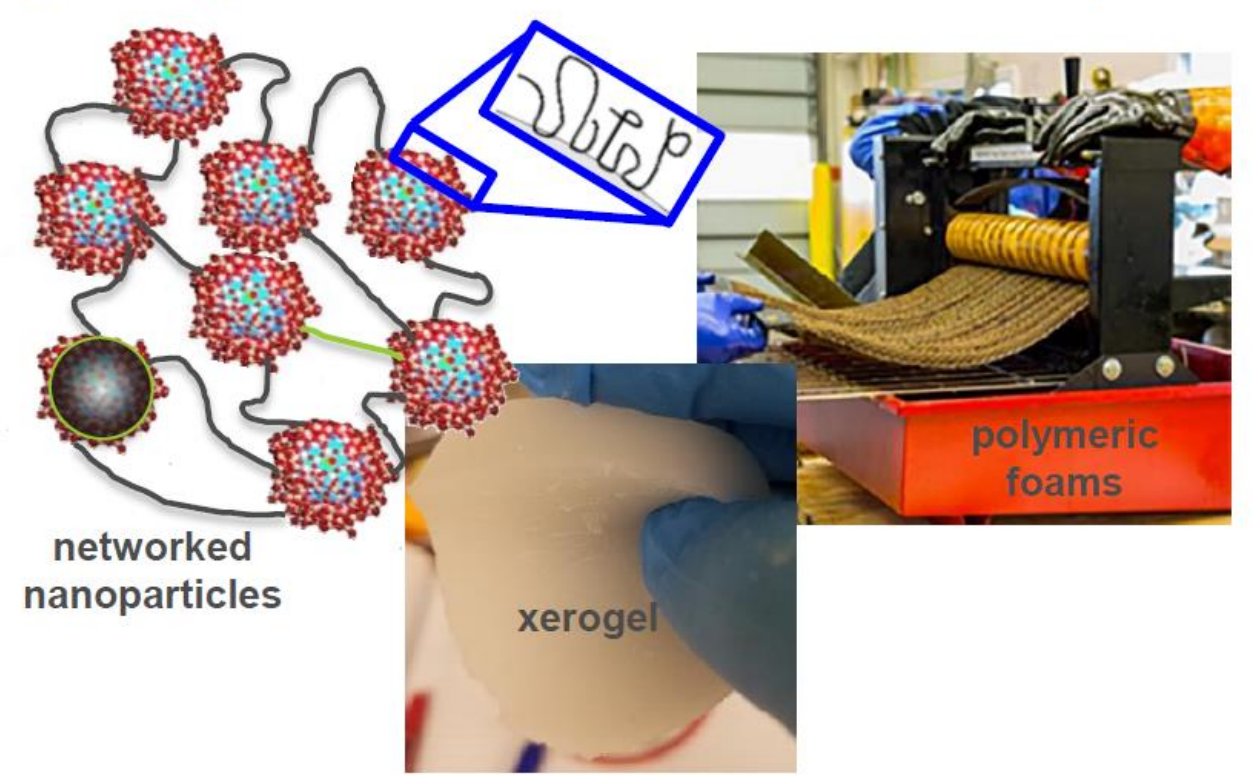

Figure 37 Materials developed in the Consortium include nanoparticles, xerogels, and polymeric foams.

NP networks are made up of chemically bonded NPs that use polymer chains with bifunctional coupling agents to form extended, looping chains of aromatic silanes. The surface treatment involves heterogeneous vapor-phase polymerization. Mixtures of hydrophobic (e.g., octyl, octadecyl, phenyl species) and hydrophilic (e.g., hydroxyl, amino, carboxyl species) elements were used to selectively target aldehydes. Primary amines are key to separations and their specificity results from strategic incorporation of hydrophobic and aromatic elements along with the amines.

Aldehydes were chosen as the target impurity because they interfere with most lignin valorization schemes, are produced by almost all lignocellulosic deconstruction strategies, and contribute to color and odor issues, which limit the potential of lignin for use in some applications (Table 5).

More than 20 designs for surface treatment combinatorics for NP were synthesized and characterized. Linkers between NP remained highly hydrophobic to limit cellular interactions. Five amine ratios and two aromatic:alkyl ratios were explored to tune aldehyde adsorption (Figure 38).

Table 5 Impurities that affect fermentation.

\begin{tabular}{c|l|l}
\multirow{2}{*}{ Target number } & \multicolumn{2}{|c}{ Toxin or inhibitory species } \\
\cline { 2 - 3 } & \multicolumn{1}{|c}{ Feedstock stream } & Fermentation broth \\
\hline 1 & Furfural/methyl furfural & Butryaldehyde \\
\hline 2 & Ferulic acid & Malondialdehyde \\
\hline 3 & Benzoic acid & Succindialdehyde \\
\hline 4 & Coumaric acid & Tolualdehyde \\
\hline 5 & Phenyl acetate & Isoprenol/geraniol \\
\hline
\end{tabular}


(a)

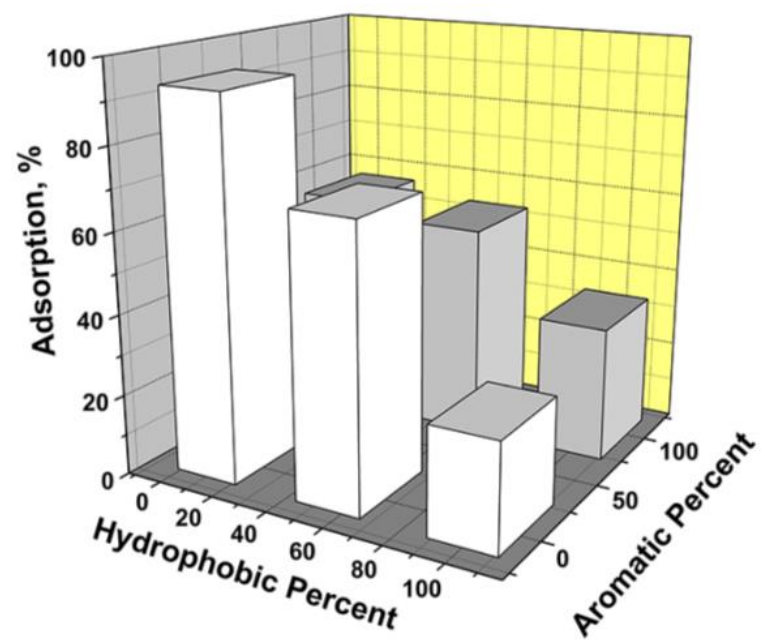

(b)

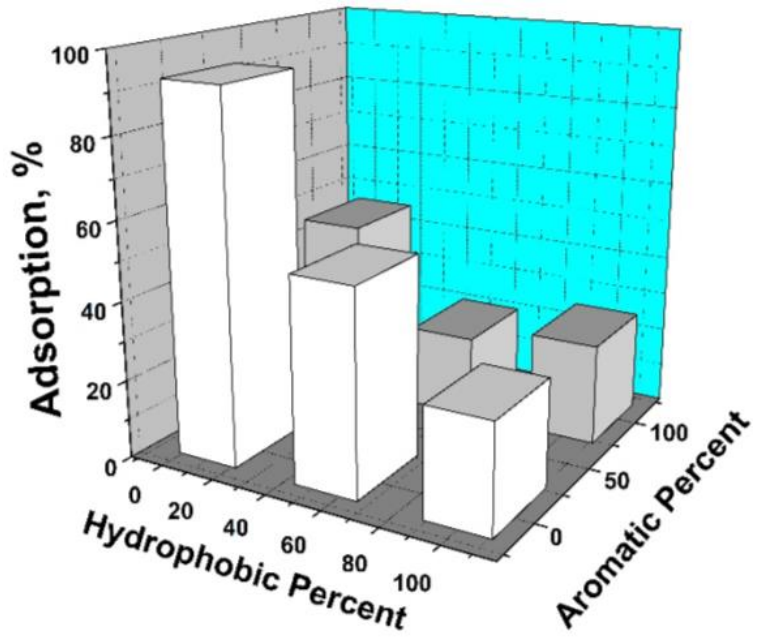

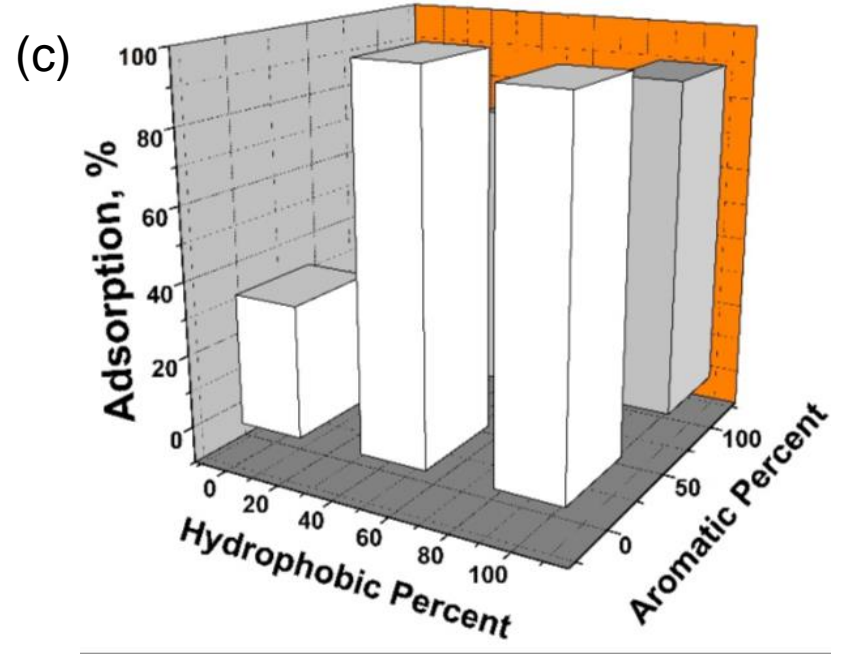

Figure 38 Adsorbent screening results for capturing three representative aldehydes: (a) formaldehyde, (b) acetaldehyde, and (c) benzaldehyde.

Process stream interference was measured with gravimetric analysis. Process steams studied (seven total) were mock feedstock hydrolysates, actual fermentation broths of mid-log-phase cultures ( $E$. coli, R. sphaeroides), and actual fermentation broths of production hosts (Pseudomonas putida KT 2440, S. cerevisiae). Each experiment ran for 3 hours with agitation at $37^{\circ} \mathrm{C}$ and $0.5 \%$ adsorbent.

Results. Table 6 lists the binding ratio of the aldehyde to the total of other bound components. Specificity is defined as the amount of toxin bound relative to the binding of all other components of the process stream. Specificity benchmarks were set at $>5$. At times, results indicated specificity of $>30$. Specificity targets were achieved for inhibitors found within a feedstock stream such as formaldehyde, acetaldehyde, and hydroxymethyl furfural. Toxic intermediates coproduced during the bio-upgrading process, such as methylglyoxal, were also successfully bound. Four or more biocatalyst inhibitors exhibited

Nanoparticle-based adsorption exceeded binding specificity (ratio of bound toxin to binding of other stream components) benchmarks of five and reached 30 in some cases. Targeted inhibitors included those found within a feedstock stream and a toxic intermediate coproduced during bio-upgrading. 
specificity (over all components of feedstock stream or fermentation broth) of $4: 1$ for one feedstock contaminant and one inhibitor produced during bio-upgrading.

Data gaps for this research include additional study of binding capacities, reuse potential, and potential for direct incorporation into process streams of passive binding elements, possibly with membrane shields.

Table 6 Binding ratios for various materials and impurities.

\begin{tabular}{|c|c|c|c|c|c|}
\hline \multirow[b]{2}{*}{ Toxin/Inhibitor } & \multirow{2}{*}{$\begin{array}{l}\text { Best Material(s) } \\
\text { Ref. No. }\end{array}$} & \multicolumn{4}{|c|}{ Specificity Binding Ratioa (aldehyde:stream interference, w:w) } \\
\hline & & DMR-EH & E. coli (LB) & Other, Minimalb & Other, Richc \\
\hline Formaldehyde & 156 & 6.3 & 15.0 & 6.7 & 5.0 \\
\hline Acetaldehyde & 156 & 5.8 & 13.8 & 6.1 & 4.6 \\
\hline \multirow[t]{2}{*}{ Furfurald } & 152 & 29.1 & 36.4 & 11.2 & 14.2 \\
\hline & 157 & 14.6 & 18.2 & 5.6 & 7.8 \\
\hline Hydroxymethylfurfural & 156 & 12.2 & 29.4 & 13.0 & 9.8 \\
\hline Methylglyoxal & 156 & 15.3 & 36.8 & 16.3 & 12.2 \\
\hline
\end{tabular}

a Errors $<2 \%$ in the analytics for the top and bottom datapoints of the ratio.

b Results on two materials shown for furfural. One is hydrophobic and the other relatively more hydrophilic. Either is likely useful in bioreactors; down-selection dictated by the medium used for growth and the target that is produced.

c Averages from P. putida KT2440 in M9-glucose medium and $R$. sphaeroides in MR26 medium.

d Averages from $P$. putida KT2440 in LB; $R$. sphaeroides in GYCC; and S. cerevisiae in YPD medium.

\subsubsection{Algae Dewatering}

Motivation. Dewatering algae cultures from approximately 0.1 to $20 \mathrm{wt} \%$ for use in downstream conversion processes imparts a significant cost to biofuels (Coons et al. 2014). Every $\mathrm{kWh} / \mathrm{m} 3$ of energy applied to harvesting contributes approximately $\$ 1 / G G E$ to the price of biofuel. This seed task evaluated ultrasonic filtration and crossflow membrane filtration for algae dewatering.

Approach. Tests were conducted as shown in Figure 39; harvesting and extraction were performed independently at each site in a single stage process. Conditions applied for ultrasonic tests represent current industry practice. Three feedstock species of microalgae were selected to cover a wide range of cell sizes. The size of the microalgae varied as shown in Figure 40. Ultrasonic separation was used in batch and hour-long flow experiments where steady-state removal was achieved rapidly, yielding concentrations as high as $10 \mathrm{wt} \%$. 


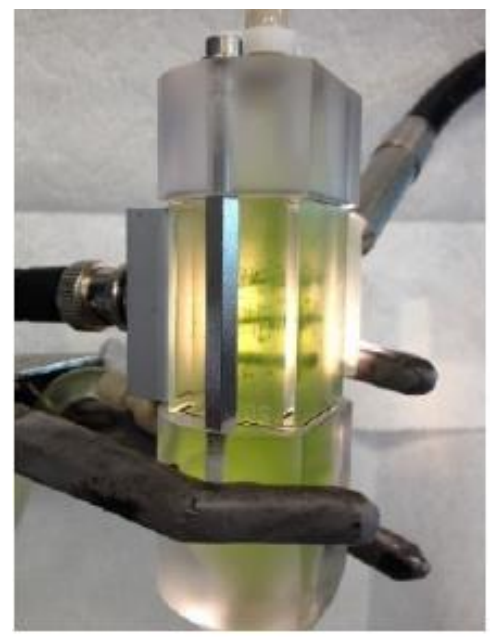

Ultrasonic Test System

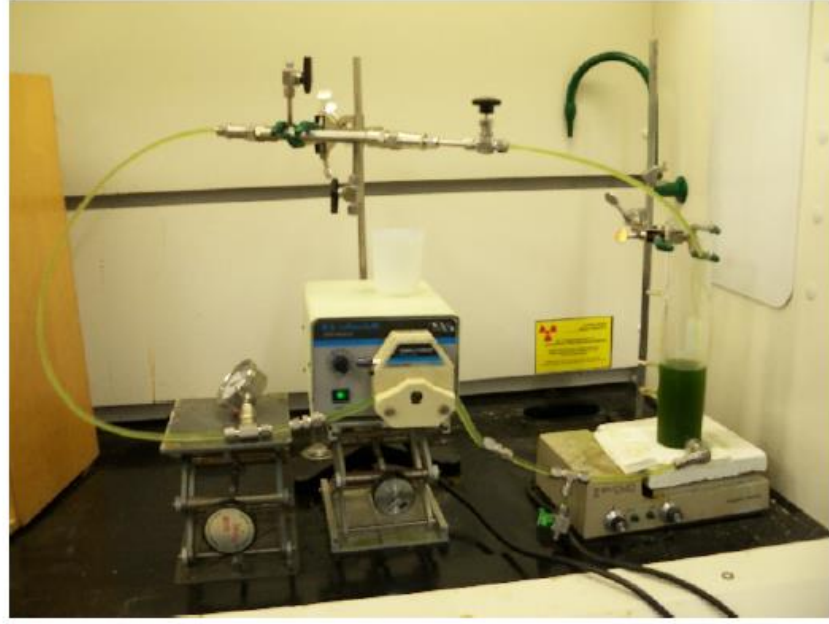

Recirculating Membrane Test System

Figure 39 Experimental setups for separations via ultrasonics and membranes.

\section{Scenedesmus obliquus}

Ellipsoidal cells $(3 \times 6 \mu \mathrm{m})$, single cells, few aggregates

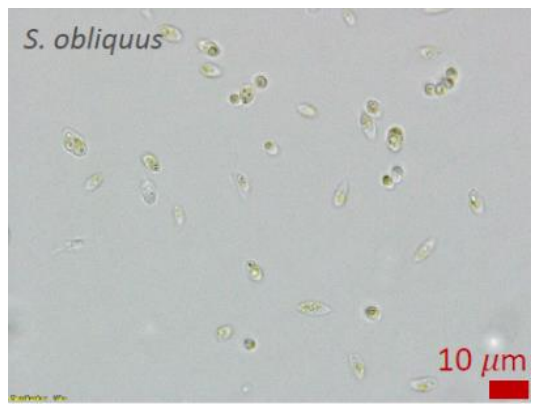

Chlorella luteoviridis

Large spherical cells $(8-16 \mu \mathrm{m})$, many aggregates of $>3$ cells

\section{C. luteoviridis}

\section{Nannochloropsis salina}

Small spherical cells $(2-3 \mu \mathrm{m})$, single cells, no aggregates

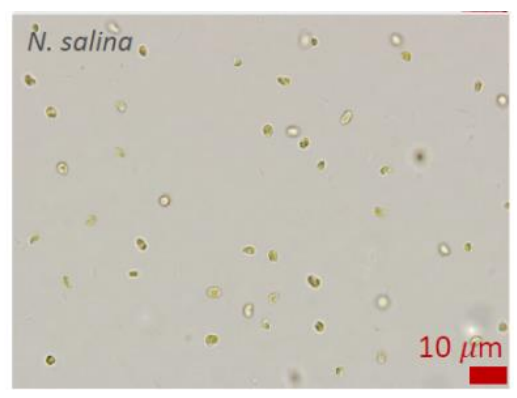

Figure 40 Characteristics of algae cultures used in the harvesting and dewatering study.

Membrane filtration was also used to dewater the microalgae. A crossflow filtration setup minimized the buildup of pore-clogging materials on the filter and concentrated the microalgae while continuously returning the retentate back to the feed. The fabricated membrane systems were stainless steel (434) with pore sizes of 4 and $0.5 \mu \mathrm{m}$. They were operated at $<10 \mathrm{psi}$ transmembrane pressure.

Results. Figure 41 shows the effects of energy input and cell size on microalgae removal. Energy inputs are similar to those of centrifugation. The figure shows agreement between batch and (steady) flow tests, which indicates the insignificance of hydrodynamic effects over the range of conditions studied. 

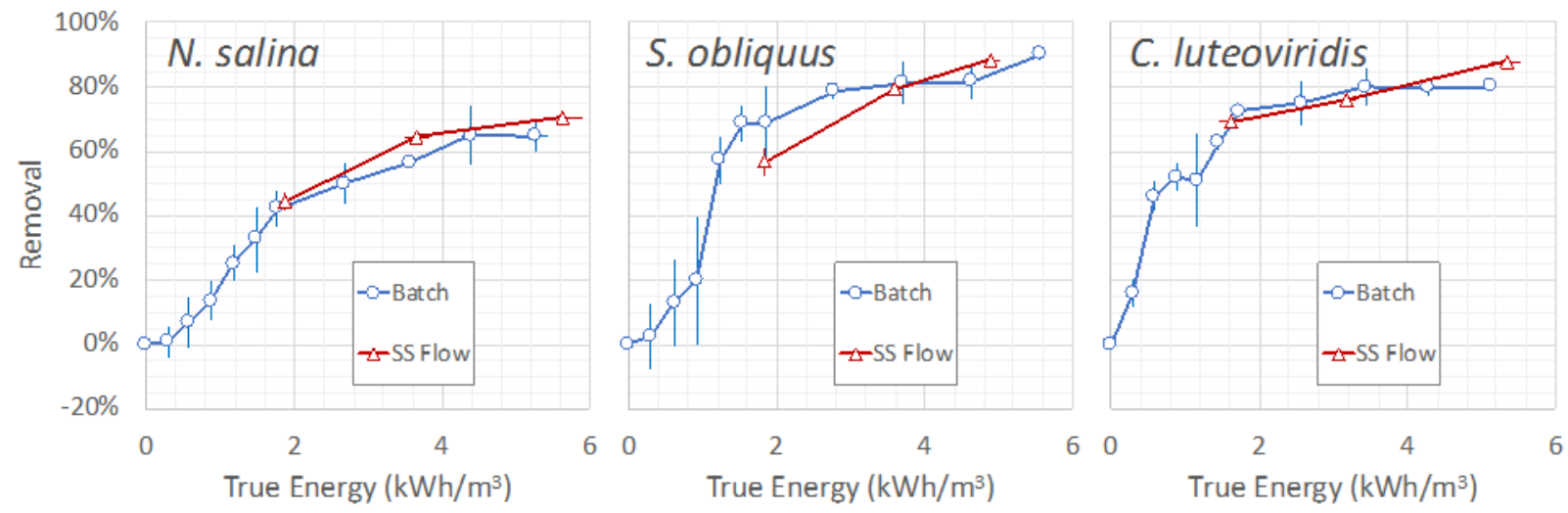

Figure 41 Ultrasonic removal of algal species showing agreement between batch and (steady) flow tests, which indicates the insignificance of hydrodynamic effects over the range of conditions studied. Microalgae cell size increases from left to right.

Concentration factors were shown to be largely a function of the ratio of filtrate to concentrate flow rates, as shown in Figure $42 a$. One metric to evaluate the viability of this technique to dewater algae is to compare the energy consumed in ultrasonic dewatering to the energy content of the algae that are recovered. Figure $42 \mathrm{~b}$ illustrates this metric for three algae species. HHV values for the microalgae varied from $14 \mathrm{MJ} / \mathrm{kg}$ for $N$. salina to around $21 \mathrm{MJ} / \mathrm{kg}$ for the other species. Even at these high energy inputs, the effects of properties on fractional energy consumption are evident. Here, cell size, HHV, and biomass concentration are shown to affect the fractional energy needed for dewatering, with cell size being the most pronounced and larger cells requiring less energy for harvesting.

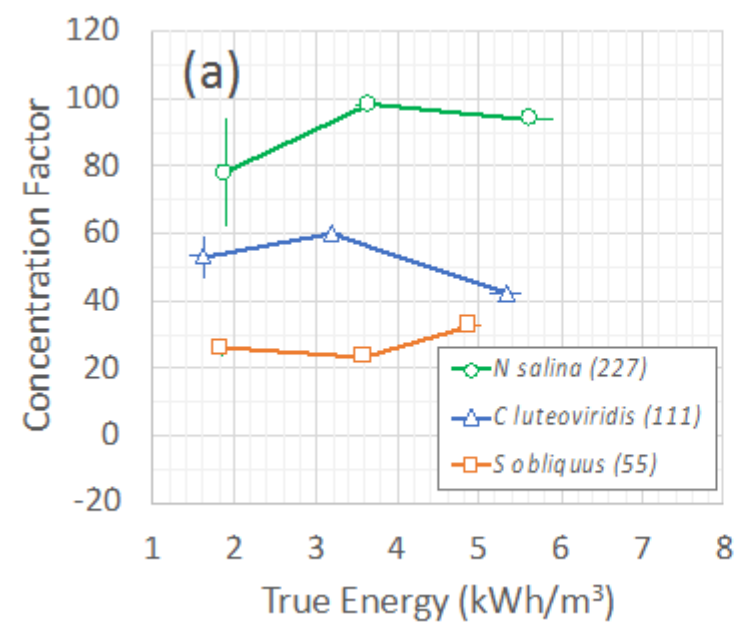

Figure 42 (a) Concentration factors obtained in flow tests increases according to the ratio of filtrate to concentrate flow rates shown in parenthesis. (b) Ultrasonic harvesting energy as a fraction of the energy in the microalgae removed using ultrasound. 
Following ultrasonic dewatering, membranes were applied to further increase algae concentration. We tested each algae strain that had no detectable algae in the permeate. $N$. salina was concentrated by a factor of 20 , to $6 \mathrm{wt} \%$, and S. obliquus by a factor of 25 , to $10 \mathrm{wt} \%$. Both far exceeded the target of achieving $1 \mathrm{wt} \%$.

Energy consumption of the membrane-based dewatering was 25 to 30 times $\left(158 \mathrm{kWh} / \mathrm{m}_{3}\right)$ more than for the ultrasonic separator. Internal membrane pressure was kept below $10 \mathrm{psi}(0.02 \mathrm{kWh} / \mathrm{m} 3)$, which suggests that a dead-end setup with no retentate recycle to the feed would consume much less energy. Although the crossflow membrane filtration setup requires much less filter area than a dead-end system, it also utilizes around four orders of magnitude more energy.

Data gaps include optimizing the configuration of ultrasonic separation and membrane filtration technologies. In addition, capital costs for ultrasonic separation need to be more fully developed to enable comparative TEA of this technology in comparison to others. 


\section{Stakeholder Engagement}

\subsection{Industrial Advisory Board (IAB)}

The IAB (Table 7) helps the Consortium maintain an industry-relevant focus and provides knowledge of recent technology advances and challenges. The board is composed of eight industry advisors as well as an advisor from the Advanced Research Projects Agency-Energy (ARPA-E). The board meets with the Consortium twice a year and provides advice, reviews results and progress in comparison with work plans, provides feedback regarding prioritization of research projects, and informs development of the Consortium's strategy for out years.

Table 7 IAB members, FYs 2017-2019.

\begin{tabular}{ll} 
Kazuhito Suzuki & \multicolumn{1}{c}{ Affiliation } \\
\hline Binita Bhattacharjee & Amyris \\
\hline Marc VonKeitz & ARPA-E \\
\hline Steve Taggart & BP \\
\hline Esteban Chornet & Enerkem \\
\hline Tom Xu & DuPont \\
\hline James Oyler & Genifuel \\
\hline Bo Chen & Genomatica \\
\hline Bob Rozmiarek & Virent
\end{tabular}

\subsection{Meetings, Conferences, and External Communications}

- Biannual face-to-face meetings with the IAB

- FY 2017: NREL, December; Baltimore, May;

- FY 2018: Argonne, December; ORNL, June; and

- FY 2019: Argonne, December; NREL, May.

- Listening Day (May 23, 2017) was held in collaboration with AltSep, an industry workshop. Half of the attendees were from industry, a quarter from the national laboratories, and the balance from federal agencies and national associations. The breakout sessions covered industry-relevant separations issues and streamlining collaborations with the national laboratories. The resultant public report served as reference for Consortium planning (Bioprocessing Separations Consortium 2017).

- Targeted conferences: Special sessions were held at two conferences in 2018 with invited speakers from industry to highlight bioprocessing separations challenges and disseminate information about the Consortium and its technical progress. In FY 2019, an overview of the Consortium was presented outlining the purpose, key results and future plans:

- 40th Symposium on Biotechnology for Fuels and Chemicals (April 29-May 2, 2018)

- BioWorld Congress on Industrial Biotechnology (July 16-19, 2018)

- Green Chemistry and Engineering-Green and Sustainable Chemistry Conference (June 11-13, 2019) 
To facilitate external communications and disseminate information about the Consortium, an external website (www.bioesep.org/) has been stablished. The website provides stakeholders information about the Consortium's current project portfolio and how to interact with the Consortium.

\subsection{Directed Funding Opportunity}

Directed Funding Opportunities (DFOs) are meant to accelerate the development of separations technologies for the commercialization of biomass-derived fuels and chemicals by engaging with industry to overcome their most pressing bioprocessing separations challenges and leveraging Separations Consortium capabilities and expertise. These opportunities allow industry to test BETO-funded separations technologies and assess their value.

The DFO project collaborations were established via conference calls with interested applicants to review industry needs and Consortium capabilities and to identify partners. Based on these initial meetings, $\$ 2.4$ million in federal funds were requested ( $>2 \times$ over subscription) and five $\$ 200,000$ federal fund projects were awarded. The five projects (Table 8 ) span a variety of feedstocks, conversion routes, and products and are an opportunity to showcase the Consortium's ability to provide comprehensive solutions to industrial bioprocessing separations challenges.

Table 8 Direct Funding Opportunity projects between industry and Consortium members.a

\begin{tabular}{|c|c|c|c|c|}
\hline Company & $\begin{array}{l}\text { Waste/gas } \\
\text { feedstock }\end{array}$ & $\begin{array}{l}\text { Cellulosic sugar } \\
\text { feedstock }\end{array}$ & Product & $\operatorname{Lab}(\mathbf{s})$ \\
\hline Visolis & & $x$ & Mevalonic acid & Argonne, LBNL \\
\hline Kalion & & $x$ & Glucaric acid & $\begin{array}{l}\text { ORNL, LBNL, } \\
\text { Argonne, NREL }\end{array}$ \\
\hline Mango Materials & Biogas & & $\begin{array}{l}\text { Polyhydroxyalkanoates from } \\
\text { methanotrophs }\end{array}$ & LBNL \\
\hline DMC Biotechnologies & & $x$ & $\begin{array}{l}\text { Farnesene, liquid } \\
\text { hydrocarbons }\end{array}$ & Argonne, LBNL \\
\hline HelioBioSys & $\begin{array}{l}\text { Atmospheric } \\
\mathrm{CO}_{2}\end{array}$ & & $\begin{array}{l}\text { Expandable Polystyrene from } \\
\text { cyanobacterial consortium }\end{array}$ & LBNL, SNL, LANL \\
\hline
\end{tabular}

a $\mathrm{LBNL}=$ Lawrence Berkeley National Laboratory; ORNL $=$ Oak Ridge National Laboratory; NREL $=$ National Renewable Energy Laboratory; SNL = Sandia National Laboratory; LANL = Los Alamos National Laboratory. 


\section{Summary}

Separations are a key challenge for industrial-scale bioprocessing applications because they are costly and complex. The Bioprocessing Separations Consortium was established in Fiscal Year 2017 to address various technical challenges that preclude the cost-competitive production of biofuels and bioproducts.

In its first three years, the Consortium developed six types of separation solutions important for efficient biochemical and thermochemical processing of biomass to fuels and chemicals. The Consortium interfaced with industry through its IAB, Listening Day, and conference special sessions to ground its portfolio in realworld challenges. Separations accomplishments included:

- Extraction technology coupled with in-situ fermentation product recovery: Research to integrate fermentation and separations through HED-ISPR for carboxylic acids and esters identified ideal extractants for these carbonyl compounds. The Consortium released a publicly available model of the HED-ISPR system. Industry and academic researchers can use the model to evaluate system design for integrated fermentation-separations challenges that are relevant to them. Laboratory-scale experiments demonstrated that this energy-efficient process recovered $95 \%$ of $\mathrm{C} 4$ compounds in fermentation broth at a purity of $98.5 \%$ mol. EDI was also integrated with ISPR and captured $>95 \%$ of pure organic acids, consuming $<1.0 \mathrm{kWh} / \mathrm{lb}$. acid, an industrially relevant benchmark. A comparison of a simulated moving bed (SMB) baseline, EDI-ISPR, and HED-ISPR, concluded that the HED-ISPR showed the lowest overall MFSP and life-cycle GHG emissions.

- Electrochemical separation for recovery of organic acids and bases (e.g., caustic, ammonia) from aqueous streams: EDI-based separations were developed to maintain high concentrations of recovered acid and $\mathrm{NaOH}$ regardless of the percentage removal. Concentrations of each species were shown to exceed target levels.

- Polymeric and ceramic membrane development for lignin fractionation: For lignin conversion, species with high molecular weights must be removed and other compounds separated as a function of molecular weight. Furthermore, lignin fractionation must occur at a sufficiently high, industrially relevant throughput. The Consortium's multi-stage filtration approach to lignin fractionation made significant progress towards these aims, removing compounds above $1 \mathrm{kDa}$ and achieving a flux five to ten times greater than a single $450 \mathrm{Da}$ filtration step.

- Adsorbent techniques for selective removal of carbonyls and small organic nitrogen containing molecules: Adsorbents tailored to remove impurities that hinder biological cultivation, such as aldehydes, showed specificity (over all components of feedstock stream or fermentation broth) of $4: 1$ for one feedstock contaminant and one inhibitor produced during bio-upgrading. Adsorbents were applied to remove $34 \%$ of carbonyl species from fast pyrolysis biofuel, corresponding to nearly $\$ 1 / G G E$ decrease in the conversion cost to approximately $\$ 2.50 / \mathrm{GGE}$.

Altogether, these technical accomplishments resulted in ten journal publications and seven patents. The Separations Consortium also established five industrial collaborations through the DFO. These five projects encompass separation of various organic acids, alcohols, and polymers from fermentation broth and gaseous streams.

Based on the portfolio of work to date and feedback from industry and BETO-internal stakeholders, the Consortium expects to undertake a new slate of projects for FYs 2020-2022, as outlined in Table 9. This portfolio balances interactions with other BETO projects and consortia, the development of new separations technologies, and analysis and computation. Furthermore, TEA and LCA will be conducted consistently and comprehensively for each Consortium project in this three-year period. 
Table 9 Consortium project slate: FYs 2020-2022.

\begin{tabular}{|c|c|c|c|}
\hline Project & Streams & Technologies & Products \\
\hline Lignin separations & $\begin{array}{l}\text { APL, Reductive Catalytic } \\
\text { Fractionation (RCF), } \\
\text { Catalytic Oxidation RCF } \\
\text { COO, RCF }\end{array}$ & $\begin{array}{l}\text { Membrane-less EDI, } \\
\text { membranes }\end{array}$ & $\begin{array}{l}\text { Monomeric acids, high- } \\
\text { molecular weight lignin } \\
\text { species, } \mathrm{NaOH}\end{array}$ \\
\hline $\begin{array}{l}\text { Redox-based } \\
\text { electrochemical } \\
\text { separations (RECS) }\end{array}$ & Fermentation broth & $\begin{array}{l}\text { Pseudo-capacitive } \\
\text { deionization }\end{array}$ & $\begin{array}{l}\text { Short-chain volatile fatty } \\
\text { acids }\end{array}$ \\
\hline $\begin{array}{l}\text { 2,3-butanediol } \\
\text { separations }\end{array}$ & Fermentation broth & $\begin{array}{l}\text { Membranes and } \\
\text { sorbents }\end{array}$ & 2,3-butanediol \\
\hline $\begin{array}{l}\text { Counter-current } \\
\text { chromatography } \\
\text { (CCC) }\end{array}$ & $\begin{array}{l}\text { HTL oils, APL, RCF, } \\
\text { pyrolysis oil }\end{array}$ & $\mathrm{CCC}$ & $\begin{array}{l}\text { Cresols, phenols, carboxylic } \\
\text { acids, metal impurities, from } \\
\text { lignin-rich streams: trimers, } \\
\text { dimers, monomers }\end{array}$ \\
\hline $\begin{array}{l}\text { Volatile product } \\
\text { recovery }\end{array}$ & $\begin{array}{l}\text { Vapor phase from } \\
\text { fermentation }\end{array}$ & $\begin{array}{l}\text { Nanostructured } \\
\text { adsorbents }\end{array}$ & $\begin{array}{l}\text { 3-methyl anisole, isoprene, } \\
\text { terpenes, } C_{5} \text { alcohols }\end{array}$ \\
\hline Computation & $\begin{array}{l}\text { Fermentation broth and } \\
\text { vapor phase }\end{array}$ & $\begin{array}{l}\text { Density functional } \\
\text { theories and classical } \\
\text { molecular dynamics } \\
\text { methods }\end{array}$ & $\begin{array}{l}\text { 3-methyl anisole, isoprene, } \\
\text { terpenes, C5 alcohols, } \\
\text { 2,3-butanediol }\end{array}$ \\
\hline
\end{tabular}




\section{References}

Agile BioFoundry, 2020, Agile BioFoundry. Available at: https://agilebiofoundry.org/

Arkell, A., J. Olsson, and O. Wallberg, 2014, "Process performance in lignin separation from softwood black liquor by membrane filtration," Chemical Engineering Research and Design. 92(9): 1792-1800.

Beckham, G.T., "Lignin-First Biorefinery Development" Presented at the 2019 Bioenergy Technologies Office Peer Review. Denver, Colorado. March 4-8. Available at: https://www.energy.gov/sites/prod/files/ 2019/04/f61/Lignin\%20First\%20Biorefinery\%20Development_NL0033400_1.pdf

Bioprocessing Separations Consortium, 2017, Summary of Bioprocessing Separations Consortium Industrial Listening Day May 2017, June 30. Available at http://www.bioesep.org/wp-content/uploads/ sites/72/2017/08/20170731_Listening-Day-Report.pdf

CCPC, 2020, Consortium for Computational Physics and Chemistry. Available at: https://www.cpcbiomass.org/

ChemCatBio, 2020, Chemical Catalysis for Bioenergy. Available at: https://www.chemcatbio.org/

Coons, J., Gasway, C., Yap, B., Bischoff, B., Sweeney, N., Dong, T., Pienkos, P., Dale, T., Sanders, C. 2019, "The Energy Costs of Dewatering Feedstock microalgae Species Using Standard Implementations of Ultrasonic and Membrane Filtration Technologies," in preparation.

Coons, J.E., D.M. Kalb, T. Dale, and B.L. Marrone, 2014, "Getting to low-cost algae biofuels: A monograph on conventional and cutting-edge harvesting and extraction technologies," Algal Research 6: 250-270.

Davis, R., N. Grundl, L. Tao, M.J. Biddy, E.C.D. Tan, G.T. Beckham, D. Humbird, D.N. Thompson, and M.S. Roni, 2018, Process Design and Economics for the Conversion of Lignocellulosic Biomass to Hydrocarbon Fuels and Coproducts: 2018 Biochemical Design Case Update, NREL/TP-5100-71949.

Dunn, J., T. Pray, T. Dale, 2019, "Bioprocessing Separations Consortium." Presented at the 2019 Bioenergy Technologies Office Peer Review. Denver, Colorado. March 4-8.

Dutta, A., K. lisa, C. Mukarakate, M. Griffin, E.C.D. Tan, J. Schaidle, D. Humbird, H. Wang, D. Hartley, D. Thompson, and H. Cai, 2018, Ex Situ Catalytic Fast Pyrolysis of Lignocellulosic Biomass to Hydrocarbon Fuels: 2018 State of Technology and Future Research, NREL/TP-5100-71954, National Renewable Energy Laboratory. Golden, Colorado. Available at: https://www.nrel.gov/docs/fy19osti/71954.pdf.

EERE (Energy Efficiency and Renewable Energy), 2015, Bioproducts to Enable Biofuels Workshop Summary Report. Available at: https://www.energy.gov/sites/prod/files/2015/12/f27/bioproducts_to_ enable_biofuels_workshop_report.pdf,

EERE, 2014, Process Integration and Carbon Efficiency Workshop Summary Report. Available at: https://www.energy.gov/sites/prod/files/2014/12/f19/process_integration_workshop_report_dec_2014.pdf

EERE, 2020, Co-Optimization of Fuels \& Engines. Available at: https://www.energy.gov/eere/bioenergy/cooptimization-fuels-engines 
Elander, R.T., D. Vardon, D.K. Johnson, Z. Li, A.D. Sutton, V. Dagle, K.K. Ramasamy, "Catalytic Upgrading of Biochemically Derived Intermediates (CUBI)." Presented at the 2019 Bioenergy Technologies Office Peer Review. Denver, Colorado. March 4-8. Available at: https://www.energy.gov/sites/prod/files/2019/ 03/f61/Catalytic\%20Upgrading\%20 of\%20Biochemically\%20Derived\%20Intermediates\%20\%28CUBI\%29 NL0026681.pdf

Fitzgerald, N. and A. Bailey, 2018, Moving Beyond Drop-In Replacements: Performance-Advantaged Biobased Chemicals Workshop Summary Report. Available at: https:/www.energy.gov/sites/prod/files/ 2018/06/f53/Performance-Advantaged\%20Biobased\%20Chemicals\%20Workshop\%20Report.pdf

Hu, M., C. Engtrakul, B.L. Bischoff, M. Lu, and M. Alemseghed, 2018, "Surface-Engineered Inorganic Nanoporous Membranes for Vapor and Pervaporative Separations of Water-Ethanol Mixtures," Membranes 8(4):95.

Humpert, D., M. Ebrahimi, and P. Czermak, 2016, "Membrane Technology for the Recovery of Lignin: A Review," Membranes 6(3):42.

Lu, M., and M. Hu, 2020, "Novel Porous Ceramic Tube-Supported Polymer Layer Membranes for Acetic Acid/Water Separation by Pervaporation Dewatering," Separation and Purification Technology 236: 116312. Available at: https://doi.org/10.1016/j.seppur.2019.116312.

Lu, M., M. Hu, S. Lee, H. Wang, and J. Liu, 2019, "Selective adsorption removal of carbonyl molecular foulants from real fast pyrolysis bio-oils," Biomass \& Bioenergy, submitted.

Lu, M., A.W. Lepore, J.S. Choi, Z. Li, Z. Wu, F. Polo-Garzon, and M.Z. Hu, 2019, "Acetic Acid/Propionic Acid Conversion on Metal Doped Molybdenum Carbide Catalyst Beads for Catalytic Hot Gas Filtration," Catalysts 8(12):643.

Peterson, B., C. Engtrakul, A.N. Wilson, S. Dell'Orco, K.A. Orton, S. Deutch, M.M. Yung, A.K. Starace, Y. Parent, D. Chiaramonti, and K.A. Magrini, 2019, "Catalytic Hot-Gas Filtration with a Supported Heteropolyacid Catalyst for Preconditioning Biomass Pyrolysis Vapors," ACS Sustainable Chemistry \& Engineering 7(17): 14941-14952. Available at http://dx.doi.org/10.1021/acssuschemeng.9b03188.

Saboe, P., L. Manker, W. Michener, D. Peterson, D. Bradner, S. Deutch, M. Kumar, R. Cywar, G. Beckham, and E. Karp, 2018, "In situ recovery of bio-based carboxylic acids," Green Chemistry 20:1791-1804.

Saboe, P., H. Monroe, W. Michener, L. Manker, S. Haugen, G. Beckham, and E. Karp, 2019, "In situ product recovery of bio-based ethyl esters via hybrid extraction-distillation," Green Chemistry 21:5306-5315. Available at: https://doi.org/10.1039/C9GC01844A.

Shao, P., and A. Kumar, 2009, "Recovery of 2, 3-butanediol from water by a solvent extraction and pervaporation separation scheme," Journal of Membrane Science 329(1-2):160-168.

Sholl, D.S., and R.P. Lively, 2016, "Seven chemical separations to change the world,". Nature. 532, 435.

Xu, S., H. Zhang, F. Yu, X. Zhao, and Y. Wang, 2018, "Enhanced ethanol recovery of PDMS mixed matrix membranes with hydrophobically modified ZIF-90," Separation and Purification Technology 206:80-89. 